\title{
Origin and phylogeny of the verrucomorph barnacles (Crustacea, Cirripedia, Thoracica).
}

\author{
Andrew Scott Gale \\ School of Earth and Environmental Sciences, University of Portsmouth, Burnaby \\ Building, Burnaby Road, Portsmouth P01 3QL UK
}

Asymmetrical thoracican cirripedes, of superfically similar "verrucomorph" morphology are shown to have evolved independently three times from pedunculate ancestors. In each case, the loss of a peduncle was accompanied by preferential attachment on one side or the other, such that the rostrum, carina and one of each paired scuta and terga ("fixed") formed a wall-like structure; the opposite scutum and tergum ("free") transforming into an opercular structure closed by the scutal adductor muscle. True Verrucomorpha (Eoverruca+Verrucidae) have their origin in the Cretaceous sessile genus Pycnolepas and the new genus Faxoelepas, which demonstrates a marked, but facultative, tendency towards capitular asymmetry, confirmed by strong morphological similarities in plate morphology with the basal verrucomorph Cretaceous genus Eoverruca. Proverruca, another Cretaceous asymmetrical form is unrelated, and evolved independently from a scalpellomorph ancestor. The extant hydrothermal vent genera Neoverruca and Imbricaverruca evolved from symmetrical scalpellomorphs of the family Neolepadidae, as demonstrated by both molecular and morphological evidence. Cladistic analysis of 38 characters in 14 living and fossil taxa yielded a consensus tree showing a monophyletic Verrucomorpha, made up of a stem group (Eoverruca) and crown group (Verrucidae). Faxoelepas bruennichi and Pycnolepas rigida are sister taxa to the Verrucomorpha, and evolved from a pedunculate ancestor. The Verrucidae are divided into a basal stem group (Altiverruca, Globosoverruca) and a derived crown group (all other genera). Within the crown group, a monophyletic subfamily Myophorinae nov is identified. Systematic revision of Cretaceous 
verrucomorphs and basal sessilians includes description of four new genera (Pedupycnolepas, Faxoelepas, Youngiverruca, Priscoverruca) and a new species, Youngiverruca withersi. The development of asymmetry was perhaps a feeding adaptation, enabling barnacles to catch crawling benthic prey in deep ocean envirronments where food is scarce.

Key words: thoracicans, verrucomorphs, phylogeny, fossil taxonomy

\section{Introduction}

The origin of the strongly asymmetrical Cretaceous to present day verrucid cirripedes has long been a subject of controversy. In these highly distinctive sessile forms, the outer wall, which attaches directly to the substrate, is made up of four plates - a strongly articulated rostrum and carina, and one fixed tergum and one fixed scutum. The interpenetrant free scutum and tergum form an operculum, opening either in an horizontal plane (e.g. Verruca itself) or a nearly vertical one (e.g. Altiverruca), permitting cirral extension close to the substrate (Anderson 1980, 1994).

Charles Darwin (1854) was uncertain as to the correct affinities of the Verrucidae, and discussed possible relationships with both chthalamine Balanidae and Lepadidae (now Scalpellomorpha). In particular, he noted the close similarity between the free terga and scuta of verrucids and those of Cretaceous species "....had I seen these very important valves separately, I should certainly have concluded that they came from a Pollicipes allied to certain Cretacean fossil species, as P. fallax and elegans" (Darwin 1854, p. 495). Today, these species would be assigned to the brachylepadid species Brachylepas fallax (Darwin) - Turonian to Maastrictian and Pycnolepas bruennichi (Withers) Palaeocene, Danian (Withers 1935). The first fossil verrucids from the Late Cretaceous (Maastrictian) of the Netherlands were described shortly after Darwin's publication (Bosquet 1857); these have been considered to be morphologically very similar to extant species assigned to the genus Verruca (Withers 1935; Buckeridge 2010). 
T.H. Withers was able to provide the first fossil evidence of the evolutionary origins of the verrucomorph cirripedes. In 1914a, he described Proverruca vinculum from Late Cretaceous (Coniacian) chalk of the UK, based on a single articulated individual and many isolated plates. This delicately constructed species has a low capitulum with well demarcated fixed and free scuta and terga, and two lateral plates on the side of the free scutum and tergum.

Subsequently, Withers (1935) described Eoverruca hewitti from isolated plates collected from the Late Cretaceous (Santonian) chalk of Suffolk and Norfolk, UK. He reconstructed this species as having two lateral plates on the side of the moveable scutum and tergum, based on an overall similarity with Proverruca. Withers (1935) noted the strong morphological similarities between plates of Eoverruca and Pycnolepas, and suggested that this supported the notion that the verrucomorpha were "at least diphyletic", with origins in both the Calanticidae, close to Scillaelepas (Proverruca), and the Brachylepadidae (Eoverruca). Newman in Newman \& Hassler (1989) subsequently placed both Eoverruca and Proverruca in a new family, the Proverrucidae.

In 1989, Newman and Hessler described a new extant cirripede, Neoverruca brachylepadiformis, from hydrothermal vents in the Mariana Basin in the West Pacific, and proposed that this form was a living fossil, a link between the dominantly Cretaceous brachylepadomorphs and Eoverruca. Newman (1989) described the ontogeny of this form, and demonstrated how it commenced life as a pedunculate form which progressively became more asymmetrical through growth. The position of Neoverruca as an ancestral verrucomorph was further cemented by Anderson (1994) who enlarged on and extended the original discussion. The notion of a monophyletic Sessilia, including Verrucomorpha, Brachylepadomorpha and Balanomorpha was championed by Newman (1987).

It was therefore surprising that the molecular phylogeny of Pérez-Losada et al. (2008) recovered Neoverruca as positioned within the Scalpellomorpha, sister taxon to other vent-dwelling forms of the family Neolepadidae (Neolepas, 
Vulcanolepas, Ashinkailepas, Leucolepas), and far removed from the traditional Verrucomorpha, which appear as sister group to the Balanomorpha. They therefore proposed that asymmetry of shell plates had evolved at least twice, once in Neoverruca, and again in the "true" Verrucomorpha (Verrucidae). PérezLosada et al. (2008) concluded that shell plates and their ontogeny do not provide a firm basis for analysing cirripede phylogeny, a statement which appears to offer little hope to palaeontological studies.

Recently, the present writer discovered new material of fossils proposed as basal verrucomorphs, originally described by Withers, and was encouraged to look at the morphology of Neoverruca by both Bill Newman and Jens Høeg. The present paper grew out of these studies.

\section{Morphology, nomenclature and homologies.}

\section{General form}

In stalked thoracicans of the Order Scalpellomorpha, the body is differentiated into a flexible peduncle and a capitulum (Darwin 1851;Newman et al. 1969). The capitulum is laterally compressed, bilaterally symmetrical, and made up of an upper whorl of large, paired terga, scuta, and a single tall carina; a shorter rostrum is present adjacent to the scuta. Lower whorls of smaller plates are called laterals and usually include a rostrolatus, an upper latus and a carinolatus, although others may also be present (Fig. 1C). The peduncle is armoured with alternating rows and columns of peduncular scales, which are added at the contact with the capitulum (Young 2001). Verrucomorphs are highly modified and asymmetrical, and have lost the peduncle and all lateral plates, and possess a wall formed of a fixed tergum, a fixed scutum, a carina and a rostrum; the moveable scutum and tergum form an opercular lid (Fig. 2A-E; Fig. 3; Darwin 1854; Newman et al. 1969). The capitulum is bilaterally symmetrical in Etcheslepas, Pedupycnolepas and Pycnolepas (Fig.1A-E) but becomes asymmetrical (slanted carina, scuta and terga with different morphology on each side) in Faxoelepas, and even more so in Eoverruca, in which fixed and moveable scuta and terga are differentiated (Fig. 1F). The asymmetry becomes even more 
marked in Altiverruca, Globosoverruca (Fig. 2A-E; Fig. 3D) and all other verrucids (Fig. 3A-C, F,H,I), as the rostrum and carina form an articular contact.

The capitulum is relatively tall and upright in Altiverruca and Globosoverruca (Fig. 3D,G), but is significantly flatter in Newmaniverruca, Rostratoverruca, Cristallinaverruca and Metaverruca (Fig. 3A,B,E,H,I) such that the opercular lid is subparallel with the base (Young 1998 fig. 24) and the capitulum has a box-like form. In Verruca, the capitulum is a low dome, and the base of the wall is reflexed (Fig. 3 C).

\section{Capitular plates}

Pollicipedids, illustrated here by the Jurassic Etcheslepas Gale, 2014 (Fig. 1C) possess a capitulum which includes numerous lateral plates. An upper whorl comprises a carinolatus, a tall upper latus, and a rostrolatus (Fig. 1D), but additional smaller plates are also present, including a subcarina, a subrostrum and un-named smaller laterals (up to 5). In Pedupycnolepas, Pycnolepas and Faxoelepas (Fig. A,B,D,E), all laterals except the tall upper latus are lost, and in verrucomorphs (Eoverruca and all more crownward taxa; Fig. 1F) laterals are completely absent.

Terga, scuta, and to a variable extent carinae and rostra, of Etcheslepas, Pedupycnolepas, Pycnolepas, Faxoelepas and Eoverruca are characterised by a highly distinctive terraced sculpture of evenly spaced, low ridges, running parallel with the growth margins (Figs 5; 6A,E). These ridges imbricate apically and in Eoverruca form low flanges in which are clearly visible as notches on the occludent margins (e.g.Fig 6E). The ridges are more irregular on the carina and rostrum (Fig. 4A-E). This same terracing is seen also on all plates of Altiverruca and Globosoverruca nitida (Fig. 3D,G) although in the former genus it is obscured by the dominant radial component of the sculpture. In more crownward verrucids, (Fig. 3A,C,E,f,H,I) the terrracing is lost from most of the external surfaces of the wall plates, but retained on the occludent ridges, and the moveable scuta and terga of all taxa. The presence of this sculpture provides evidence to support the monophyly of the Pycnolepas-Eoverruca-Verrucidae 
clade; it is entirely absent in Neoverruca (Fig. 2F-I; 6K,0) and Proverruca (Fig. $6 G)$.

Terga in Pedupycnolepas, Pycnolepas and Faxoelepas are rhombic in outline, possess a strong apicobasal ridge (Fig.4Q,S; Fig. 6A,N) and a well developed wing-like scutal auricle (Gale \& Sørensen 2014a) for articulation with the tergal notch on the interior of the scutum. The auricle is absent in both Proverruca and Neoverruca. A low secondary ridge, set between the apicobasal line and the scutal auricle, is present in Faxoelepas, Eoverruca and verrucids. Right and left terga of Etcheslapas, Pedupycnolepas and Pycnolepas are mirror images of each other, but in Faxoelepas the left and right terga are significantly different; on one side the apicobasal ridge is broader and the secondary ridge better developed than on the other (Fig. 7M,N; 8M,N). In Eoverruca, and all crownward verrucid taxa, distinctively different fixed and free terga are present (Figs 7,8).

The free terga (Fig. 7B,F,J,D,H,L,P) are more conservative morphologically, retaining a rhombic outline, a strong apicobasal ridge, a scutal auricle, and a secondary ridge on the scutal surface. In Altiverruca, Newmaniverruca and Rostratoverruca and (Fig. 7F,P,K) one to three further ridges are developed between the secondary ridge and the scutal auricle on the scutal surface, and in Rostratoverruca and Brochiverruca, these are also developed on the occludentcarinal surface also (Fig. 7L; 10F). The morphological evolution of the fixed tergum is far more complex, as shown in Fig. 7, and shows progressively greater morphological disparity with the free tergum crownwards. In Eoverruca, the fixed tergum is simply a broader, more robust version of the free tergum, but with an apicobasal ridge which is three times broader than that of the free valve (Fig. 7I,J). This has become a broad tergal buttress in Altiverruca and Globosoverruca, representing over half the width of the valve, and the carinaloccludent surface is concomitantly narrower (Fig. 7A,B,E,F). The scutal surface is flat, and the scutal auricle poorly demarcated; minor apicobasal ridges and grooves at the base of the scutal surface interdigitate with corresponding structures on the fixed scutum. Striking changes in are seen Newmaniverruca and all crownward taxa (Fig. 7 C,G,K,O). The tergal buttress broadens, and may 
develop irregular apicobasal corrugations at the base, strongly developed in Rostratoverruca but absent in Cristallinaverruca. The scutal surface becomes inset beneath the buttress, and one to three strong ridges and grooves strengthen the articulation with the fixed scutum. The scutal auricle is variably sized, but always present (Fig. 8 C,G,K,O). The carinal-occludent surface of the valve develops into a wing-like structure, called the occludent wing, which has a convex, thickened occludent margin, separated from the buttress by a flat to convex, smooth region marked by regular growth increments. The carinal margin is straight or concave, and ridges and grooves for articulation with the carina run along the occludent side of the buttress. Further dramatic changes are seen in Verruca; the occludent ridge is straight, and the base of the buttress elongated, giving the fixed tergum a rectangular outline (Fig. 7C). Three strong ridges, and intervening grooves, for carinal articulation, protrude from the carinal end of the buttress. The articulation with the fixed scutum is also modified; a short, deep notch, which retains a scutal auricle in its surface is developed to accommodate a process on the scutum (Fig. 5H).

Changes in the scuta broadly parallel those in the terga, but importantly also involve the scutal adductor muscle (Figs 8,9). The scuta of Pedupycnolepas (Fig. 1A,D) and Pycnolepas (Fig. 4S) are triangular, with a strongly curved occludent margin and a well developed, curved apicobasal ridge. The tergal surface is shorter than the rostral-occludent surface, and is slanted down towards the tergal contact. The scuta are symmetrical in these genera, but in Faxoelepas (Fig. $8 \mathrm{M}, \mathrm{N}$ ) the apicobasal ridge is about three times broader in one of the pair, reflecting incipient asymmetry. In Eoverruca, and all verrucid genera, separate fixed and free scuta are present (Fig. 8). Differences in the scuta of Eoverruca are more marked than those in the terga; the free scutum resembles that of Pycnolepas in shape and development of the apicobasal ridge (Withers, 1935), but a low secondary ridge, between the tergal margin and the apicobasal ridge is present and involved in tergal articulation (Fig. 8I,J). As in the free terga, the morphology of the free scuta remains relatively conservative in a crownward direction; indeed, the free terga of Eoverruca, Globosoverruca and Cristallinaverruca are so similar that they would probably be placed in the same 
genus if found separately. The main modifications seen are multiplication of ridges and grooves on the tergal surface of the free scuta in Altiverruca, Newmaniverruca and Rostratoverruca (Fig. 8F,P,L) and the presence of three ridges on the occludent surface of Rostratoverruca. (Fig. 8L). On the interior of the free scuta (Fig. 9) a deep tergal notch is present, and the scutal adductor scar has migrated apically in Eoverruca and all more derived taxa.

Changes in the fixed scuta also parallel those seen in the fixed terga, with the apicobasal ridge broadening and forming a scutal buttress in Altiverruca and all more crownward taxa (Fig. 8). On the occludent surface, an occludent wing, with a strongly convex occludent margin develops; and the tergal surface becomes inset, and develops ridges and grooves for tergal articulation. In the interior of the valves (Fig. 9), a subapical tergal notch, to accommodate the scutal auricle, is well developed, and lies adjacent to a prominent articular ridge which fits into a groove on the tergum. The site for attachment of the scutal adductor has moved to a lower, more central position in Eoverruca and all verrucids, and in Rostratoverruca and Cristallinaverruca, a raised lip is developed on the basal margin of the adductor scar (Fig. 8G,K). This develops into a sheet-like extension called a myophore in Metaverruca, Priscoverruca nov. and Verruca (Fig. 8C; 10B;20F;23). The myophore is positioned vertically in Metaverruca and Priscoverruca nov., but is horizontal in Verruca.

\section{Carina and rostrum}

The carina and rostrum are broadly similar in construction in Etcheslepas, Pedupycnolepas and Pycnolepas, Faxoelepas, and Eoverruca (Fig. 4A-E, P). The carina is symmetrically triangular and two to four times taller than broad in outer view; the cross section is rounded, and concavo-convex, and the valve is inwardly curved towards the tergum. The rostrum is similar, but lower and broader, being slightly taller than broad. In Faxoelepas and Eoverruca, the carina and rostrum are variably slanted to either the right or left side (Fig. 4A-E). Major changes are seen in Altiverruca, and all other Verrucidae (Fig. 2A-E; Fig. 3), as the carina and rostrum develop an interpenetrant articulation of ridges and grooves, and form the wall on the side of the free valves. At the same time, the apices 
change from an upwards orientation to become directed obliquely outwards, and become less prominent. In Rostratoverruca and Brochiverruca, the rostral apex is marginal in position (Fig. 3; see also Young 1998). In Cristallinaverruca, ridges and grooves run from the apex of the rostrum to articulate with radial ridges and grooves on the moveable scutum (Fig. 3H), and in Rostratoverruca and Brochiverruca comparable, but more oblique ridges run from the apex of the carina to the carinal surface of the moveable tergum (Fig. 3B,E; see Young 1998 fig. 25). In Verruca, a ridge runs from the carinal apex to slot into a groove adjacent to the apicobasal ridge of the free tergum (Fig. 3C). The carina and rostrum change in shape from the ancestral symmetrical form to become broader and asymmetrically concavo-convex.

\section{Peduncular scales and imbricating plates}

Peduncular scales are thought to be homologous with the rows of imbricating plates which surround the capitulum in sessilians (Darwin 1854). In basal sessilians, these are only seen in place in one specimen of B. naissanti (Hébert 1855) (Woodward 1901; Withers 1935; Newman 1987; Gale \& Sørensen 2014a). The uppermost row of these plates have been homologised with balanomorph wall plates (Newman 1987), disputed by Gale \& Sørensen (2014a). The morphology and arrangement of peduncular plates is very similar in Pycnolepas, Faxoelepas and Eoverruca. The lower plates, adjacent to the substrate, have an interiorly directed ledge (Fig. 4I,J,L,N,O), which progressively reduces in width and is lost apically (Fig. 4M,N,O). The inner margin of the ledge of each plate in Pycnolepas and Pedupycnolepas has an interiorly directed oval socket (Withers 1935)which may have acted as an insertion site for a peduncular muscle or even a ligament (Fig. 4L). No corresponding structures exist in extant cirripedes (Anderson 1994). Imbricating scales are absent in all verrucomorphs crownward of Eoverruca.

\section{Origin and evolution of asymmetrical sessile barnacles}

In this section, the morphological support for each of the three evolutionary proposals for the origin of the verrucomorphs is assessed independently, using 
extensive new material of the fossil taxa and reappraisal of living ones, particularly by the use of SEM imaging of plate morphology.

\section{Neoverrucidae and Neolepadidae}

Neoverruca brachylepadiformis Newman (in Newman \& Hessler 1989) was described on the basis of abundant material from hydrothermal vents in the Mariana Back-Arc Basin, Western Pacific. The genus has subsequently proved to be common in Western Pacific vent fields (W.N. Newman, personal communication), but specific assignment of material from other localities is currently uncertain. Neoverruca was interpreted by Newman (1989) and Newman \& Hessler (1989) as an intermediate form between brachylepadids and verrucids, and shown as immediately basal to the Cretaceous Eoverruca in their phylogeny (Newman \& Hessler 1989 Fig. 4).

Subsequently, a further taxon, Imbricaverruca yamaguchii (Newman 2000) was discovered in the Lau Back-Arc Basin, Tonga, Pacific Ocean. This has an operculum, formed of the moveable scutum and tergum; it also has an upper latus, plus four whorls of imbricating plates surrounding the primary wall. The latter features were interpreted as derived from a brachylepadid ancestor.

Evidence presented for the verrucomorph affinities of these taxa include the absence of a peduncle, and the asymmetry developed in the capitular valves, specifically, the formation of a fixed scutum and tergum on one side, and the articulation of the rostrum with the carina on the other (Fig. 2F-I). The "free" scutum and tergum are not strongly differentiated in Neoverruca, and the capitulum is upright, tall and laterally compressed, but low and box-like in Imbricaverruca, thus paralleling the diversity of morphology of verrucids, respectively Altiverruca and Metaverruca (Newman 2000, fig 1).

However, on the basis of molecular evidence, Pérez-Losada et al. (2008) concluded that Neoverruca was actually close to the scalpellomorph family Neolepadidae, and thus represented an independently derived homeomorph of the true Verrucidae rather than a basal form of that group. If neoverrucids are 
closely related to Verrucidae, they would be expected to share some of the synapomorphies of Pycnolepas and Eoverruca (see above);

- Sculpture of the valves. Pycnolepas and all verrucids have a unique and distinctive terraced sculpture of evenly spaced, stepped growth increments (restricted to the moveable plates in more derived forms). This is absent on Neoverruca and Imbricaverruca, where the growth lines are irregular and weak (Fig. 0,K) and similar to those in Calantica (Fig. 6C,P).

- Raised, sharply defined apicobasal ridges on terga and scuta, which form buttress-like struts on the fixed scuta and terga of verrucids, and interlocking structures on the moveable scuta and terga. These are present in Pycnolepas and verrucids, but absent in Neoverruca (compare Pycnolepas and Eoverruca, Fig. 6AB,E,F with Neoverruca, Fig. 6K,0).

- The articulation between scuta and terga in Pycnolepas and basal verrucids is specialised, with a ridge on the tergum slotting into a notch on the scutum (Fig. 6B,F - also Gale \& Sørensen 2014a). No such articulation is found in Neoverruca (Fig. 6L), which is more like that in Calantica (Fig. 6D) .

- The form of the peduncular scales/imbricating lateral plates is distinctive in Pycnolepas and Eoverruca (see above), with an internally directed flange. The equivalent plates in Neoverruca lack these structures (Fig. 2FI).

In terms of detailed morphology, therefore, neoverrucids share little with the Pycnolepas-verrucid clade other than their asymmetry and incipient development of fixed and free valves. The close relationship between Neoverruca and the scalpellomorph family Neolepadidae identified by Pérez-Losada et al. (2008) on the basis of molecular evidence is supported here by morphological data. The morphology of Neoverruca individuals with tall capitula is strikingly similar to that of juvenile neolepadids such as Leucolepas longa - compare Tunnicliffe \& Southward fig. 17E-G with Newman 1989 Fig. 1 (herein Fig. 11C,D). Note in particular the shape and arrangement of the capitular plates and the 
presence of the upper latus which is the sole lateral developed in Neoverruca and neolepadids. Neoverruca is apparently unusual in that it adds new plates between the capitular valves and the inferred carinolatus and rostrolatus (Newman 1989 fig. 1) rather than at the junction between the peduncle and lateral plates as in all scalpellomorphs (Young 2001). However, if the supposed latera in Neoverruca are actually just peduncular scales, the similarities with neolepadids are much closer; an upper latus is generated first, then peduncular scales are added at the base of the capitulum, exactly as in neolepadids (Fig. 11 Tunnicliffe \& Southward 2004).

These observations are supported by the similarity of cyprid larvae of Neoverruca with those of the neolepadid Ashkainolepas, and their dissimilarity with those of verrucids (Jens Hoeg, personal communication). Additionally, close similarities in mouth part morphology between Neoverruca and Neolepas were noted by Newman \& Yamaguchi (1989).

It is concluded that Neoverruca and Imbricaverruca are homeomorphs of Verrucidae, derived from the Neolepadidae, which have independently evolved an asymmetric body plan. Comparison between Neoverruca and immature stages of Leucolepas suggests that paedomorphic heterochronic processes were involved in the evolutionary transition.

\section{Proverruca}

The second known example of asymmetrical thoracican development is less well known, and its evolutionary origin more cryptic. Proverruca is a well characterised Cretaceous (Turonian-Maastrichtian) genus known from a single articulated individual, and a few hundred isolated plates belonging to four species which may be distinguished by their sculpture (Withers 1935, and herein). Withers (1935, p.324) thought that Proverruca shared a common ancestor with the calanticid Scillaelepas, and gave rise to verrucids with a low profile, by loss of the two lateral valves and interlocking of the carina and rostrum. 
The reconstruction published by Withers $(1914 \mathrm{a}, 1935)$ based on the articulated holotype has been widely re-used without further study (e.g. Newman et al. 1969; Newman 1989; Newman \& Hessler 1989). The specimen is refigured and redescribed here (see Systematic Palaeontology). The holotype, although partially articulated, has significant displacement of the terga, moveable scutum and carina which convey a false impression of the form of the capitulum, Thirdly, Withers (1935) misidentified the rostrum (pl 43 fig. 10) of P. vinculum as a carina; as these are significantly different in Proverruca, this is of some importance.

The present redescription of Proverruca is based on Wither's type series of $P$. vinculum from the English Coniacian Chalk, plus material of a new species based on isolated plates from the Campanian of Ivõ Klack (see Gale \& Sørensen 2014b) in southern Sweden, described below as $P$. dentifer sp nov. This is important because it includes two well preserved carinae, lacking from the type material of P. vinculum. The original material of Withers is refigured in Fig. 13, and a new reconstruction in Fig. 12. The outline is nearly symmetrical, oval, and the convex outer margins of the rostrum and carina form the ends of the long axis (Fig. 12B); in side view, the upper margin slopes from the rostrum to an apex formed by the apices of the terga, set above the carina. The wall on the fixed side is formed by one side of the rostrum, the large fixed scutum, and the erect fixed tergum (Fig. 12 A). On the other side, the carina and a low process from the rostrum do not make contact, and are covered by a pair of imbricating lateral plates, identified as respectively carinolateral and rostrolateral (Withers 1935). The free tergum and scutum form an opercular lid which is angled at about $15^{\circ}$ to the basal margin. The surface sculpture in P. vinculum consist of regularly spaced ridges and radial narrow ridges (Fig. 14) which forma reticular pattern. Thorn-like nodes are present where these intersect.

The articulations between the plates in Proverruca are very simple; the interior of a well preserved fixed scutum (Fig. 6H) has two narrow, bevelled margins for contact with respectively the fixed tergum and moveable scutum, very similar to those developed in the scutum of Calantica sp. (Fig. 6D). This type of contact is 
quite different to that developed in Eoverruca and Pycnolepas (Fig. 6A,B,E,F) in which a scutal auricle on the tergum articulates tightly with a tergal notch on the scutum (Gale \& Sørensen 2014a).

Although Proverruca is constructed in a similar way to verrucomorphs, with a wall made up of fixed tergum, scutum, carina and rostrum, and an opercular lid made of the moveable tergum and scutum, several lines of evidence suggest that it is convergent with verrucomorphs, rather than part of their ancestry. The presence of two large lateral plates in Proverruca was taken as evidence that the ancestor was a form in which these plates were well developed - a calanticid or scalpellid (Withers 1935). Additionally, the morphology of the scuta and terga (weak tergal-scutal articulations, variable reticulate sculpture) is suggestive of a scalpellomorph ancestry.

The absence of numerous synapomorphies which link Pycnolepas, Faxoelepas, Eoverruca and the Verrucidae (e.g. sculpture, interlocking ridges on terga and scuta, scutal-tergal articulation, imbricating plates - see below) indicate that Proverruca is unrelated to the verrucid lineage, and represents a second, independent evolution of an asymmetrical body form in thoracicans, probably originating from within the Scalpellidae or Calanticidae. However, the morphological changes (e.g. formation of fixed and mobile scuta and terga, primary wall formed of C,FT,FS,R) closely parallel the pattern seen in the Pycnolepas-Eoverruca-Verrucidae lineage, generating an overall morphology which is remarkably similar to that of the Verrucidae. This lead Withers (1935) to place Proverruca at the base of part of the family, and Newman (1989) to put Proverruca and Eoverruca in the family Proverrucidae.

\section{Pycnolepas - Verrucidae}

Withers (1935, p. 324) stated that "Eoverruca.....in the general structure of its valves, has much resemblance to the sessile Pycnolepas." He originally identified the carina and rostrum of Eoverruca as an undescribed species of Pycnolepas, before the tergum and scutum were found (p. 338), and he believed that Eoverruca was ancestral to Altiverruca. The similarities in valve shapes and 
sculpture between Pycnolepas and Eoverruca are indeed striking (e.g. Fig. 4AE;Fig. 6A,B,E,F,M,N; Fig. 7M,N; Fig. 8I,J,M,N; Fig. 9I,J,M,N) and the new discovery that Eoverruca possessed several rows of imbricating scales around the capitulum (see Systematic Palaeontology, below, and Fig. 17) strengthens the likely relationship between the genera.

Pycnolepas, and the new genus identified here as Faxoelepas (F. bruennichi) have a highly distinctive sculpture which consists of evenly spaced, low ridges parallel with the growing margins of the valves, which imbricate weakly towards the apex (e.g. Fig. 6A, nb. occludent margin). A similar sculpture is present on Eoverruca, but the amount of imbrication has increased (e.g. Fig. 6E,M). This very regular sculpture is best developed on the scuta and terga, but is also present on the carina and rostrum (Fig. 4A-E). The carinae and rostra in Faxoelepas and Eoverruca are similar in their semiconical shape, and the carinae also show the unusual feature of an asymmetrical slant (Fig. 4A-E). The terga and acuta of Faxoelepas and Eoverruca also share very similar shapes (rhombic terga, triangular scuta with a convex occludent margin), and well developed, curved apicobasal ridges (e.g. Fig. 7I,J,M,N; Fig. 8 I,J,M,N). F. bruennich also shows a consistent asymmetry between tergal and scutal pairs - the incipient development of free and fixed valves, and slight development of a secondary ridge between the apicobasal ridge and tergal-scutal contact, well developed in Eoverruca. The tergal:scutal articulation is distinctive in Pycnolepas and Faxoelepas, comprising a well marked groove on the scutum (tergal notch) into which the tergal auricle fits (Fig. 9I,J,M,N - see Gale \& Sørensen 2014b). This is equally well developed in Eoverruca, and indeed in extant Verrucidae (Fig. 9).

Withers' reconstruction of Eoverruca $(1935$ figs 37,38$)$ was based largely on the articulated specimen of Proverruca, which has two lateral plates on one side only (Fig. 14A-C). In fact, the capitulum of Eoverruca was surrounded by at least three alternating rows of imbricating plates, with eight to ten plates in each row (Fig. 17A-G). The peduncular scales have a similar morphology to those of Pycnolepas and Faxoelepas; the lower ones have an inwardly directed basal ledge (compare Eoverruca, Fig. 4I,J with Pycnolepas, Fig. 4G,H,K-O), and the upper scales are 
rhombic and flat, with downwardly V-ing ridges (compare Faxoelepas, Fig. 4F, with Eoverruca, Fig. 18A-H).

The case for a close relationship between Pycnolepas, Faxoelepas and Eoverruca is compelling, with the probability that the Verrucomorpha evolved from Faxoelepas by stabilising the asymmetry seen in F. bruennichi and concomitant loss of the upper latus. The most basal verrucomorph known, Eoverruca hewitti, resembled a small, squat sessile Pycnolepas, with several whorls of lateral plates (Fig. 1E,F), but had moderately well differentiated fixed and mobile scuta and terga articulated by means of interlocking flanges and grooves as in Altiverruca. E. hewitti therefore forms a morphological link between Pycnolepas and Altiverruca, as suggested explicitly by Withers in 1935. The relationships of Pedupycnolepas, Pycnolepas, Faxoelpas with the Verrucomorpha are therefore investigated by cladistics analysis.

\section{Cladistic analysis of the Verrucomorpha}

The foregoing section confirms the close relationship between Pycnolepas and the basal verrucomorph Eoverruca proposed by Withers (1935), and rejects Proverruca and Neoverruca as part of the ancestry of the group; these groups evolved an asymmetrical form convergently. In this section, the relationships between Pycnolepas, Eoverruca and Verrucidae are tested using cladistic analysis.

Unconstrained heuristic analysis using PAUP, optimised to Deltran, was applied to fourteen species, using a list of 38 characters (Table 2). A single consensus tree was recovered from 21 best trees, and robustness was tested using bootstrap and Bremer support (Fig. 13).

A monophyletic Verrucomorpha, including Eoverruca and all Verrucidae was well supported (100\% bootstrap, >10 Bremer), and is divided into a stem group (Eoverruca) and a crown group (Verrucidae). Successively more basal sister taxa are Verrucomorpha + Faxoelepas (92\%, Bremer $>10)$, and Pycnolepas + 
Faxoelelas + Verrucomopha (63\%, >10 Bremer). The Verrucidae is divided into a basal stem group (Globosoverruca, Altiverruca) and a well supported crown group (all other Verrucidae). The crown group includes a derived monophyletic clade comprising Verruca, Priscoverruca nov. and Metaverruca, here called the Myophorinae nov. The relationships of this clade, Newmaniverruca, Brochiverruca, Rostratoverruca, and Cristallinaverruca were not resolved, and remain as a polytomy in the consensus tree.

Some stratigraphical calibration of the phylogeny is possible. Eoverruca is known from Late Santonian to Early Campanian sediments dating from about 84 to 80 Ma, and Priscoverruca was already were present by the Late Campanian, at approximately $78 \mathrm{Ma}$, and Verruca by the Late Maastrichtian, at about $68 \mathrm{Ma}$. This makes it likely that either:

a) The verrucomorph radiation took place rapidly in the Late Cretaceous, between the first appearance of a stem group member (Eoverruca) at $84 \mathrm{Ma}$, and the most highly derived clade in the crown group (Priscoverruca) at $78 \mathrm{Ma}$. With the appearance of Verruca in the Maastrictian, the radiation was effectively over by about 68Ma.

b) The appearance of genera is rather sporadic and in no way reflects the order which the phylogeny presented here would suggest. Thus, Priscoverruca, a member of the most derived crown group clade, appears 6 million years after the first occurrence of stem group verrucomorphs, with no representation of more basal crown group members until the Maastrichtian (about 68Ma) when Youngiverruca is found. It is therefore possible that the verrucomorphs had a longer fossil record extending further back into the Cretaceous which remains unknown at present. Pérez-Losada et al. (2008) suggested that the split between verrucomorphs and balanomorphs took place at approximately the Jurassic - Cretaceous boundary, at about 145Ma. However, this pre-dates the first occurrences of definite members of stem group Sessilia, such as Pycnolepas rigida, which appear at about 110Ma (Albian - Gale \& Sorensen 2014) and is probably too early. The most likely date for the 
division of the Sessilia, on the available evidence, falls at about 100Ma (Albian-Cenomanian boundary).

\section{Systematic Palaeontology}

Order Scalpellomorpha Buckeridge \& Newman, 2006

Incertae sedis.

Genus Proverruca Withers, 1914a

Diagnosis: Body form small, squat, with a wall made up of a fixed scutum, a fixed tergum, a carina and a rostrum, and an opercular lid made of a moveable scutum and a moveable tergum. Plates simply overlap and lack specialised articular surfaces; a single rostrolatus and a carinolatus are present on the free side

Discussion: Proverruca is represented by a single articulated individual of $P$. vinculum Withers, 1914a from the Coniacian Chalk of the UK (Withers 1914a; 1935), refigured (Fig. 14A-C) and redescribed here. Unfortunately, this specimen is coated with secondary silica, and detail is therefore partly obscured. The new SEM images provide a better impression of the form of the taxon than Withers' somewhat stylised drawings. In addition, new material from the Campanian (c. $80 \mathrm{Ma}$ ) rocky shoreline at Ivõ Klack in southern Sweden includes the first true carina of Proverruca, and the species is here described as $P$. dentifer sp. nov ( see also Gale \& Sørensen 2014b). A selection of the material used by Withers (1914a, 1935 ) is refigured here (Fig. 14D-I), and the following description is based on all the available material of the genus (see also Figs 15,16).

Description. The type specimen of $P$. vinculum (Fig. 14 A-C) is articulated, but the free scutum and tergum are slightly displaced. The rostrum (Fig. 14E,G) has a concavo-convex region which articulates with the fixed scutum, and a flat, elongated process which runs along the side towards the carina, with the top of which the base of the free scutum articulates. The fixed scutum (Fig. 14H,I) is 
quadrangular, with an oblique apicobasal ridge, and forms much of the wall on the fixed side. A large adductor scar is positioned low on the interior of the valve (Fig. 14H; Fig. 15I,J). The triangular free scutum articulates with the occludent margin of the fixed scutum, and the upper margin of the rostrum. The fixed scutum overlaps the fixed tergum by means of a short flange (Fig. 14E,G). The rhombic fixed tergum (Fig. 15B) has a rounded contact with the free valve and an central apicobasal ridge. The semiconical carina (Fig. 15A-C) has an obliquely directed apex, and appears to wrap loosely around the fixed tergum. Two lateral plates are present (Fig. 14A,B); the larger, triangular one, which Withers (1914, 1935) described as a rostrolatus, overlaps the carina and the rostrum. The smaller, low, elongated plate, identified as a carinolatus, overlaps the wing of the rostrum, and the rostrolatus.

There are some enigmas associated with the precise construction of Proverruca. Firstly, the carina is now known in $P$. dentifer sp nov. (the plate figured by Withers 1935 pl 43 fig. 10 as a carina is really a rostrum), and has some unusual features, particularly the presence of a thickened margin on one wing, which has a concave facet apparently for a firm articulation (Fig. 15A,B). In the type specimen of $P$. vinculum, the carina wraps around the fixed tergum, and presumably its tergal margin originally articulated with the lower carinal margin of the free tergum, which is now displaced. An irregular groove is visible on the tergal margin of the carina (Fig. 14B) which presumably originally made contact with the free tergum. However, there does not appear to be any specialised surface on the lower carinal margin of the free tergum (Fig. 14D; Fig. 15D,E), so perhaps it simply slotted into the groove. The new reconstruction (Fig. 12A-C) shows this arrangement.

The wall plates in Proverruca are only loosely articulated, and entirely lack the interpenetrant ridges present in verrucids. Furthermore, the articulation between the fixed tergum and scutum is very simple, and completely lacks a scutal auricle and tergal notch, well developed in Pycnolepas, Brachylepas, verrucids and balanomorphs (Gale \& Sørensen 2014a). The region of the scutum which articulates with the tergum in Proverruca is similar to that in Calantica 
(Fig. 6, compare D,H), and a bevelled edge on the interior of the scutum simply rests on the tergum. Proverruca is identified as homeomorphic with verrucids, and probably evolved from a calanticid or scalpellid, as suggested by Withers (1935).

\section{Proverruca dentifer sp nov.}

(Fig. 6G,H; 15A-0; fig. 16A-I)

Diagnosis. Proverruca with a highly variable sculpture including rather few, coarse apicobasal ribs, intersected by narrow, low flanges parallel with the growth lines of the plates; short rugosities, resembling file teeth, are variably developed.

Types. The free tergum figured (Fig. 15E) is holotype. NHM In.XXXXXX. The other figured valves are paratypes (In. XXXXXXX-XXXXXX)

Material. 38 valves from Ivõ Klack, including 3 fixed scuta, 22 moveable scuta, a carina, 4 moveable terga and 2 fixed terga. The rocky shoreline deposits at Ivõ are of lower upper Campanian age (Surlyk \& Christensen 1974; Surlyk \& Sørensen 2010).

Description. The sculpture of the external surfaces of the scuta and carina is made up of numerous, apicobasal, radiating ridges, which are traversed by low flanges parallel with the growth lines. The relative prominence of the radial elements and growth parallel ones is highly variable; at one extreme, (e.g. Fig. 16C) the growth parallel element is dominant, at the other (Fig. 16B,E) the radial ridges are prominent. The radial ridges develop nodes at the intersections with the growth lines, which are also highly variable in prominence. Additionally, growth interruptions, marked by changes in sculpture and growth, are variably present (Fig. 16C).

The carina (Fig. Fig. 15A-C; Fig.16 G) is semi-conical in form, and slightly truncated apically. The two wings are set at right angles, and the one which is 
identified as contacting the free tergum (see above) is longer; the tergal margin is thickened, concave, and traversed by horizontal grooves and ridges. The rostrum is unknown. The fixed scutum (Fig. $15 \mathrm{H}-\mathrm{K}$ ) has a low, nearly equilateral triangular form, with long gently convex basal and occludent margins, and a straight to slightly concave tergal margin. The exterior surface carries evenly spaced apicobasal radial ribs, interrupted by prominent growth lines, and nodes where these intersect. The interior shows a large scutal adductor scar low on the face, and narrow, depressed margins for contact with the fixed tergum and free scutum respectively. The moveable scuta (Fig. 15L-0; Fig. 16A-F, H,I) are the plates most commonly found; they have the form of asymmetrical right triangles with apices inclined towards the tergum. The occludent margin is gently convex, the tergal margin slightly concave. There is considerable variation in proportion of the plates, with narrow, taller forms (Fig. 15N,0; 16B,D,E), and lower ones with longer basal margins (Fig. 15L,M; Fig. 16C,F). Some show very irregularly developed growth increments, with clear interruptions to growth (Fig. 16C,F). The fixed terga (Fig. 15F,G) are rhomboidal, and have separate upper and lower carinal margins. There is a weak apicobasal ridge, and the scutal surface is broad and flat with weak sculpture. The carinal surface is arched and the occludent margin is straight. The moveable terga (Fig. 15D,E) are sub-rhomboidal, with a low apicobasal ridges carrying a noded sculpture where the growth increments intersect. The broad scutal surface bears seven to ten weak radial ridges which carry variably prominent low flanges. The broad, flat carinal surface shows strong growth lines and weak nodes. The interior surface is flat.

Discussion. The valves can be directly compared with those of Proverruca species figured by Withers (1935); P. dentifer differs from P. vinculum Withers (Fig. 14), P. cancellata Withers and P. laurae Withers in the more prominent radial ridges weaker growth parallel flanges, and stronger nodose sculpture.

\section{Genus Pedupycnolepas nov.}

Type species. Pycnolepas articulata Collins, 1980 
Diagnosis. Capitulum and peduncle of a equal height, peduncle constructed of approximately 20 columns of rather large plates, set in 12-15 rows. Tergum lacks secondary ridge, apicobasal ridge almost straight.

Remarks. Although the morphology of the capitular plates have been used to place P. articulata in the genus Pycnolepas (Collins 1980; Jagt et al. 2006), the clear presence of a peduncle in the type material separates the species from the best known species of the genus, $P$. rigida, which lack a peduncle, and has a low skirt of imbricating plates (Withers, 1935, confirmed here). Pycnolepas is a thus paraphyletic genus, comprised of an assortment of derived scalpellomorphs ( $P$. articulata), basal sessilians (P. rigida) and a species basal to the verrucomorphs (P. bruennichi) (Gale \& Sørensen 2014a). P. bruennichi is here assigned to a new genus, Faxoelepas (see below).

Pedupycnolepas articulata (Collins, 1980)

(Fig. 1A,B,D)

Type. Fossil Bluff Formation, ? Lower Aptian, Alexander Island, Antarctica. KG. 1657b, paratypes KG 1657a,c. BAS Coll.

Description. The type material consists of three partially articulated specimens, closely associated, and preserved as external moulds; a cast from this specimen is figured here (Fig. 1A). The three individuals have the form of a bouquet, itself suggestive of the presence of peduncles rather than short skirts of imbricating plates. Peduncular scales are present on the middle individual, and although partially disarticulated, these provide evidence that a peduncle approximately equivalent in height to the capitulum was present, composed of about 15 rows of scales. The width of these scales, in comparison with that of the tergum, provides an accurate estimate of the number of columns, and the species is reconstructed accordingly (Fig. 1D).

The capitular plates have a distinctive sculpture of low, narrowly spaced growthparallel ridges, and radial ridges of somewhat narrower spacing; low thorn-like 
structures are present where the ridges intersect, especially developed on the terga. The tergum is rhombic, with a narrow, straight apicobasal ridge and a low, broad scutal auricle. The scuta are all incomplete, but possessed a strongly curved apicobasal ridge, and similar sculpture to the terga. The carina is tall, concavo-convex in cross section, and inclined towards the tergum.

Order Sessilia Lamarck, 1817.

Pérez-Losada et al. (2008) recovered a monophyletic Sessilia on the basis of molecular analysis, supported by the morphological analysis of Gale \& Sørensen (2014a). The transition between pedunculate forms and basal sessile taxa falls between Pedupycnolepas nov. which retains a peduncle, and Pycnolepas which lacks one, possessing a low skirt of imbricating plates (Withers 1935). Faxoelepas nov. develops incipient asymmetry, and is sister taxon to the Verrucomorpha. Another descendant of Pycnolepas, the paraphyletic Brachylepas, gave rise to the Balanomorpha (Gale \& Sørensen 2014a).

Genus Pycnolepas Withers, 1914b.

Type species. Pycnolepas rigida (J.de C. Sowerby, 1836)

Diagnosis. Tall, erect capitulum comprised of symmetrical carina, rostrum, and paired scuta, terga and upper lata. Imbricating plates form low skirt around base of capitulum, peduncle absent.

Pycnolepas rigida (J.de C. Sowerby, 1836)

(Fig. 4G,H,K-T)

Discussion. In light of discoveries made recently, it has been been necessary to subdivide Pycnolepas as used by Withers (1935) and Jagt et al. (2006), by separating off a species with a peduncle (Pedupycnolepas articulata) and an asymmetrical form (Faxoelepas bruennichi). P. rigida is figured here to show the contrasts with the other two genera. 


\section{Genus Faxoelepas nov.}

Type species. Pycnolepas bruennichi (Withers, 1914b)

Diagnosis. Capitulum constructed of paired terga, scuta, a carina, a rostrum and an upper latus; the scuta and terga display two forms, one with a broad apicobasal ridge and a secondary tergal ridge, the other with a narrow apicobasal ridge - incipient development of fixed and free valves. The carinae are usually slanted asymmetrically to one side.

Derivation of name. After the town of Faxoe in Denmark, from which the type material came, and where the species is locally abundant (Donovan \& Jacobsen 2010).

Faxoelepas bruennichi (Withers, 1914)

(Fig. 4A,C,F; Fig. 6A,B,N; Fig. 7M,N; Fig. 8M,N; Fig. 9M,N)

Discussion. Although F. bruennichi has an overall morphological similarity with P. rigida, and has always been considered as a natural member of Pycnolepas, the marked asymmetry presented by both the slanted carinae and the tergal and scutal pairs is similar to, but less consistent than, the development seen in Eoverruca (Withers 1935; herein, see below). The asymmetry was probably variably developed, because upright carinae are found. However, the cladistic analysis conducted here places $F$. bruennichi as sister taxon to the monophyletic Verrucomopha. Similarities of valve sculpture and the morphology of the peduncular scales strengthen this relationship.

\section{Suborder Verrucomorpha Pilsbry, 1916}

Diagnosis. Sessilians which have lost the upper latus $(8,0->1)$, and in which the terga and scuta have developed into separate fixed and free valves (10, 1->2). 
Discussion. It is apparent that the upper latus was lost twice in the Sessilia, one in basal verrucomorphs, and once in the Neobalanomorpha (Gale \& Sørensen 2014).

\section{Stem Group Verrucomorpha}

\section{Genus Eoverruca Withers, 1935}

Diagnosis. Basal verrucomorph which retains peduncular plates, and in which there is no contact between the rostrum and carina, but fixed and moveable terga and scuta ar developed. Basis calcified in fully grown individuals.

\section{Eoverruca hewitti Withers, 1935}

(Figs 1F; 17-19)

v.1935 Eoverruca hewitti Withers, p. 338, figs 37,38, pl.44, figs 9-18

2008 Eoverruca hewitti Withers, Jagt et al., figs 2,3.

Types. The holotype fixed scutum from the Santonian Uintacrinus socialis Zone of East Harling, Norfolk, Withers 1935. In. 27598.

Material. New collecting from the Santonian Uintacrinus Zone of Hinderclay Lane, Haslingfield, Suffolk, by processing about $50 \mathrm{~kg}$ of chalk has provided abundant new material of the species. In addition to approximately 450 isolated valves, the finds include two complete calcareous bases in which peduncular scales are embedded, and fragments of other individuals.

Description. All plates carry a distinctive terracing of evenly spaced, apically imbricating short flanges, which is more evenly developed on the tergum and scutum and less so on the carina and rostrum. The flanges are very conspicuous on the occludent margins of the scuta and terga, where they form tooth-like short protrusions (e.g. Fig. 19G,J,M). The carina (Fig. 18I-L) is approximately twice as tall as broad, with a straight basal margin and an evenly rounded cross 
section. The rostrum (Fig. 18M-P) is similar, but is as broad as it is tall, and commonly three or more apicobasal ridges are present, which serve to define separate, angled faces on the basal margin. The rostrum is invariably slanted asymmetrically, and the carina variably so.

The terga (Fig. 19A-H) are rhombic, and half to two thirds as broad as tall. A strong, curved apicobasal ridge expands into a short talon at the junction of the scutal and carinal boundaries. The occludent margin is convex, the carinal margin straight. A secondary ridge, which takes the form of a broad fold, is present between the apicobasal ridge and the scutal auricle. The terga can be consistently divided into fixed and free types (Withers 1935), using three criteria;

1) The talon-like extension of the apicobasal ridge is twice as broad in the fixed terga, and has a separate, elongated basal surface on the carinal side (Fig $19 \mathrm{E}-\mathrm{H}$ ). In free terga, it is narrower and has a rounded base (Fig. 19A-D).

2) The distance between the scutal side of the apicobasal ridge and the secondary ridge is twice as great in the free terga ((Fig. 19 A-D) than in the fixed ones (Fig. 19E-H).

3) The scutal auricle is sharply defined by an inflexion of the growth lines in the free terga (Fig. 19A-D), absent in the fixed terga (Fig. 19E-H).

These differences are not very great, but appear to be consistent in the hundred or so valves examined.

The scuta (Fig. 19 I-0) are triangular, with a convex occludent margin, and a well developed apicobasal ridge which extends as a short projection from the join of the basal and tergal margins. Two low secondary ridges are present on the tergal margin, which are simply raised regions of the imbricating terraces (Fig. 19J,M). The fixed and free scuta display greater differences than do the terga;

1) The occludent margin is more strongly convex in the free scuta ((Fig. 19 J,M) than in the fixed ones (Fig. 19K,L), and the basal margin is straight in the free terga but concave in the fixed ones. 
2) The apicobasal ridge is straight and twice as broad in the fixed scuta (Fig. $19 \mathrm{~K}$ ), whereas it is narrow and strongly curved in the free valves (Fig. 19J,M).

3) The tergal portion of the fixed valves (Fig. 19K) is much narrower than that of the free valves (Fig. 19J,M), and is inset, rather like a tergal slip (Withers 1935). The two secondary ridges on the fixed valve are narrower and better defined than on the free one.

4) The tergal notch is short and deep on the free valves (Fig. 19I), and relatively broad and shallow on the fixed valves (Fig. 19L,0).

The loose peduncular scales are of two types. Those which have a more apical position are rhombic in outline, with three to six downwardly V-ing terraces, which are deflected down to form a central ridge (Fig. 18A-H); the interior is flat. The other type, which was more basal in position, has an inwardly directed shelf similar to that in Pycnolepas, and are seen to carry smaller adventitious scales developed on the basal margin (Fig. 17I-L). The tiny scale figured in $17 \mathrm{~K}$ was originally found in place in the slot on the base of the larger one shown in 17I,L. They are cemented in place in individuals which have calcified the basis (Fig. 17H).

The bowl-like calcareous basis (Fig. 17A-G) has an irregular oval outline $(2.5 \mathrm{~mm}$ x $2 \mathrm{~mm}$ ), a moderately flat base and a low wall composed of peduncular scales fused together by the basis. The base is thin and slightly undulating, and has a narrow slit-like gap near the centre. The upper part of the wall is constructed of nine relatively large triangular scales which are directed slightly outwards, and stand proud of the wall. A lower row of smaller but similar scales which alternate with the upper row is present, and below this, numerous tiny scales are embedded in the basis (Fig. 17E-G).

Reconstruction. Fig. 1F. The bowl-like structure of cemented peduncular scales evidently served as a base for articulation of the capitular plates, and was presumably attached to a soft bodied substrate which has not left any distinctive markings. However, the presence of isolated peduncular scales in the residues, 
including both forms with a large incurved shelf, which occupied a basal position, and larger rhombic plates like those in the top of the wall, indicates that calcification and fusion was not ubiquitous in all individuals. Possibly secretion of the basis only took place in fully grown individuals. The presence of tiny, adventitious scales on larger ones, and their common presence on the basis itself indicates that these were introduced widely, and not just at the peduncularcapitular contact as in scalpellomorphs (Young 2003).

Occurrence. Late Santonian, Suffolk, UK, Lower Campanian of Poland (Jagt et al. 2004).

\section{Crown Group Verrucomorpha}

Family Verrucidae Darwin, 1854

Diagnosis. Verrucomorphs in which there is an articulation between the carina and rostrum (31, 0->1), in which the apicobasal ridges of the fixed terga and scuta broaden to form buttresses $(11,0->1)$, the peduncular scales and upper latus are lost $(1,1->2),(8,0->1)$, and the operculum is angled at $30-40^{\circ}$ to the base $(4,0->1)$.

\section{Stem group Verrucidae}

There are two stem verrucid genera Altiverruca and Globosoverruca, which are not known from the fossil record. They lack the synapomorphies of the crown group (see below).

\section{Crown group Verrucidae}

This group is very well supported by numerous characters. Capitulum flattened, box-like,opercular lid horizontal (4, 1->2); regular terraced sculpture restricted to lateral parts of fixed plates $(6,0->1)$; secondary ridges on fixed scuta and terga deeply interlocking $(12,1->2)$; prominent articular ridge present on fixed scutum (13, 0->1); umbones of rostrum and carina short (28, 0->1); carina-fixed 
tergum contact forms interpenetrant zig zag (33, 0->1); rostrum-fixed scutum contact forms interpenetrant zig zag (34, 0->1).

This group is well defined, but the relationships between the constituent genera and the Myophorinae nov. are not resolved (Fig. 13) and remain as a polytomy.

\section{Genus Youngiverruca nov.}

Diagnosis. Fixed scutum with large, flat, triangular buttress, and a strong, straight ridge running from the apex to the base of carinal margin; behind this, the occludent wing is short and recessed. In the fixed tergum, the tergal buttress is tall, triangular, gently convex, with a short, broad occludent wing.

Type species. $Y$. withersi nov.

Derivation of name. The genus is named after the late Paulo Young, remembering his great contributions to the study of living cirripedes, and verrucids in particular.

Remarks. Among the material from the Maastrichtian of Rugen figured and cited by T.H. Withers in 1923 and 1935 as Verruca prisca Bosquet there are a number of valves which are very different to that species, and cannot be placed in any extant verrucid genus. These include two fixed terga and a fixed scutum (Fig. 20 A-D, J-L) which are here placed in Youngiverruca withersi nov. The morphology of the fixed tergum is closest to that of the extant Cristallinaverruca cristallina (Gruvel) in its tall triangular tergal buttress, but has a shorter occludent wing, and a more prominent tergal auricle. The fixed scutum is quite unlike that of any known verrucid in its strongly recessed, short occludent wing, but has some slight similarity with $C$. cristallina in the presence of a straight ridge running from the apex to the base of the carinal margin.

Youngiverruca withersi sp. nov. 
(Fig. 20, A-D, J-L)

p.1935 Verruca prisca Bosquet, Withers pl 45 fig. 13 only.

Types. The fixed tergum figured by Withers (In. 16224) is holotype, the other fixed tergum and the fixed scutum are paratypes (In. XXXXXXX).

Material. Three valves, two fixed terga and a fixed scutum.

Description. The tergal buttress is nearly an isosceles triangle in outline, and is twice as tall as broad (Fig. 20A,B,D). The surface is gently convex, and smooth except for regular growth lines. The occludent wing is broad, but short, extending for between half to two thirds the length of the buttress margin. The occludent margin is very slightly convex. On the carinal side of the buttress, two strong ridges for articulation with the carina are present (Fig. 20C). A prominent, triangular tergal auricle is developed (Fig. 20A-D), adjacent to which is a deep groove for articulation with the main articular ridge of the scutum, and two minor articular ridges are developed. The fixed scutum (fig. $20 \mathrm{~J}$-L) has a large nearly flat buttress, with the outline of a right triangle; the tergal margin is straight. A straight ridge runs from the apex to the base of the carinal margin, and the carinal and occludent part of the valve is inflected behind this. The occludent wing is narrow, and only extends for half of the buttress margin. Strong articular ridges for contact with the rostrum are present. In the interior of the valve, a tergal notch is present, and a large, centrally placed adductor scar.

\section{Subfamily Myophorinae nov.}

Diagnosis. Verrucids which posses a tongue-like myophore on the fixed scutum for insertion of the scutal adductor $(19,1->2)$. Additional characters are: the occludent margin of the fixed valves is set at right angles to the maximum height of the valves $(15,0->1 ; 16,0->1)$; tergal notch deeply inset $(17,0->1)$; articulation between fixed scutum and tergum, short, apical, internal (18, 0->1). 
Included genera. Verruca, Priscoverruca nov., Metaverruca.

Remarks. The cladistic analysis recovered a strongly supported monophyletic group including these three genera.

\section{Genus Priscoverruca nov.}

Type species $V$. prisca Bosquet, 1854.

Diagnosis. Capitulum twice as broad as high, carina and rostrum not inflexed on free side of capitulum. Butresses of fixed valves and carina and rostrum smooth, slightly convex, with more or less regular growth lines. Free scutum with occludent margin strongly incurved at apex.

Remarks. Priscoverruca is closest to Verruca, but differs importantly in taller capitulum, the lack of basal inflexion of the carina and rostrum, the vertical rather than horizontal orientation of the myophore, the deep apical invaginations of the fixed scutum tergum and carina, the smooth exterior of the wall, marked only by regular growth lines, rather then the irregular growth lines and corrugations and present in Verruca. Additionally, Priscoverruca lacks the distinctive small pores on all valves characteristic of Verruca. The two genera share a number of derived characters, including the nature of the upper part of the fixed tergum:scutum articulation (Fig. 20N,O,P), and the distinctive ridge on the carina which articulates with the moveable tergum .

Priscoverruca shares the apical internal cavities with Cameraverruca Pilsbry, 1916, but differs from this genus importantly in the nature of the contact between the fixed terga and scuta; this is a straight external contact between the buttresses in Priscoverruca, whereas in Cameraverruca, and the closely related Metaverruca Pilbry 1916 there is a broad region of exposed scutal auricle which contacts a flange on the fixed tergum (Fig. 10A). 
1923 Verruca prisca (Bosquet), Withers, Figs.......

p.1835 Verruca prisca Bosquet, Withers, pl. 45 figs. 7-12, 14 only.

1989 Verruca prisca (Bosquet), Jagt \& Collins, fig. 4, d,e,g,

Lectotype. The moveable scutum figured by Bosquet (1854, pl. I figs 2a,2b) was selected as lectotype by Withers (1923).

Material. The present description is based on the well preserved entire individuals from the Campanian Vijlen Chalk Member of the CPL Quarry, Haccourt, Belgium (Jagt \& Collins 1989; In. XXXXXX) and the late Campanian Belemnitella mucronata Zone of Norwich, Norfolk UK (In. 27155, In. 27156), augmented by isolated valves from Rugen, Germany, described by Withers $(1923,1935)$.

Description. The capitulum (Fig. 3F, 21A, 23E,F) is oval in apical outline, and twice as broad as tall. The upper surface, formed by the free valves, is flat, and the slightly concave sides slope in to the top of the capitulum (Fig. 21A). The carina and rostrum (Fig. 21I,J,L,M) are concavo-convex, and asymmetrically curved; the deeply interpenetrate contact between the two plates is formed of four ridges and intervening grooves on each plate. The articulation forms a broad triangular region on the side of the capitulum.The scutal:rostral and carinal: tergal contacts are also formed by interdigitating ridges, but these are smaller. A ridge from the apex of the carina articulates with base of the free tergum. The interior of the carina has an apical recess (Fig. 21J) like the scutum and tergum.

On the fixed tergum (Fig. 20E-I) the buttress has the outline of an isoceles triangle, with a convex basal margin and a gently convex external surface (Fig. 20 E-I). The occludent wing is very prominent, set at $90^{\circ}$ to the midline of the buttress, and has a convex occludent margin. Two ribs, tucked beneath the edge of the buttress, articulate with the carina. The articulation with the scutum is 
straight, without ridges. The fixed scutum is rectangular in outline, and the base of the triangular buttress extends across the width of the valve. A large, triangular occludent wing, with a straight to slightly convex occludent margin is present, and two en echelon ridges for tergal articulation run to the lower rostral margin. The interior of the valve shows a well-developed myophore, which is situated on the rostral side of an inverted, V-shaped hollow platform; the crest of the platform carries three articular ridges with intervening grooves for tergal articulation. The tergal notch is deeply inset and positioned close to the apex of the valve.

The free tergum (Fig. 22B) is rectangular, with a curved apicobasal ridge which projects slightly from the basal angle. There is a notch on the carinal side into which a carinal ridge fits (Fig. 23F). The secondary ridge is broad and flat, the scutal auricle projects slightly. The free scutum has a very distinctive triangular shape (Fig 21C); it is twice as tall as broad, and the occludent margin of the apex is strongly incurved. The apicobasal ridge runs to the basitergal angle, and the occludent surface is flat and marked by regular, strong growth increments.

Priscoverruca elongata sp. nov.

Diagnosis. Priscoverruca in which the fixed terga have tall, narrow, triangular buttresses and a short occludent wing.

Types. The fixed tergum depicted in Fig $21 \mathrm{~A}$ is selected as holotype, the other valves, also terga, are paratypes. Maastrichtian, Rugen, In. XXXXXX

Material. Four fixed terga. NHM XXXXXX.

Derivation of name. in allusion to the tall, narrow form of the fixed tergum.

Description. The only known valve is the fixed tergum (Fig. 22A-E). The valve is twice as tall as broad, the buttress is very large, triangular, smooth, slightly convex and marked by irregular growth lines. The occludent wing is short and its 
surface is set at an angle to surface of the buttress. A short scutal auricle is present, and the articular structures for contact with the scutum and carina are well developed. The articulation with the scutum (Fig. 22 D) consists of four subparallel ridges and intervening grooves, and that with the carina is similar (Fig. 22 C). On the interior, a deep apical invagination is present (fig. 22 C,E) which is overlain by a grooved shelf.

Remarks. This species differs from P. prisca in the proportionately large, tall tergal buttress, and the small dimensions of the occludent wing.

Verruca Schumacher, 1817

Type species: V. stroemia (Muller, 1776)

Diagnosis. Form of a low dome, the basal parts of all wall plates are inflexed, giving a low profile to the capitulum; the myophore is a horizontal sheet. Growth lines are highly irregular and convoluted and form irregular lobes. The lower parts of the wall plates are irregularly corrugated. Irregularly arranged to concentrically aligned tiny pores penetrate all valves of the wall and opercular lid.

Remarks. Many fossil species have been referred to Verruca (reviewed by Buckeridge 2010), and these are briefly reconsidered here in light of the criteria used here to define the genus, plus the separation of Priscoverruca as a separate entity.

V. pusilla Bosquet, 1854, from the Maastrichtian of Limburg, Netherlands. Bosquet illustrated a series of separate valves (pl. i fig. 3), missing only the moveable scutum, in apical aspect, following the exact style of Darwin's 1854 illustration of his species $V$. nexta (Darwin 1854, pl fig.). The drawing looks stylised and is very close to Darwin's figure in detail. The folds in the wall of the FS and FT are similar to those in Rostratoverruca or Costatoverruca. The material requires refiguring in order to assess its generic status. 
V. rocana Steinmann, 1921, Danian Rocca Beds, Roca, Rio Negro, Argentina, was based on numerous individuals attached to oysters, and the material in the NHM, London, has been examined. Although deeply weathered, enough can be seen to identify the carinal ridge which extends to contact the base of the MT, characteristic of Priscoverruca and Verruca. The smooth, evenly rounded form of the carina and rostrum, and the lack of perforations are suggestive of Priscoverruca.

Verruca digitali Buckeridge in Buckeridge \& Finger, 2001 from the Miocene of Orange County, California, is based on a number of rather poorly preserved individuals, and a reconstruction is figured, based on a latex cast of one of these (Fig. 3). The most apical of the carinal ridges appears to contact the moveable tergum, and the valves are evenly rounded and smooth, carrying growth lines parallel to the basal margin. This would therefore appear to be Priscoverruca.

Verruca punica Buckeridge et al. 2008, from the Lower Danian of el Kef, Tunisia, is based on a single articulated specimen (Fig. 3A-G) and a number of isolated moveable terga and scuta (Fig. 4 A-R). The moveable scutum (E-F) is very close to that of $P$. prisca figured here (Fig. 21C) in shape, and in the position and development of the apicobasal ridge, plus the straight growth lines extending to the occludent border. The moveable terga (Buckeridge et al. Fig. 4A-D, G-R) are also similar with a very rectangular form, and a talon-like extension of the apicobasal ridge. However, the partial articulated specimen (Fig. 3) has evenly spaced, raised growth lines, quite unlike both Verruca and Priscoverruca. The material needs further cleaning and examination in an SEM.

Verruca sauria Buckeridge 2010, from the Maastrichtian of Canterbury, New Zealand evidently had smooth, evenly rounded carina and rostrum, suggestive of Priscoverruca. However, in the reconstruction the moveable scutum and tergum are upside down, such that one cannot see the relationship between the carina and moveable tergum (Buckeridge 2011 text-fig. 4).

Verruca jagti sp. nov. 
Diagnosis. A Verruca which lacks apicobasal ridges on the carina and rostrum, and has an irregular arrangement of pores.

Derivation of name. In honour of the work of John Jagt of Maastricht, who found the type specimen, and has made significant contributions to the study of Cretaceous cirripedes.

Holotype. NHMM JJ 13472, complete individual, ENCI-Heidelberg Cement Group quarry Maastricht, southern Limburg, the Netherlands. Top $10 \mathrm{~cm}$ of IVf-1 (hardground surface), Meerssen Member (Maastricht Formation, latest Mastrichtian.

Description. The entire holotype (Fig. 23A,B) is abraded on the free side (carina, rostrum) and the boring of a predatory gastropod (Oichnus sp.) has partially cut through the upper part of the junction of the carina and rostrum. The outline is subrectangular, and the margin of the carina is incomplete. The profile is low, approximately four times longer than high (Fig 21G). The growth lines are irregular and lobate, slightly inset, and low rounded ridges are present between them. Irregular digitate protrusions extend from the margins of the FT and FS which carry large occludent ridges. The rostrum is broad, and the contact with the FS consists of interdigitating ridges. The FS (Fig. 21H) has a convex occludent margin, and a curved apicobasal ridge. The MT (Fig. 21H) is quadrangular, with a long, basally expanding apicobasal ridge and a well developed secondary ridge. The interior of the capitulum shows a horizontal myophore, and shallow apical invaginations in the FS and FT. Tiny, rather irregularly arranged pores are seen to perforate the external surface (Fig. 21H).

Discussion. The inflexion of the basal portions of the wall plates, providing a low profile, the highly irregular, convoluted growth lines, and the irregular digitate projections, particularly from basal margins of the FS and FT are diagnostic of Verruca sensu stricto; the tiny perforations, clearly visible in higher 
magnification confirm the assignation. V. jagti is perhaps closest to the $V$. stroemia, but lacks the apicobasal ridges on the base of the rostrum, and the nature of the articulation of the carina and FT differs; a median process from the carina projects into a corresponding notch in V. jagti, absent in $V$. stroemia. The presence of the highly derived genus Verruca in the Maastrictian is highly significant, and provides evidence that all the major evolutionary changes in the Verrucidae (see cladogram) had taken place by the end of the Cretaceous.

\section{Discussion}

It is concluded that the asymmetrical "verrucomorph" body plan has evolved independently from symmetrical ancestors at least three times in the history of the Thoracica - Neoverruca from Neolepadidae; Proverruca from an unknown calanticid or scalpellid, and the Verrucomorpha from the basal sessilians Pycnolepas and Faxoelepas. The pattern of convergent evolution is remarkably similar, involving:

- loss of the peduncle in Neoverruca and Proverruca.

- loss or reduction of lateral plates/peduncular scales

- Progressively developed asymmetry between pairs of scuta and terga, forming free and fixed valves

- Formation of primary wall comprising a fixed scutum and tergum, the carina and the rostrum

- development of an opercular lid, formed of the closely articulated moveable tergum and scutum

In each of the tree cases described here there are subtle differences which reflect aspects of the ancestral morphology. Thus, Neoverruca evolved from the neolepadids which have only a single lateral plate, the upper latus, and they retain this. Likewise, the two lateral plates (rostro- and carinolatus) in Proverruca were presumably retained from a scalpellid or calanticid ancestor. Verrucids retain quite a number of characters from their Pycnolepas-like ancestors, such as the terracing on valves. 
The convergence of body plan is none the less quite remarkable. Most thoracicans undergo a similar ontogeny in which the paired scuta, terga and single carina appear first, followed by the rostrum and lateral plates (Broch 1922). The origin of asymmetrical forms therefore probably involves paedomorphic retention of the six plated stage into adulthood. In Neoverruca there is considerable variation between relatively symmetrical forms, in which the carina and rostrum do not make contact, such as that illustrated here (Fig. 2F-I), and the form illustrated by Newman (Fig. 2 in Newman \& Hessler 1989) in which the carina and rostrum overlap on the free side, and the asymmetry of the scuta and terga is greater.

The transition between symmetrical, slightly asymmetrical and strongly asymmetrical forms is recorded in the Pycnolepas-Faxoelepas-EoverrucaAltiverruca lineage described above. The relatively slight asymmetry shown by $F$. bruennichi involves slanting of the carina towards the free side, and minor morphological differences between the scutal and tergal pairs on each side (Fig. 7M,N; Fig. 8M,N). This trend is continued and strengthened in Eoverruca hewitti, which shows greater differentiation of free and fixed valves (Fig. 19), but in Altiverruca (Fig. 2A-E) two innovations result in the formation of a firmly articulated wall; the rostrum and carina form a firm, interdigitating artiticulation on the free side, and the apicobasal ridges of the fixed scuta and terga are broadened to form buttresses which provide a firm base to the wall. The subsequent evolution of the Verrucidae involves i) development of a lower profile, ii) strengthening the articulation of the wall plates by the development of interdigitating ridges, and iii) evolution of a shelf on the fixed tergum for attachment of the scutal adductor - a myophore (Young 1998). To this can be added fusion of the wall plates in Metaverruca recta and Brochiverruca dens.

The development of a strongly articulated wall may partly explain the success of the Verrucidae in terms of diversity, widespread distribution and abundance. The other forms convergent with Verrucomorpha, whilst superficially similar, 
have very weakly articulated walls and are geographically (Neoverruca) or temporally (Proverruca) restricted, and have a low diversity.

The repeated evolution of asymmetrical thoracicans my have an origin in feeding specialisation. The asymmetrical orientation permits fishing close to the substratum, enabling the capture of small benthic crawling prey (Anderson 1994). Indeed, the morphology and cirral activity recorded in the deep water Metaverruca recta indicate that it is primarily adapted to the capture of active prey (Southward and Southward 1958). In deep water habitats the paucity of planktic prey makes the capture of small benthos an alternative food source. The uniformity of functional morphology between extant verrucids lead Anderson (1994) to suggests that other deep water species feed in the same way. Verruca stroemia, in contrast, is a shallow water taxon which feeds primarily on zooplankton and particulate matter (Anderson 1994).

\section{Acknowledgements.}

Work in Sweden, which yielded the new Proverruca material, was made possible by a VILLUM Foundation grant to ASG, which supported a 4 month sabbatical stay in the University of Copenhagen, 2011-2012. Bill Newman (San Diego) kindly provided specimens of Neoverruca and Altiverruca and most helpful advice. Benny Chan (Taiwan) kindly provided the material of Rostratoverruca. Jens Høeg (University of Copenhagen) is thanked for his support for the research. My work in the University of Copenhagen Zoology Museum was supported by a SYNTHESIS grant, which is gratefully acknowledged. BGS, in Keyworth, Nottingham, kindly provided SEM images of Proverruca.

\section{References}

Anderson, D.T. 1980. Cirral activity and feeding in the verrucomorph barnacles Verruca recta Aurivillius, and Verruca stroemia (O.F. Muller) (Cirripedia). Journal of the Marine Biological Association of the United Kingdom 60, 349-66. 
Anderson, D.T. 1994. Barnacles: structure, function, development and evolution. Chapman \& Hall, London, Glasgow, New York, Tokyo, Melbourne, Madras. 357pp.

Bosquet, J. 1857. Notice sur quelques cirripedes recemment découvert dans le Terrain Crétacé du Duche de Limbourg. 36pp. Harlem.

Broch, H. 1922. Papers from Dr. Th. Mortensen's Pacific Expedition. 1914-16. No. 10. Studies on Pacific Cirripeds. Videnskabelige Meddelelser Dansk Naturalhistorisk Forening 73, 215 -358..

Buckeridge, J. S. 1983. Fossil barnacles (Cirripedia: Thoracica) of New Zealand and Australia. New Zealand Geological Survey Palaeontological Bulletin 50, 151pp, 13pls.

Buckeridge, J.S. 1996. Phylogeny and biogeography of the primitive Sessilia and consideration of a Tethyan origin for the group. In: Schram, F.R. \& Hoeg, J.T. (eds): New frontiers in barnacle evolution. Crustacean Issues, 10, 255-267. A.A. Balkema Rotterdam, Brookfield.

Buckeridge, J.S. 2011. Taphonomy and systematics of a new Late Cretaceous verrucid barnacle (Cirripedia, Thoracica) from Canterbury, New Zealand. Palaeontology 54, 365-372.

Buckeridge, J.S. \& Finger, K.L. 2001. First record of a fossil verrucid barnacle in California - Verruca digitalis sp. nov. (Cirripedia, Thoracica) from the Late Miocene. Journal of Crustacean Biology 21, 439449.

Buckeridge, J.S., Jagt, J.W.M. \& Speijer R.P. 2008. Verruca punica, a new species of verrucomorph barnacle (Crustacea, Cirripedia, Thoracica) from the Lower Danian (Palaeocene). Zootaxa, 1844, 37-46.

Buckeridge, J.S. \& Newman, W.A. 2006. A revision of the Iblidae and the stalked barnacles (Crustacea: Cirripedia: Thoracica), including new ordinal, 
familial and generic taxa, and two new species from New Zealand and Tasmanian waters. Zootaxa 1136, 1-38.

Chan, B.K.K., Prabowo, R.E. \& Kwen-Shen, L. 2009. Crustacean fauna of Taiwan: Barnacles, volume 1 - Cirripedia: Thoracica excluding Pyrgomatidae and Acastinae. 297pp. National Taiwan Ocean University.

Collins, J.S.H. 1980. A new Pycnolepas (Cirripedia) from the (?) Lower Aptian of Alexander Island. Bulletin of the Antarctic Survey, 50: 21-6.

Darwin, C.R. 1851a. A monograph on the Fossil Lepadidae, or pedunculated cirripedes of Great Britain. Palaeontographical Society (Monograph), 88pp.

Darwin, C.R. 1851b. A monograph on the sub-class Cirripedia. The Lepadidae or pedunculated Cirripedes. Ray Society, London. 400pp, 10 pls.

Darwin, C.R. 1854. A monograph on the sub-class Cirripedia. The Balanidae, the Verrucidae etc. Ray Society, London. 648pp, 30 pls.

Donovan, S. K. \& Jakobsen, S,L. 2004. An unusual crinoid-barnacle association in the type area of the Danian (Paleocene). Lethaia 37, 407-415.

Foster, B.A. \& Buckeridge, J.S. 1987. Barnacle Palaeontology. In: Southward, A.J. (ed.), Barnacle Biology. Crustacean Issues 5, 43-61.

Gale, A.S. 2014. Submitted. New thoracican cirripedes (Crustacea) from the Jurassic and Cretaceous of the UK. Proceedings of the Geologists' Association.

Gale, A.S. \& Sørensen, A.M. 2014a. submitted. Cirripedes from a Cretaceous rocky shoreline at Ivö Klack, southern Sweden. Cretaceous Research. 
Gale, A.S. \& Sørensen, A.M. 2014b. submitted. Origin of the balanomorph barnacles (Crustacea, Cirripedia, Thoracica)- new evidence from the Late Cretaceous (Campanian) of Sweden. Journal of Systematic Palaeontology.

Hébert, E. ,1855. Tableau des Fossiles de la Craie de Meudon, et description de quelques especes nouvelles. Mémoire de la Societe géologique de France (2), 5, 345-74.

Jagt, J.W.M. \& Collins, J.S.H. 1989. Upper Cretaceous cirripedes from N.E. Belgium. Proceedings of the Geologists' Association 100, 183-192,

Jagt, J.W.M., Jaskula, I., Witek, A. \& Jagt-Yazykova, E. 2008. A new record of the Late Cretaceous cirripede Eoverruca hewitti (Verrucomopha, Proverrucidae) from southern Poland. Zootaxa 1671, 59-68.

Jagt, J.W.M., Zonova, T.D. \& Jagt-Yazkova, E.A. 2007. Review of the brachylepadomorph cirripede genus Pycnolepas, including an Early Cretaceous species from the Russian Far East. Zootaxa 1545, 33-47.

Lamarck, J.B. de 1818. Histoire naturelles des animaux sans vértébres 5. 382-3, cirrhipedes sessiles; 401, cirrhipedes pédoncules. Paris.

Muller, O.F. 1776. Zoologicae Danicae Prodromus, seu Animaliae Daniaeet Norvegiae, indigenarum charactheres, nomina, et synonima imprimis popularium. Havniae, 1-27, 282pp.

Newman, W.A. 1987. Evolution of cirripedes and their major groups. In: Southward, A.J. (ed.), Barnacle Biology. Crustacean Issues 5, 3-43. A.A. Balkema, Rotterdam.

Newman, W.A. 1989. Juvenile ontogeny and metamorphosis in the most primitive living sessile barnacle, Neoverruca, from abyssal hydrothermal springs. Bulletin of Marine Science, 45(2), 467-477. 
Newman, W.A. 2000. A new genus and species of barnacle (Cirripedia, Verrucomorpha) associated with vents of the Lau Back-Arc Basin: its gross morphology, inferred first juvenile stage and affinities. Zoosystema, 22(1), 71-84.

Newman, W.A. \& Hessler, R.R. 1989. A new abyssal hydrothermal verrucomorphan (Cirripedia, Sessilia): The most primitive living sessile barnacle. Transactions of the San Diego Society of Natural History. 21, 259-273.

Newman, W.A., Zullo, V.A. \& Withers, T.H. 1969. Cirripedia. In: Moore, R.C. (ed.) Treatise on Invertebrate Paleontology, Part R, Arthropoda 4,1: R206-295. Pérez-Losada, M., Harp, M., Høeg, J.T., Actituv, Y., Jones, D., Watanabe, H. \& Crandall, K.A. 2008. The tempo and mode of barnacle evolution. Molecular Phylogenetics and Evolution 46, 328-346.

Pilsbry, H.A. 1916. The sessile barnacles (Cirripedia) contained in the collections of the US National Museum, including a monograph of the American species. Bulletin of the United States National Museum 93, 366pp.

Schumacher, C.F. 1817. Essai d'une nouveau systeme des habitations des vers Testacés. Copenhagen, 287pp.

Southward, A.J. 2006. Barnacles. Keys and notes for the Identification of British Species. Synopses of the British Fauna (New Series) no. 57. Field Studies Council.

Southward, A.J. \& Southward, E.C. 1958. On the occurrence and behaviour of two little known barnacles, Hexalasma hirsutum and Verruca recta from the Continental slope. Journal of the Marine Biological Association of the United Kingdom 37, 633-47.

Sowerby, J. de C. 1836. Descriptive Notes respecting the Shells figured in Plates 11-23 (pp. 335-348). Appendix A, to Fitton, ,W.H., Observations on some of the 
Strata between the Chalk and the Oxford Oolite in the South-East of England. Transactions of the Geological Society of London, (2) 4 ,103-389, pls 11-23.

Steenstrup, J. 1839. Bidrag til Cirripedernes Historie i Fortid og Nutid. Forste Bidrag. Anatiferidae og Pollicipedidae fra Kritperioden. Kroyer, Naturhist Tidsskrift 11, 396-415.

Steinmann, G.1921. in Wilckens, O. Beitrage zur palaontologie von Patagonien. Mit einem Beitrag von G. Steinmann (pp4-5, pl .2 fig. 1;pl. 3 fig. 7). Neues Jarhbuch fur Mineralogie, I, pp. 1-14, pls 1-3.

Surlyk, F. \& Christensen, W.K. 1974. Epifaunal zonation on an Upper Cretaceous rocky coast. Geology, 2, 529-34.

Surlyk, F. \& Sørensen, A.M. 2010. An early Campanian rocky shore at Ivõ Klack, southern Sweden. Cretaceous Research, 31, 567-576.

Tunnicliffe, V. \& Southward, A.J. 2004. Growth and breeding of a primitive stalked barnacle Leucolepas longa (Cirripedia,: Scalpellomorpha: Eolepadidae: Neolepadinae) inhabiting a volcanic seamount off Papua New Guinea. Journal of the Marine Biological Association of the United Kingdom, 84, 121-132.

Withers, T.H. 1913. Verruca prisca from the Chalk of Norwich. Geological Magazine (dec 5) 10, 103-6.

Withers, T.H. 1914a. A remarkable new cirripede from Chalk of Surrey and Hertfordshire. Proceedings of the Zoological Society London. 945-53.

Withers, T. H. 1914b. Some Cretaceous and Tertiary cirripedes referred to Pollicipes. Annals and Magazine of Natural History 8, 14, 167-206.

Withers, T.H. 1923. Die Cirripeden der Kreide Rugens. Abhandlungen der geologische-Palaontologische Institute Greifswald, 3, 54pp, 3pls. 
Withers, T.H. 1935. British Museum (Natural History). Catalogue of the Fossil Cirripedia in the Department of Geology Vol. 2. Cretaceous. 534pp, 50pls. London, Dulau \& Co.

Woodward, H.B. 1901. On "Pyrgoma cretacea", a cirripede from the Upper Chalk of Norwich and Margate. Geological Magazine, Decade 4, 8, 145-152.

Young, P. S. 1998. Cirripedia (Crustacea) from the "Campagne Biacores" in the Azores, including a generic revision of the Verrucidae. Zoosystema, 20(1), 31-92.

Young, P. S. 2001. Redescription of Scalpellopsis striatociliata, with a discussion on its phylogenetic position and the peduncular plate pattern in scalpellids. Journal of Crustacean Biology 21, 456-468.

Young, P.S. 2002. The Verrucidae from the west coast of North America, with a revision of the genus Altiverruca. Arquivos do Museu Nacional, Rio de Janerio, 60, $5-40$.

Figure captions

Fig. 1. A,B, D. Pedupycnolepas articulata (Collins 1980), Fossil Bluff Formation, ? Lower Aptian, Alexander Island, Antarctica. KG. Holotype, 1657b, and 2 paratypes KG 1657a,c. BAS Coll. B, drawing of peduncle of central specimen. Flanges on interior of bases stippled. D, reconstruction. C, Etcheslepas durotrigensis Gale 2014, reconstruction. Tithonian, pallasioides Zone, Kimmeridge Dorset, UK. E, reconstruction of Pycnolepas rigida (J. de C. Sowerby). Based on material from the Mid and Late Albian Gault Clay, southern England. F, reconstruction of Eoverruca hewitti Withers, lateral view. Based on new material figured herein, Figs. 17-19, Santonian, Uintacrinus socialis Zone, Hinderclay Lane, Wattisfield, Suffolk, UK. Scale bars; A, 10mm; B-E, 5mm; F, $1 \mathrm{~mm}$. 
Fig. 2. A-E, Altiverruca sp. in different views to show overall morphology and comparison with Neoverruca. NHM IC 1160, off Madagascar. A, free side. B, rostral view. C, fixed side. D, apical view. E, carinal view. F-I, Neoverruca brachylepadiformis Newman, in Hessler 1989. NHM IC 1153, Marianas Island, Pacific. F, rostral view. G, "moveable” side. H, carinal view. I, "fixed” side. See Table 1 for details of locality and other information. Note the differences in sculpture between the genera and the lack of contact between the carina and rostrum in Neoverruca. The overall asymmetry, and that between the scuta and terga is much more marked in Altiverruca. See also Fig. 11. Scale bar $5 \mathrm{~mm}$.

Fig. 3. Entire verrucids, to show general form, photographed at right angles to the surface of the free valves. A, Newmaniverruca albatrossiana (Pilsbry), NHM IC 1156. B, Brochiverruca dens (Broch) NHM IC 1155 . C, Verruca stroemia (O.H. Muller) NHM IC 1158. D, Globosoverruca nitida (Hoek) NHM IC 1157. E, Rostratoverruca koehleri (Gruvel) NHM IC 1154. F, Priscoverruca prisca (Bosquet), attached to Echinocorys sp. Campanian, B. mucronata Zone, Pit 154, Whitlingham, Norwich, Norfolk, UK. Rowe colln. NHM In. 27156. Original of Withers 1913, figs 2a,b; Withers 1935, p.342, figs 41,42. G, Altiverruca sp. NHM IC 1160. H, Cristallinaverruca cristallina (Gruvel) NHM IC 1168. I, Metaverruca recta (Aurivillius) NHM IC 1159. See Table I for locality details and other information. Scale bar $1 \mathrm{~mm}$.

Fig. 4. Comparative morphology of Pycnolepas, Faxoelepas and Eoverruca. A, C, F, Faxoelepas bruennichi (Withers 1914a), Middle Danian (Palaeocene), Faske, Denmark. , A, carina in external aspect (NHM IC 1022), C, rostrum (NHM IC 1023) F, G peduncular plates (NHM IC 1024-5). B,D,I,J, Eoverruca hewitti Withers, 1935. Santonian, Uintacrinus socialis Zone, Hinderclay Lane, Wattisfield, Suffolk, UK. B, carina (NHM IC 1057), D, rostrum (NHM IC 1058), I-J peduncular plate (NHM IC 1060). G,H,K-T, Pycnolepas rigida (J. de C. Sowerby). G,H, K-O, peduncular plates, Lower Gault Clay (Lower Albian), 21 Acre Pit, Miletree Farm,Leighton Buzzard, Bedfordshire, UK. H,K, exterior of plates from position near base (In. 32224-39). L, interior view of K. G, interior view of plate from a high position. M-O, laterial view of plates from basal whorl $(0)$, middle $(\mathrm{N})$ and 
top (M), to show decrease in size of inwardly directed ledge. P-T, Upper Gault Clay, Late Albian, varicosum Subzone, Naccolt Brickworks near Ashford, Kent. P, carina in external view (NHM IC 1031), Q, tergum (NHM IC 1032), R, upper latus (NHM IC 1033), S, scutum (NHM IC 1034), T, rostrum (NHM IC 1035). Scale bars, A-E, R, 1mm; F-H, K-O, 0.5mm; P,Q,S,T, 5mm; IJJ, 0.2mm.

Fig. 5. Nomenclature applied to terga and scuta in this paper. A, C, E, I, Newmaniverruca albatrossiana (Pilsbry). A, external view of moveable scutum. C, interior view of fixed scutum. $\mathrm{N}$, enlargement of region of interior of fixed scutum which articulates with the fixed tergum. I, exterior of free tergum. B, G, Rostratoverruca koehleri (Gruvel). B, interior of free scutum. G, exterior of fixed tergum. D, Altiverruca sp. Exterior of fixed tergum. F,H, Verruca stroemia (O.H. Muller). F, interior of fixed scutum. H, enlargement of articular region of fixed tergum. See Table 1 for details of localities and other information. Abr, apicobasal ridge. Ar, articular ridge on fixed scutum. Myo, myophore. Ow, occludent wing. Sa, scutal adductor scar. Sr, secondary ridge. Tb, tergal buttress. tn, tergal notch. Scale bars $1 \mathrm{~mm}$.

Fig. 6. Scuta and terga of thoracicans to show comparative morphology. A,B,N, Faxoelepas bruennichi (Withers), Danian, Faxoe, Denmark. A, interior view of scutum, B, interior (NHM IC 1019). N, exterior view of tergum (NHM IC 1020). C,D,P. Calantica sp. Recent, Western Australia (NHM IC 1144). C, D, scutum in external (C) and internal (D) views. P, tergum. E,F,M, Eoverruca hewitti Withers, Santonian, Uintacrinus socialis Zone, Hinderclay Lane, Wattisfield, Suffolk, UK. E, $\mathrm{F}$, fixed scutum in external and internal views (NHM IC 1061). M, fixed tergum (NHM IC 1062). G,H, Proverruca dentifer sp nov. Lower Upper Campanian, Roper Lense, Ivõ Klack, southern Sweden (see Gale \& Sorensen 2014a,b). Fixed scutum in external and internal views (NHM IC 1046). I,J, Altiverruca sp. Recent. Fixed scutum in internal and external views (NHM IC 1060). K,L,O. Neoverruca brachylepadiformis Newman. Recent (NHM IC 1153). K,L, fixed scutum, in external and internal views. 0 , fixed tergum. See Table 1 for details of modern material. Scale bars A-D, P, 5mm; E,F, M, 0.5mm; G-O, $1 \mathrm{~mm}$. 
Fig. 7. External view of free and fixed terga. Details of localities etc. for Recent species are given in Table 1. A,B, Globosoverruca nitida (Hoek). C,D, Verruca stroemia (O.F. Muller). E,F, Altiverruca sp. G,H, Cristallinaverruca cristallina (Gruvel). K,L, Rostratoverruca koehleri (Gruvel). O,P, Newmaniverruca albatrossiana (Pilsbry). I,J, Eoverruca hewitti Withers, Santonian, Wattisfield, Suffolk (NHM IC 1062,1063). M,N, Faxoelepas bruennichi (Withers), middle Danian, Palaeocene, Faxoe, Denmark (M, NHM IC 1021; N, 1020) . Note the overall increase in morphological disparity between free and fixed valves from the most basal form (bottom left) to the most derived (top right). The free valves are morphologically conservative, but integration into the wall resulted in dramatic modification of the fixed valves. Scale bars A-H, K-P,1mm; I,J, 0.5mm.

Fig. 8. External view of free and fixed scuta. Details of localities etc. for Recent species are given in Table 1. A,B, Globosoverruca nitida (Hoek). C,D, Verruca stroemia (O.F. Muller). E,F, Altiverruca sp. G,H, Cristallinaverruca cristallina (Gruvel).. K,L, Rostratoverruca koehleri (Gruvel) O,P, Newmaniverruca albatrossiana (Pilsbry). M,N, Faxoelepas bruennichi (Withers), middle Danian, Palaeocene, Faxoe, Denmark (NHM IC 1026, 1019). I,J, Eoverruca hewitti Withers, Santonian, Wattisfield, Suffolk (NHM IC 1061, 1064). Note the overall increase in morphological disparity between free and fixed valves from the most basal form (bottom left) to the most derived (top right). The free valves are morphologically conservative, but integration into the wall resulted in dramatic modification of the fixed valves. Scale bars A-H, K-P,1mm; I,J, 0.5mm.

Fig. 9. Internal view of free and fixed scuta. Details of localities etc. are given in Table 1. A,B, Globosoverruca nitida (Hoek). C,D, Verruca stroemia (O.F. Muller). E,F, Altiverruca sp. G,H, Cristallinaverruca cristallina (Gruvel). K,L, Rostratoverruca koehleri (Gruvel). 0,P, Newmaniverruca albatrossiana (Pilsbry). M,N, Faxoelepas bruennichi (Withers), middle Danian, Palaeocene, Denmark (NHM IC 1019, 1026). I,J, Eoverruca hewitti Withers, Santonian Wattisfield, Suffolk (NHM IC 1061, 1065). Note the evolutionary changes in the adductor site on the fixed scutum, which develops an underlying ridge $(K, G)$, and eventually is positioned on a discrete platform, and becomes the myophore (C). Note also the 
changes in the scutal-tergal articulation in the fixed scuta, with progressive development of an articular ridge (see Fig. 5E) in $0, K, G$. In $C$, this ridge becomes positioned on the same platform as the myophore. Scale bars A-H, K-P, 1mm; I,J, $0.5 \mathrm{~mm}$.

Fig. 10. Recent verrucids, details of localities and occurrences are given in Table 1.A-D, G,H, Metaverruca recta (Aurivillius). View of fixed side to show form of fixed scutum and tergum. B, interior view from base, to show vertical myophore and fused basal rim. C,G, exterior and interior views of free tergum. D,H, exterior and interior views of free scutum. E,F,I,J, Brochiverruca dens (Broch). E,I, free scutum in exterior and interior views. F,J, free tergum in exterior and interior views. Scale bars A,B, 5mm; C-J, $1 \mathrm{~mm}$.

Fig. 11. A,B,E,F, growth stages of Neoverruca brachylepadiformis Newman in Hessler 1989, after Newman (1989) Fig. . A,B, and E,F, are opposite sides of the same individuals. C,D, early growth stages of Leucolepas longa Southward \& Jones, after Tunnicliffe \& Southward 2004 fig. 17. The upper latus is coloured yellow. $N$. brachylepadiformis shows a progressive increase in asymmetry with increasing size. Note the similarities between the early growth stages of $L$. longa $(\mathrm{C}, \mathrm{D})$ and those of $N$. brachylepadiformis $(\mathrm{A}, \mathrm{B})$; the irregularly sized and arranged peduncular plates in L. longa are similar to the plates identified as carinolatus ("cl") and rostrolatus ("rl") in N. brachylepadiformis by Newman (1989) and it is suggested that these are peduncular plates rather than lateral ones. Scale bars $1 \mathrm{~mm}$.

Fig. 12. Reconstruction of Proverruca vinculum, based largely on the holotype specimen. A, fixed side; B, apical view; C, free side. R, rostrum; C, carina; FT, fixed tergum; FS, fixed scutum; MS, moveable scutum; MT, moveable tergum. Scale bar $1 \mathrm{~mm}$.

Fig. 13. Strict consensus cladogram of Verrucomorpha and basal Sessilia, based on heuristic analysis of 38 characters (Tables 2,3). The numbers are are boostrap values. A monophyletic Verrucomorpha is well supported, and is divided into a 
basal stem group (Eoverruca) and a crown group (Verrucidae). The Verrucidae is also divided into a basal stem group (Altiverruca, Globosoverruca) and derived crown group (all other verrucids). The derived Myophorinae is nested within the crown group. The analysis failed to resolve relationships between the Myophorinae and other crown group verrucids, which remains as a polytomy.

Fig. 14. A-I, Proverruca vinculum Withers. A-C, the holotype, found in the interior of a flint nodule, Watford Tunnel, Hertfordshire, UK. BGS 3204. Original of Withers 1914a and 1935, figs 33-36. The specimen is partially overgrown with silica, and the free valves are slightly displaced. This forms the basis for the reconstruction given in Fig. 12. B,H,I, Micraster coranguinum Zone, Late Coniacian or Early Santonian, Northfleet, Kent, UK. B, fixed tergum. In.31038, original of Withers 1935 pl.43 fig. 13. H,I, fixed scuta. In. 31037, 31038. Originals of Withers 1935 pl. 43 figs 11,12. F, M. cortestudinarium Zone, Coniacian, Sline’s Oak Pit, Worm's Heath, Warlingham, Surrey, UK. Moveable tergum, In.16710. Paratype of Scalpellum vimineum Withers, 1914, pl.i figs 12a,b, and Withers 1935 pl 43 fig. 9. E, G, from the M. cortestudinarium Zone, Coniacian, Pebble Coombe Corner, Headley Heath, Surrey. Rostrum, in lateral (E) and apical (G) views. In. 31033. Original of Withers $1935 \mathrm{pl}$ 43, fig. 10. Note that Withers mistakenly figured this as a carina. The form of the true carina of Proverruca is shown in Fig. 15A-C. Scale bars A-C, D, F, H, I, 1mm; E,G, 0.5mm.

Fig. 15. A-0, Proverruca dentifer sp. nov. Lower Upper Campanian, Roper Lense, Ivõ Klack, southern Sweden (see Gale \& Sorensen 2014a,b). A-C, carina in apical, internal and external views. Note the expanded flange with a concave facet on the left side, into which the free tergum probably fitted. In. XXXXX. D,E, free terga, in external view. D is holotype (In. XXXXXX). F, G, fixed terga in external view. In. XXXXX. H-I, J-K, fixed scuta. In. XXXXX, XXXXXX. Note the low flanges on the tergal and occludent margins for articulation with the fixed tergum and free scutum respectively. L-M, N-0, free scuta. In. XXXXX-XXXXX. Scale bars $1 \mathrm{~mm}$.

Fig. 16. A-I, Proverruca dentifer sp. nov. Lower Upper Campanian, Roper Lense, Ivõ Klack, southern Sweden (see Gale \& Sorensen 2014a,b). A,B,D-F, H,I, free 
scuta, external view. In. XXXXXX-XXXXXX. C, fixed scutum, external view. In. XXXXXX. Note the considerable variation in sculpture. G, carina, external view. In. XXXXXX. Scale bars $1 \mathrm{~mm}$.

Fig. 17. A-L, Eoverruca hewitti Withers, Santonian, Uintacrinus socialis Zone, Hinderclay Lane, Wattisfield, Suffolk, UK. A-G, calcified basis, in which are incorporated peduncular scales. In. XXXXXX. A, basal view, B apical view, C,D, lateral views. E,G, enlargement of parts of base to show small scales partially overgrown by basis. $\mathrm{H}$, fragment of calcified basis to show adventitious small scales. In XXXXXX. I-L, peduncular scale from basal row, to show interiorly directed ledge, and small adventitious scale $(\mathrm{K})$ which was articulated with the notch in the base of I,L. In XXXXXX. Scale bar A-G 0.5mm; H-L, 0.2mm.

Fig. 18. A-P, Eoverruca hewitti Withers, 1935, Santonian, Uintacrinus socialis Zone, Hinderclay Lane, Wattisfield, Suffolk, UK. A-H, peduncular scales from the upper tier; A,B, asymmetrical scale in exterior and interior views. In. XXXXX. C-E, external (C) and external (D-H) views, to show diversity of form. In. XXXXXXX. I-L, carinae. M-P, rostra. Scale bars A,B, 0.5mm; C-P, $1 \mathrm{~mm}$.

Fig. 19. A-0, Eoverruca hewitti Withers, Santonian, Uintacrinus socialis Zone, Hinderclay Lane, Wattisfield, Suffolk, UK. A-D, free terga, external view. In XXXXX-XXXXXX. E,F, fixed terga, external view. In.XXXXXX-XXXXX. Note the minor but consistent differences between these - the broader based apicobasal ridge on the fixed side, the broader secondary ridge on the free side, and the better demarcated scutal auricle on the free side. I,J,M, free scuta. In. XXXXXXXXXX.K,L,O, fixed scutum, In. XXXXXX. Differences between the fixed and free scuta are more marked than between equivalent terga, and involve curvature and relative width of the apicobasal ridge, and the size and width of the scutal portion of the valves. $\mathrm{N}$, enlargement of apex of free tergum illustrated (B) to show primordial valve. Scale bars A-M, 0.5mm; N,O, 0.2mm. 
Fig. 20. A-D, J-L, Youngiverruca withersi gen et sp. nov. A-C, holotype fixed tergum in external, scutal and internal views. Original of Withers 1923, Pl. 2 fig. 48; Withers 1935 Pl 45 fig. 13. In.16224. D, external view of fixed tergum, original of Withers 1923, pl. 2, fig. 49; In.16225. J-L, paratype, fixed scutum, in external, internal and oblique views, original of Withers $1923 \mathrm{pl}$ 2, figs 46a,b. In.16222. All from the Maastrichtian chalk of Rugen. E-I, M,N,P, Priscoverruca prisca (Bosquet). E-G, fixed tergum, in external, scutal and internal views. Campanian, Haccourt, Belgium, referred to by Jagt and Collins, 1989, In. 62169. H,I, fixed tergum in scutal and lateral views. Maastrichtian chalk of Rugen. Original of Withers 1923 pl 2 fig. 50, In.16226. E1-3, M,N, fixed scutum, in external and interior views, original of Withers 1923 pl 2, figs. 47a,b; Withers 1935 pl. 45, fig. 12a,b. In.16223. Maastrictian chalk of Rugen. P, fixed scutum, oblique internal view. Maastrichtian chalk, Rugen. In XXXXXX. 0, Verruca stroemia (O.H.Muller), internal view of fixed scutum, for comparison with P. prisca (N,P); note the similar development of an inverted V-shaped shelf which carries the myophore on the carinal side, and the apical part of the scutal-tergal articulation of the scutal side. Recent, Murvagh beach, Donegal, Ireland. Scale bars $0.5 \mathrm{~mm}$.

Fig. 21. A -C, I,J,L,M, Priscoverruca prisca (Bosquet), A, fixed side of individual,; original of Jagt \& Collins 1989. Fig. 49. In.62170. B, moveable tergum, original of Withers 1935, pl xlv, fig.8; In.16218. C, moveable scutum, Maastrictian chalk, Rugen. In XXXXXX. I,J carina, Maastrichtian chalk, Rugen, In.21185. L,M, rostrum, Maastrichtian chalk, Rugen. In. 21184. G, H, Verruca jagti sp.nov. G, fixed side, lateral view; $\mathrm{H}$, enlargement of moveable tergum and scutum; note pores. D-F, K,N, Verruca stroemia, Murvagh, Donegal, Ireland. D, fixed side of individual. E,F, moveable tergum and scutum. $\mathrm{K}, \mathrm{N}$, rostrum and carina. Scale bars $0.5 \mathrm{~mm}$.

Fig. 22. Priscoverruca elongata sp. nov., fixed terga, In.16224-5. Maastrictian, Rugen, Germany. Scale bars $1 \mathrm{~mm}$.

Fig. 23. Interior view (left) and apical view (right) of verrucids. A, B. Holotype, Verruca jagti sp. nov. C, D. Verruca stroemeri (O.H. Muller), present day, Murvagh beach, Donegal, Ireland, attached to Laminaria holdfasts. E,F, Priscoverruca 
prisca (Bosquet), Campanian,, Haccourt, Belgium; original of Jagt \& Collins 1989. Fig. 49. In.62170. Scale bars $1 \mathrm{~mm}$.

Table 1. Extant species studied.

Neoverruca brachylepadiformis Newman 1989. Volcanic shallow water seep, Marianas Island, Pacific. Ex. W.N. Newman coll.

Rostraoverruca koehleri (Gruvel). Tung Kan Taiwan. Donation of Dr. Benny Chan.

Brochiverruca dens (Broch, 1931), Station 51 Dynd trawl, 1922. 348m. 50 46' 30" S $132^{0}$ 51' W. 7-V. Kei Islands, Indonesia. Ex NHM Copenhagen.

Newmaniverruca albatrossiana (Pilsbry), Zamboanga, Mindanao, Philippines. Pacific Expedition, Sigsbee trawl, 4-3-14. Ex NHM Copenhagen.

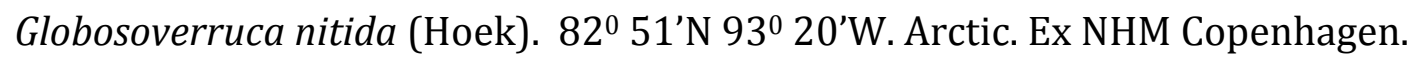

Cristallinaverruca cristallina (Gruvel). Dynd 245m. Expedition. Station 41. $5^{0} 28^{\prime}$ 40” S $132^{0} 28^{\prime}$ E. Kai Islands, Indonesia. Ex NHM Copenhagen.

Altiverruca sp. Station no. CH-128, Chalutage, Madagascar $18^{\circ} 5^{\prime} \mathrm{S}, 4^{\circ}{ }^{\circ} 53^{\prime} \mathrm{E}$, 1930m. Gifted from Invertebrate Coll. UCSD.

Verruca stroemia (O.H.Muller). On Laminaria holdfasts, Murvagh Beach, County Donegal, Ireland. ASG.

Metaverruca recta (Aurivillius). 10km S. of Rodrigues Island, Indian Ocean, 1500m. ASG.

Table 2. Character list 
1 - Peduncle as long or longer than capitulum > 8 whorls of plates (0); shorter than capitulum, 3-4 whorls (1); absent (2)

2- Peduncular plates all similar (0); lower plates carry inwardly directed transverse flange at base, which decreases in size in more apical rows (1)

3 - Peduncular plates with irregular transverse growth lines (0); 3-4 downwardly V-ing terraces (1)

4 - Capitulum tall, upright (0); angled at $30-40^{\circ}(1)$, box-like, operculum horizontal (1); low dome with depressed margins, operculum horizontal (2)

5 - regularly spaced ridges (0); imbricate, even terracing on some valves (1)

6 - Terracing present on all of wall plates (0); restricted to lateral portions and moveable plates (1) absent (2)

7 - Lateral plates other than UL present (0); absent (1)

8 - Upper latus present (0); absent (1)

9 - plates of wall separate (0); fused (1)

10 - Terga and scuta form symmetrical pairs (0); slightly asymmetrical (1); fixed and moveable tergum and scutum present (2)

11 - Narrow apicobasal ridges (0); broad buttresses contact substratum (1)

12 - Secondary ridges weak or absent on terga and scuta (0) present, superficially interlocking (1); form deeply interlocking ridges (2)

13 - Secondary ridges on FS all similar (0); ridge adjacent to tergal notch forms prominent articular ridge (1) 
14 - Occludent region not differentiated on FT, FS, (0) differentiated occludent wings developed (1)

15 - Occludent margin of FT at acute angle to FS margin (0); set at right angles (1)

16 - Occludent margin of FS at acute angle to maximum height of FS (0); at right angles (1)

17 - Shallow tergal notch on FS articulates with FT tergal auricle (0); deeply inset tergal notch accommodates short ridge-like tergal auricle (1)

18 - FT, FS articulation consists of conspicuous interpenetrant ridges and grooves over full height of plates (0); articular processes restricted to apical region, internal (1)

19 - Scutal adductor scar on FS indistinct (0); sharply defined, lower margin bears ridge (1) myophore present (2)

20 - Simple myophore, vertical, pendant (0); forms horizontal sheet, incorporated with articular ridge on inverted V- shelf (1)

21 - Base of FT and FS not inflexed (0); inflexed, form flattened margin (1)

22 - Buttresses of FT, FS flat, terraced (0); irregularly folded, only showing growth lines (1)

23 - No accessory ridges on MT (0); weak ridge developed between apicobasal ridge and scutal articulation (1); strong single ridge (2); several ridges (3)

24 - Accessory ridge on MT narrow (0), broad, flat (1) 
25 - Occludent surface of MT and MS smooth (0); 3-4 apicobasal ridges present (1)

26 - Apicobasal ridge of MS forms part of MT articulation (0); placed close to occludent margin (1)

27 - Carina and rostrum conical, semicircular, taller than broad (0); broad, subquadrangular, concavo-convex (1)

28 - Umbones of rostrum and carina prominent, divergent (0); short, inconspicuous (1)

29 - Umbones of rostrum and carina marginal (0); apical, adjacent to FT-MT-FSMS contact

30 - Rostrum and carina always symmetrical (0); variably slanted towards "free" side (1); strongly and invariably asymmetrical (2)

31 - Rostrum and carina do not articulate (0); articulate by means of interpenetrant processes (1)

32 - Contact between $\mathrm{R}$ and $\mathrm{C}$ consists of 2-3 asymmetrical interpenetrant ridges (0); 4-7 symmetrically interpenetrant zig-zag ridges form broad triangular zone (1)

33 - Carina-FT contact simple (0); forms interpenetrant zig zag (1)

34 - Rostrum - FS contact simple (0); interpenetrant zigzag (1)

35 - Contact between MS and R simple (0); interpenetrant ridges present (1)

36 - Contact between MT and C simple (0); interpenetrant ridges present (1) 
37 - Straight articulation between MT and carina (0); Ridge from apex of carina slots into base of MT

38 - Basal part of R \& C not inflexed (0); inflexed to form flatter margin

Table 3. Character matrix. 

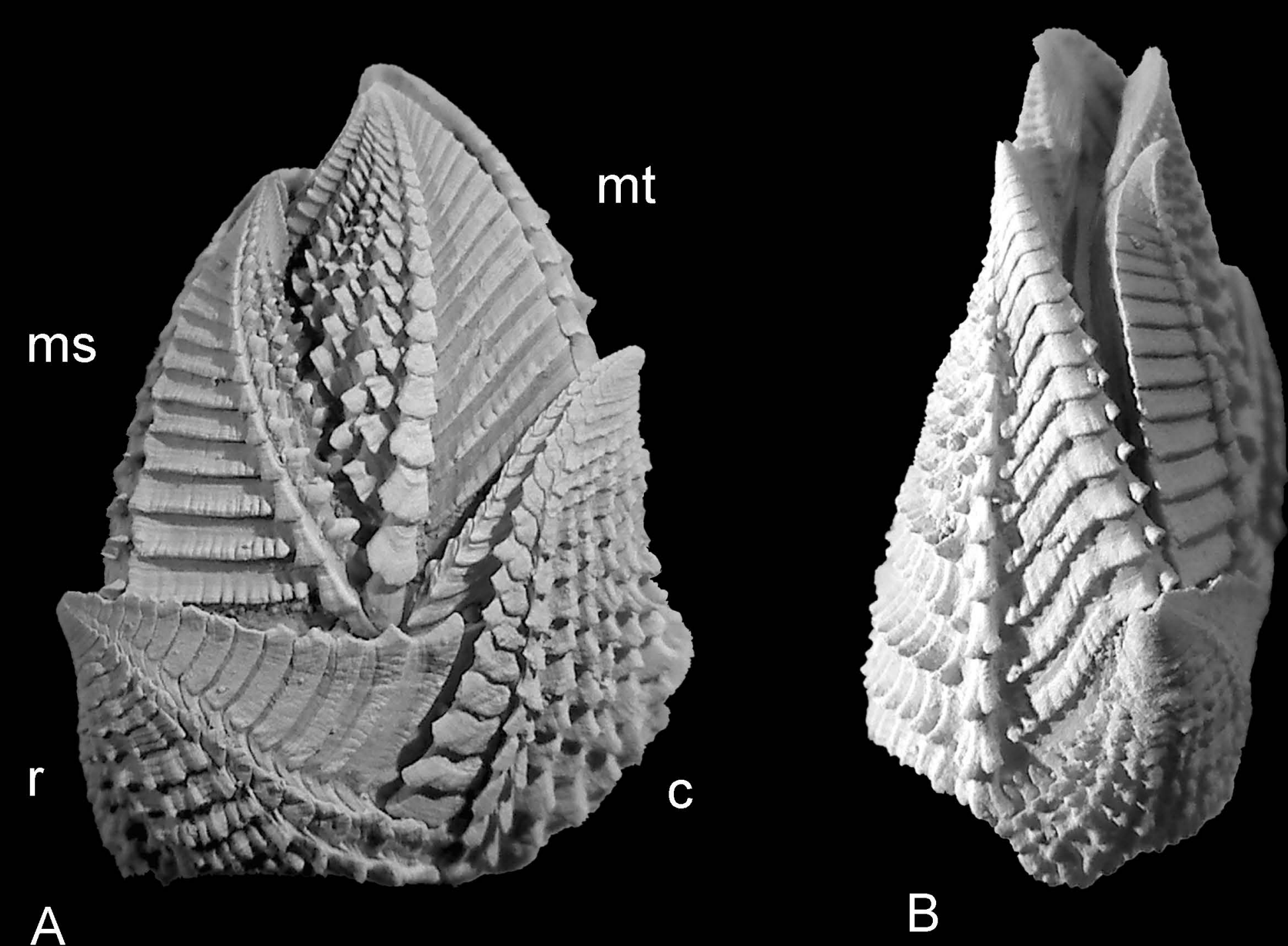

A
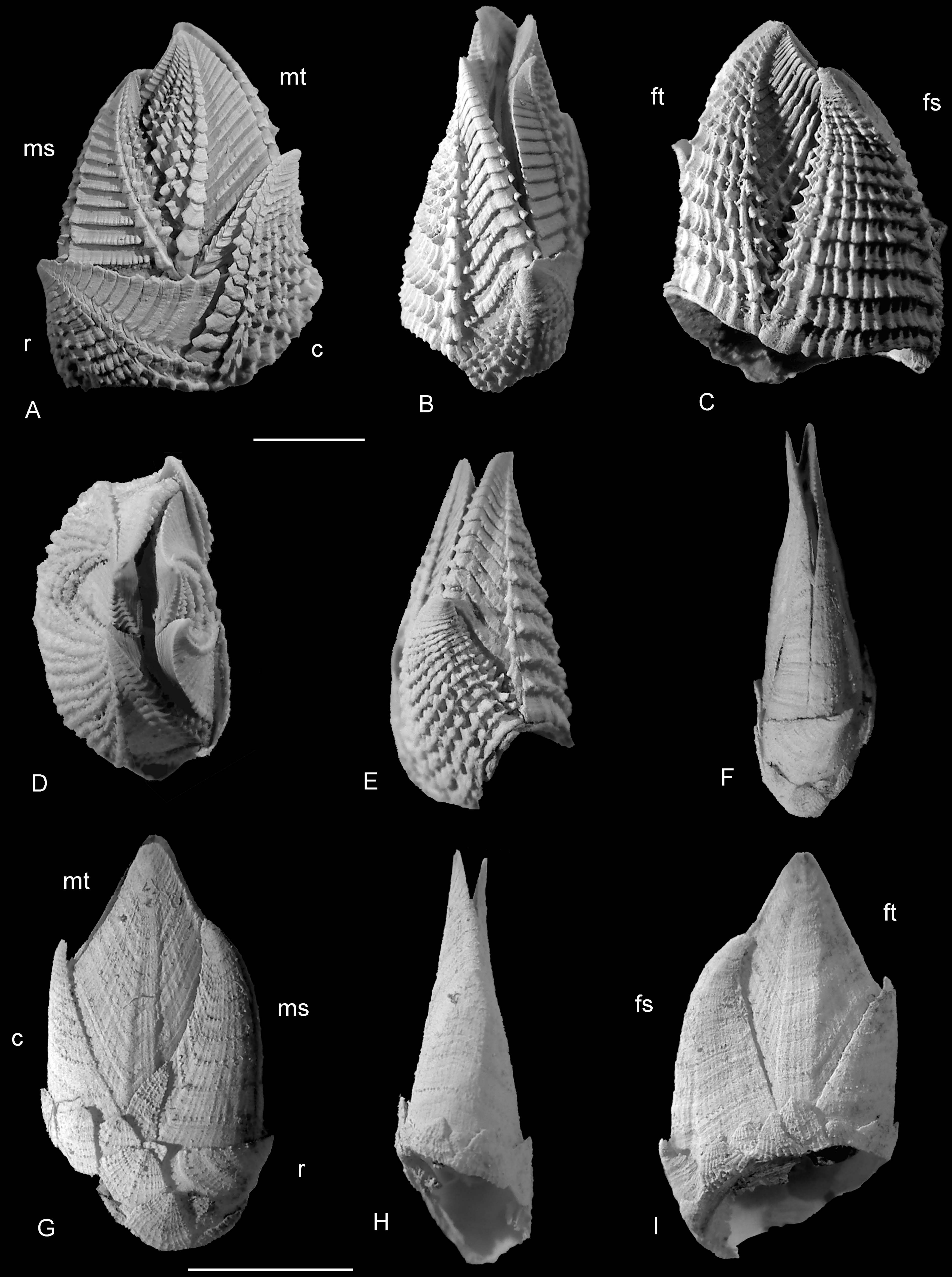

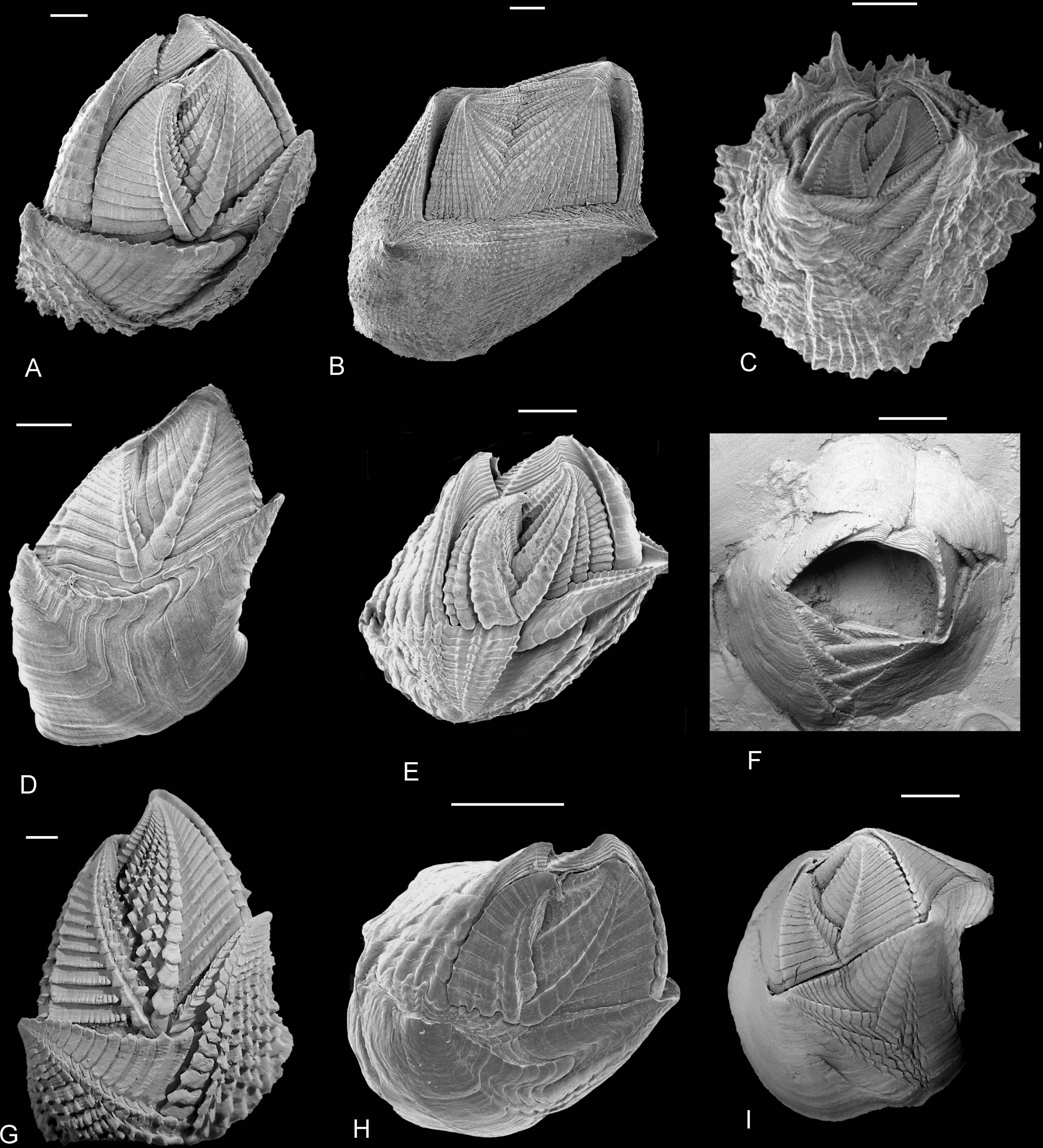

E

F
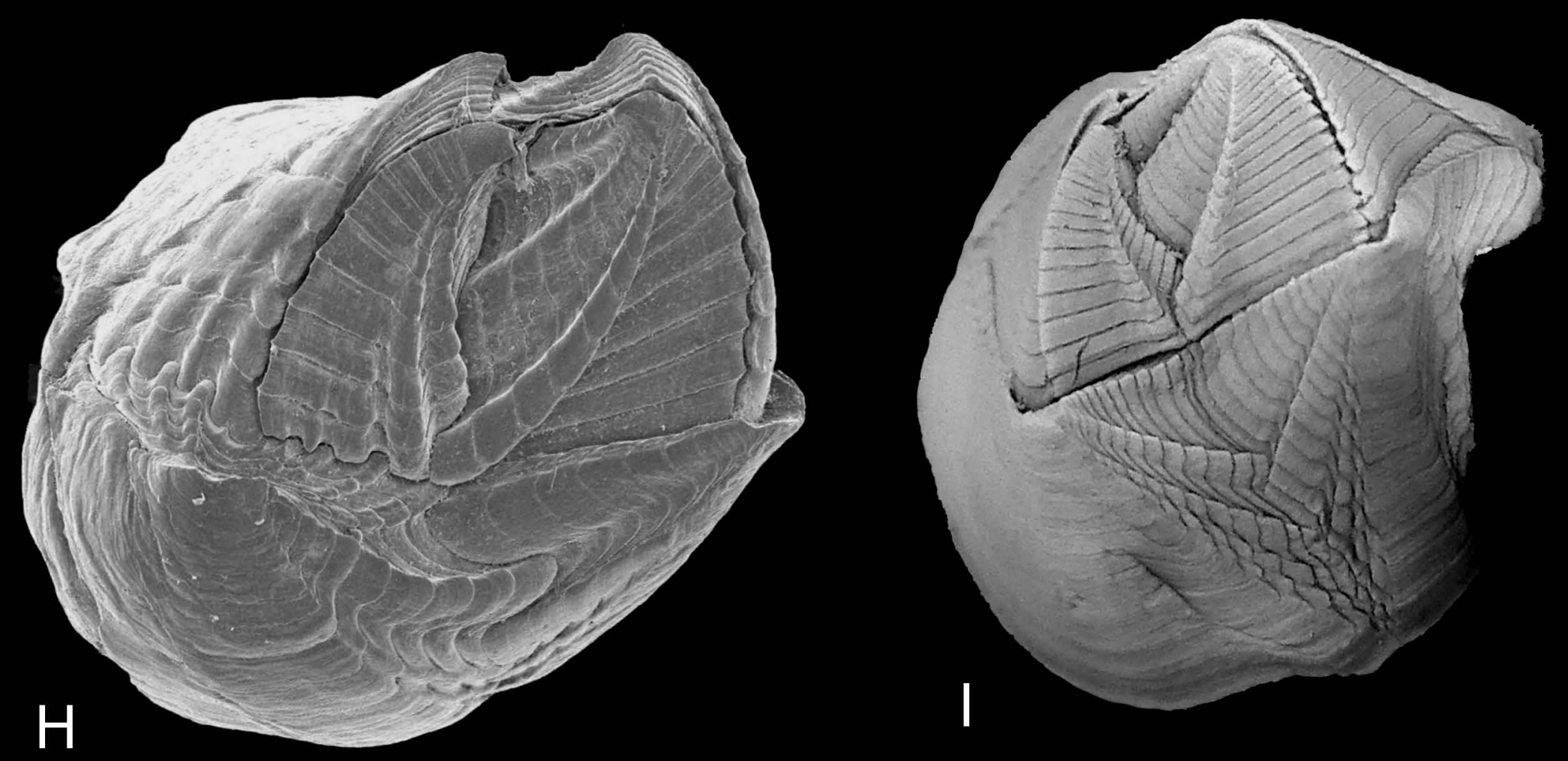


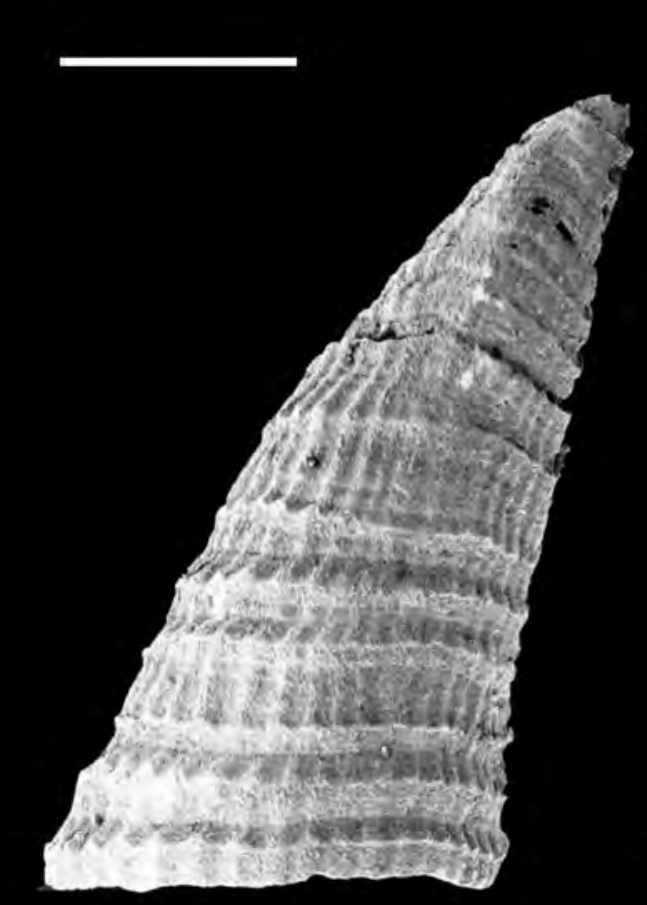

A
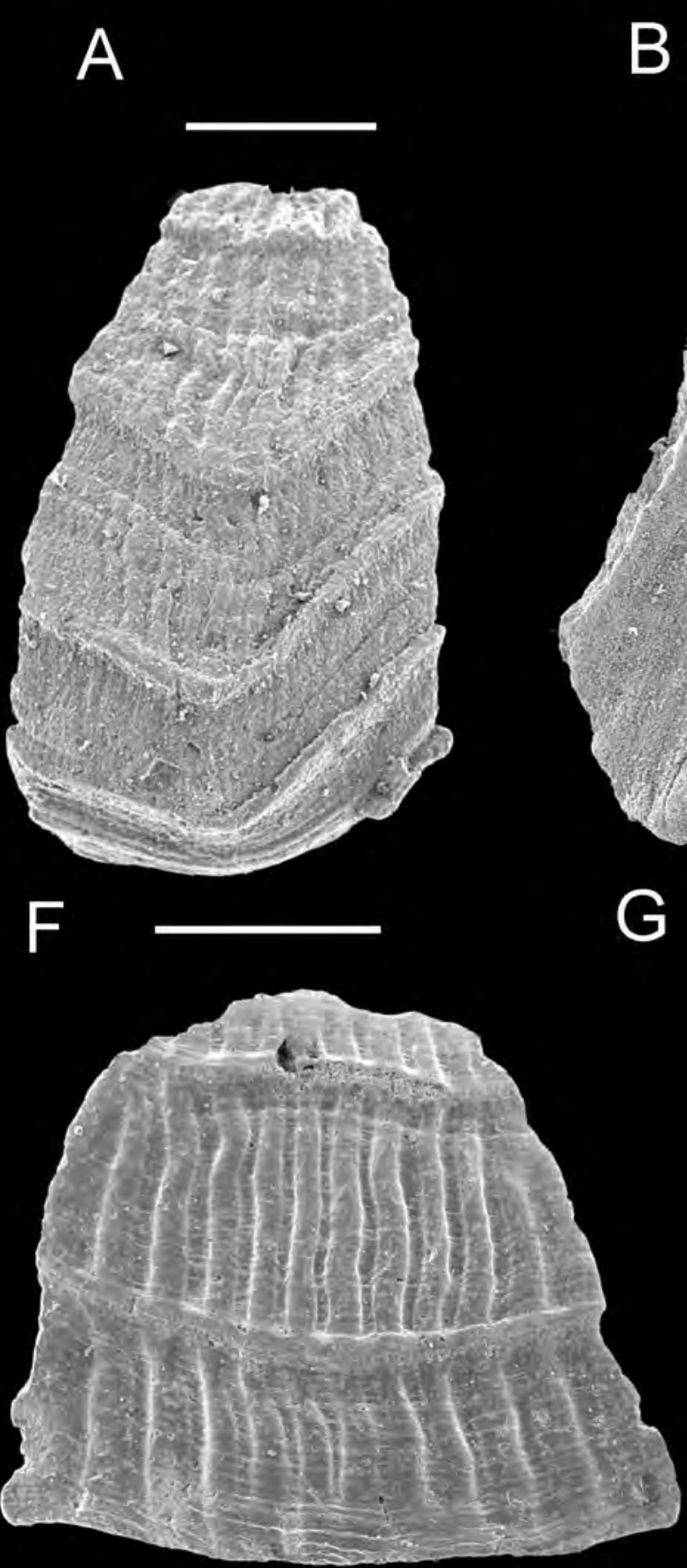

K
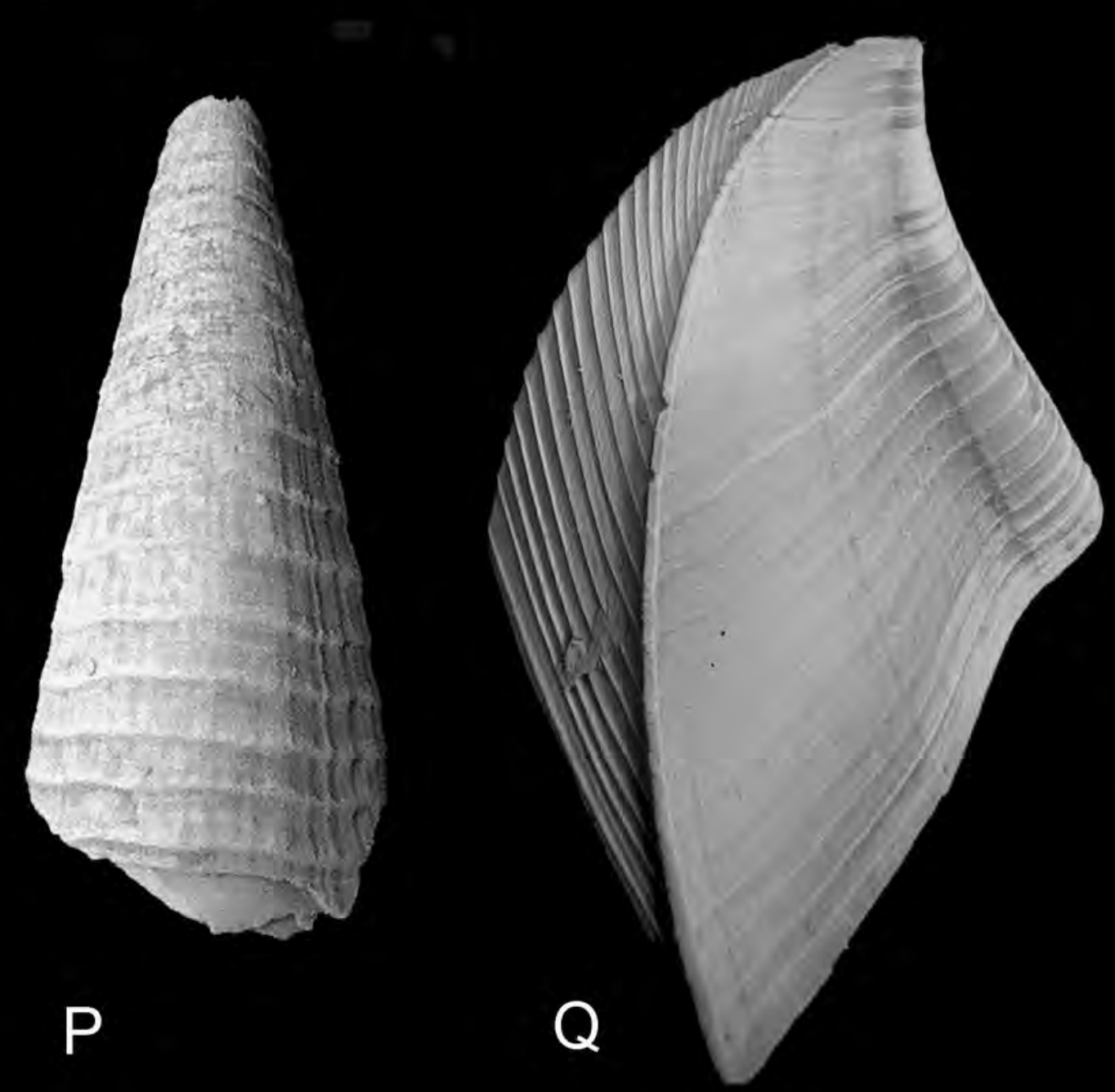

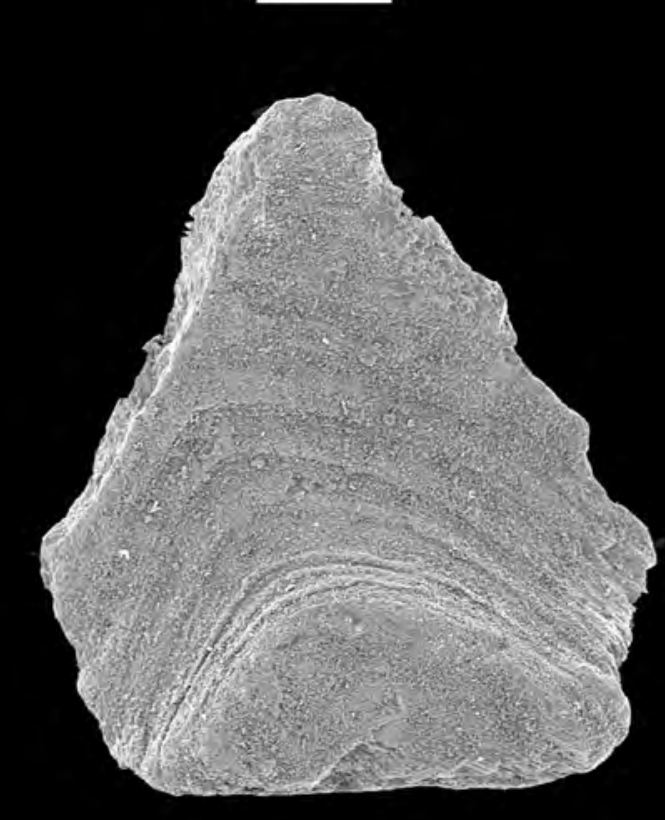

G

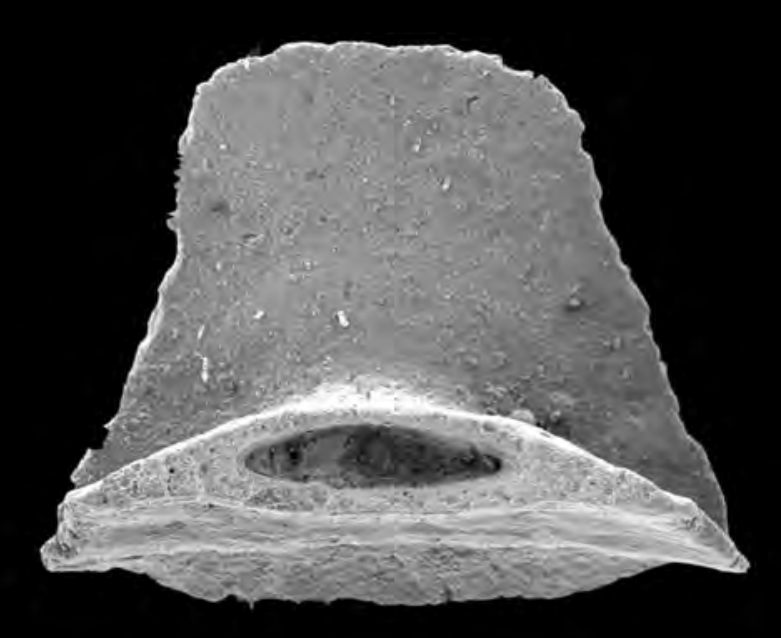

L

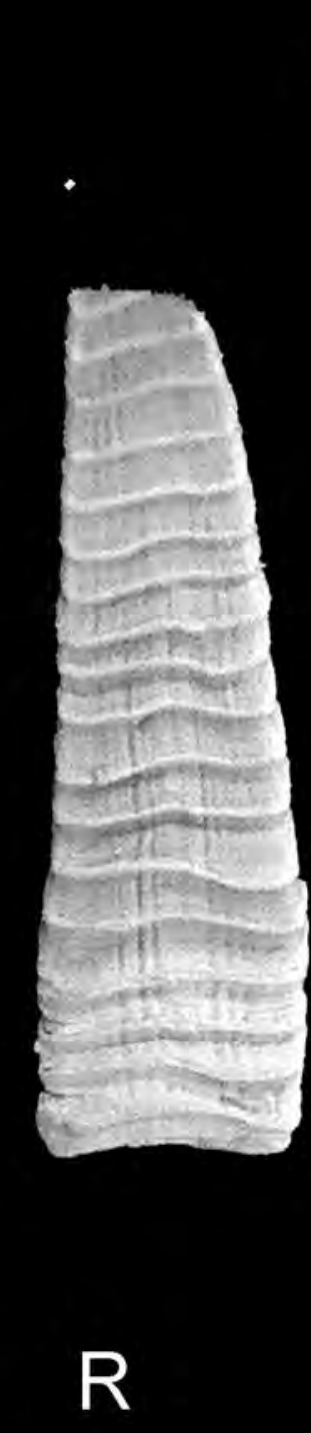

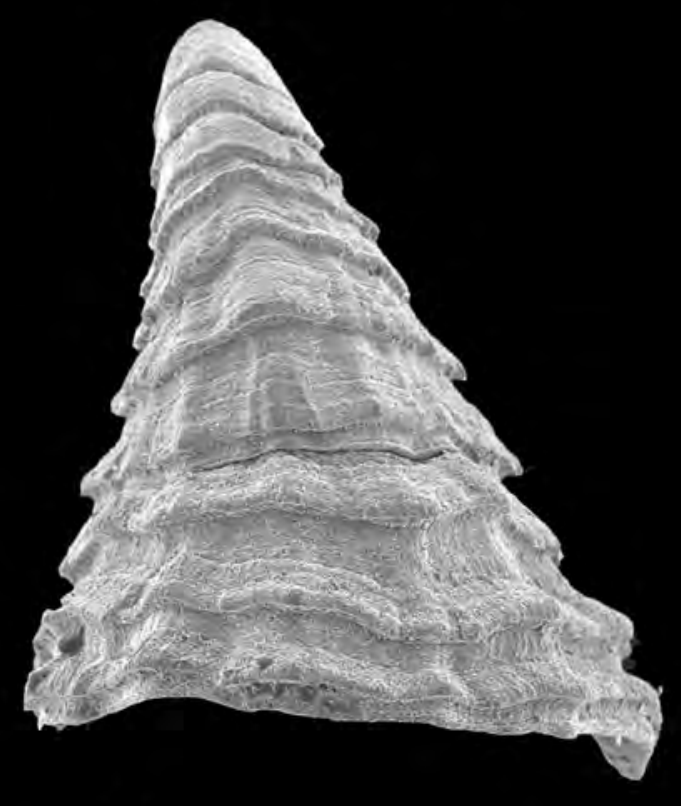

C
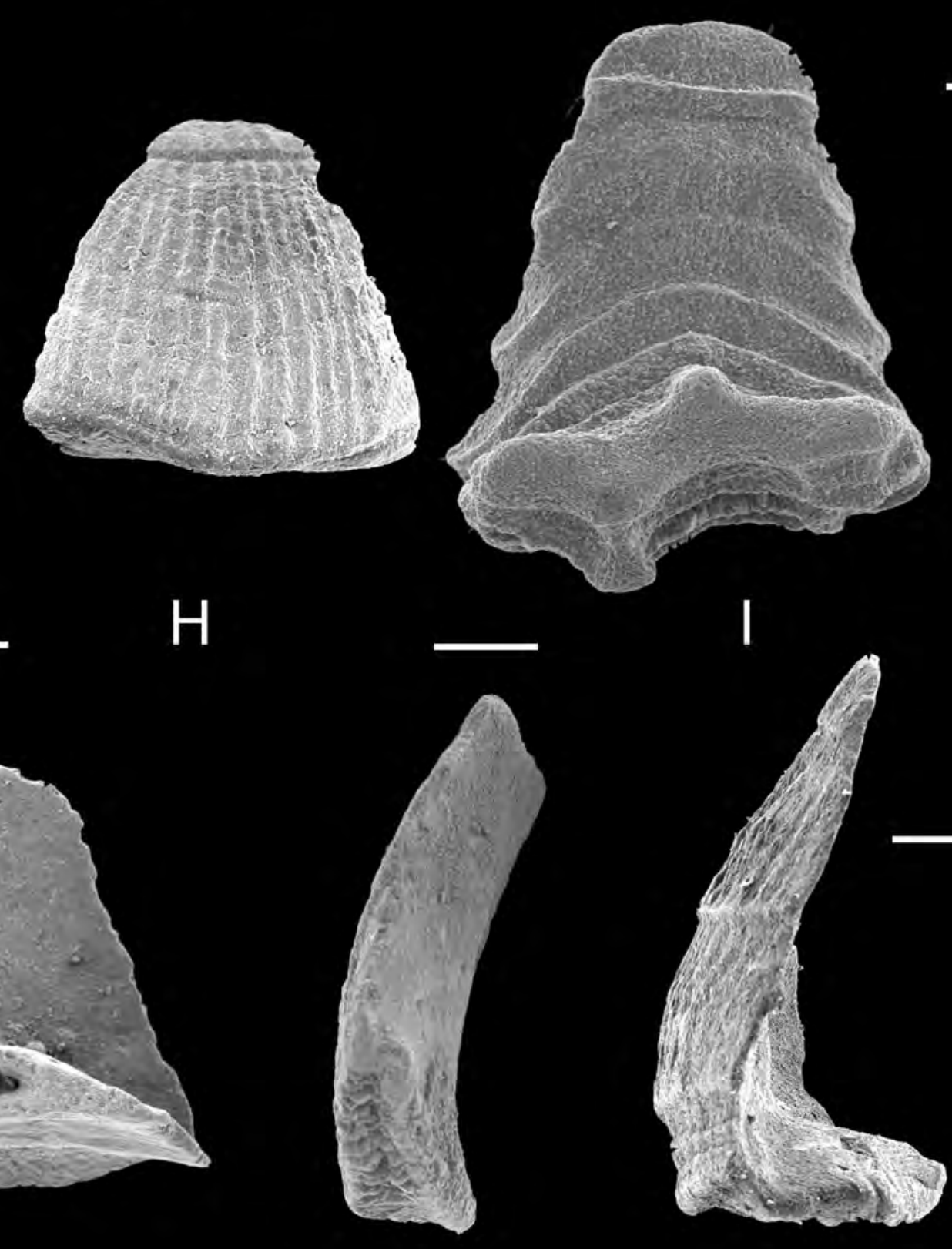

M

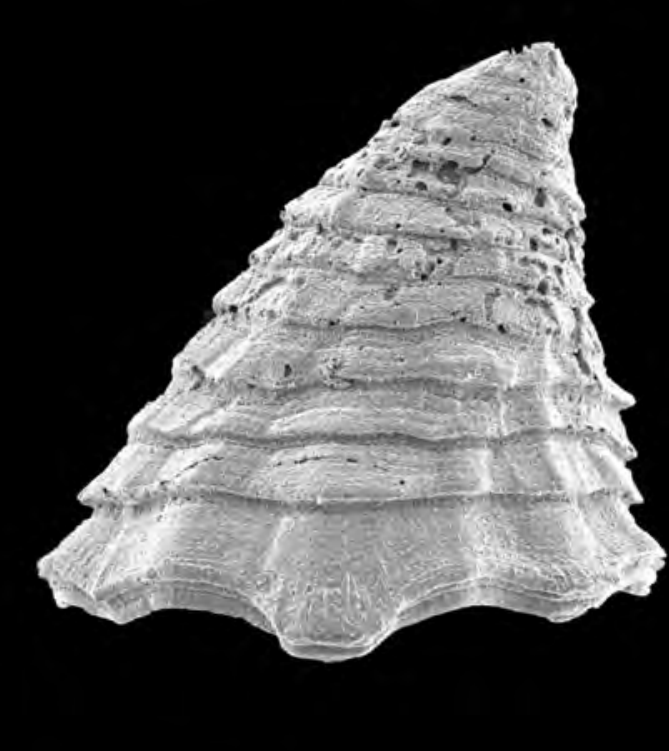

E

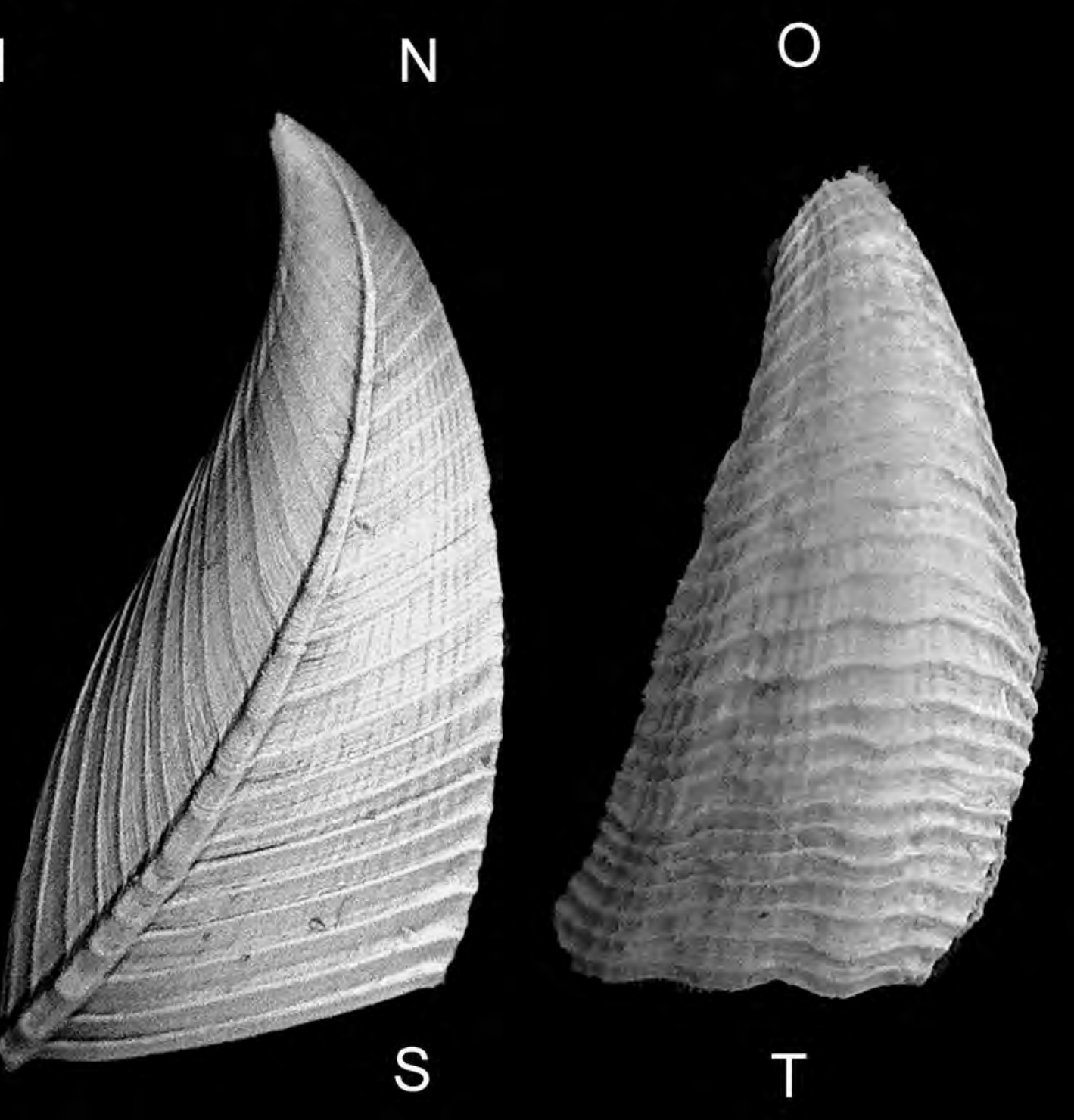

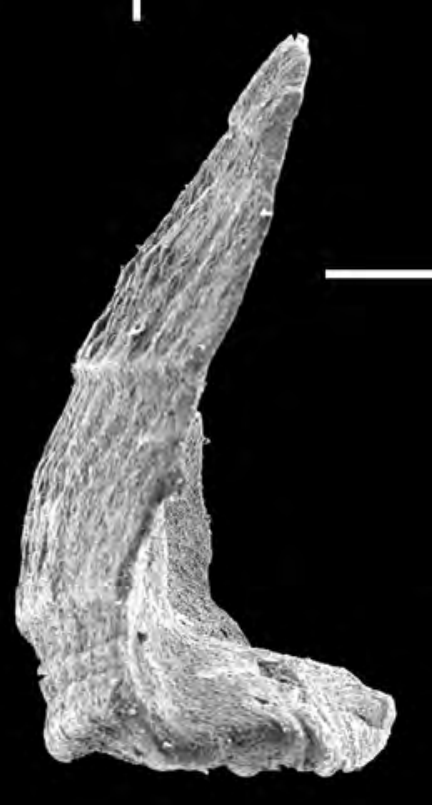

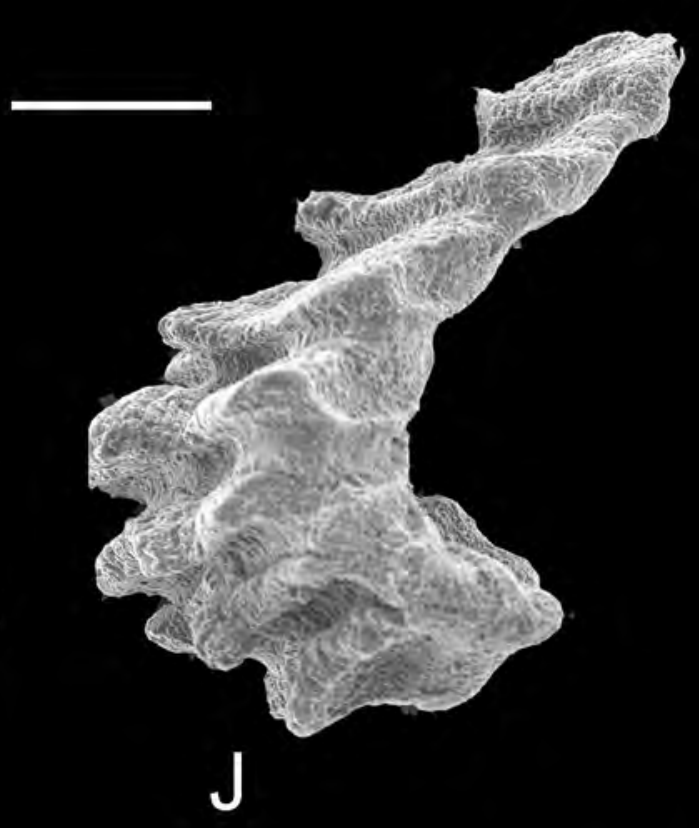



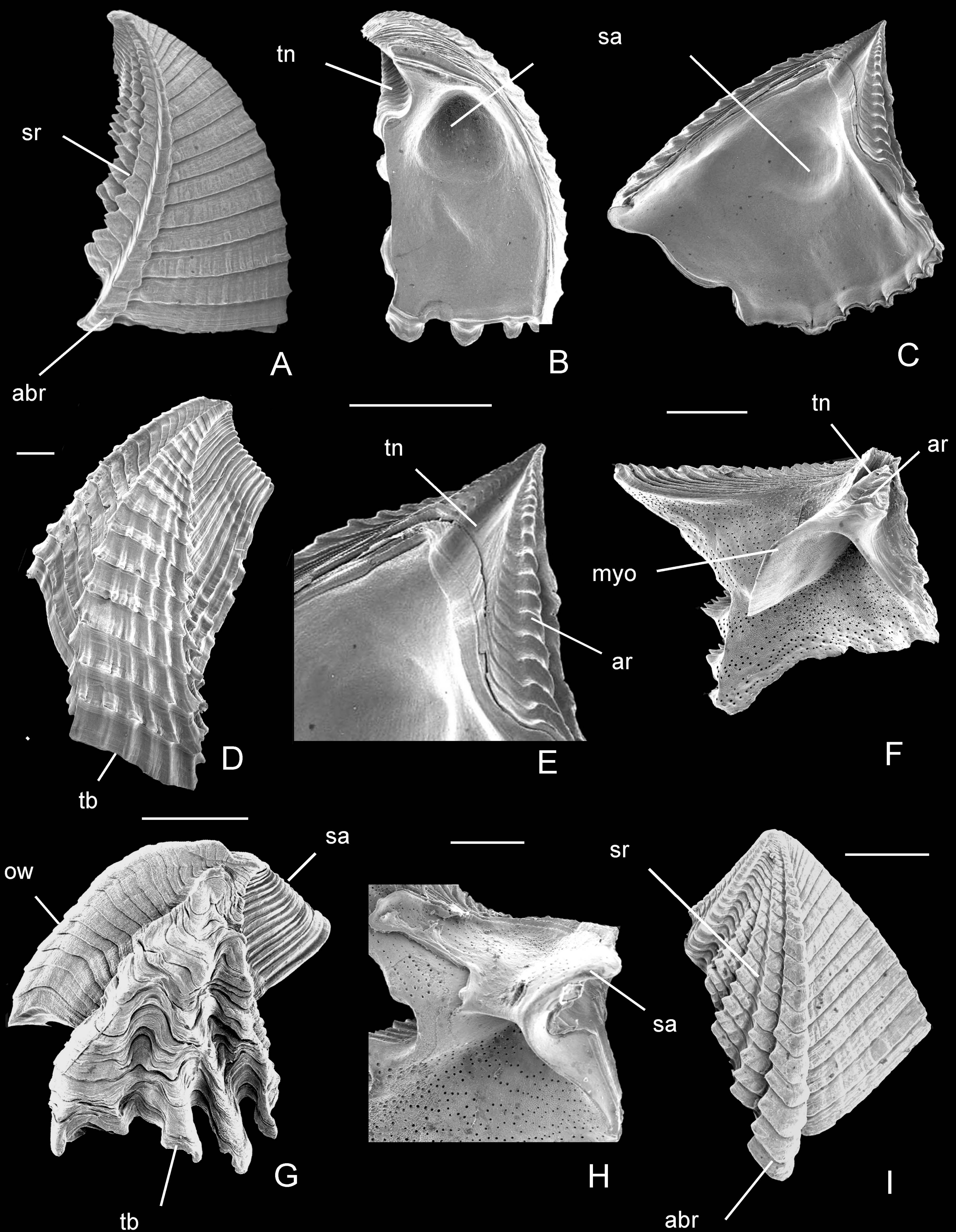

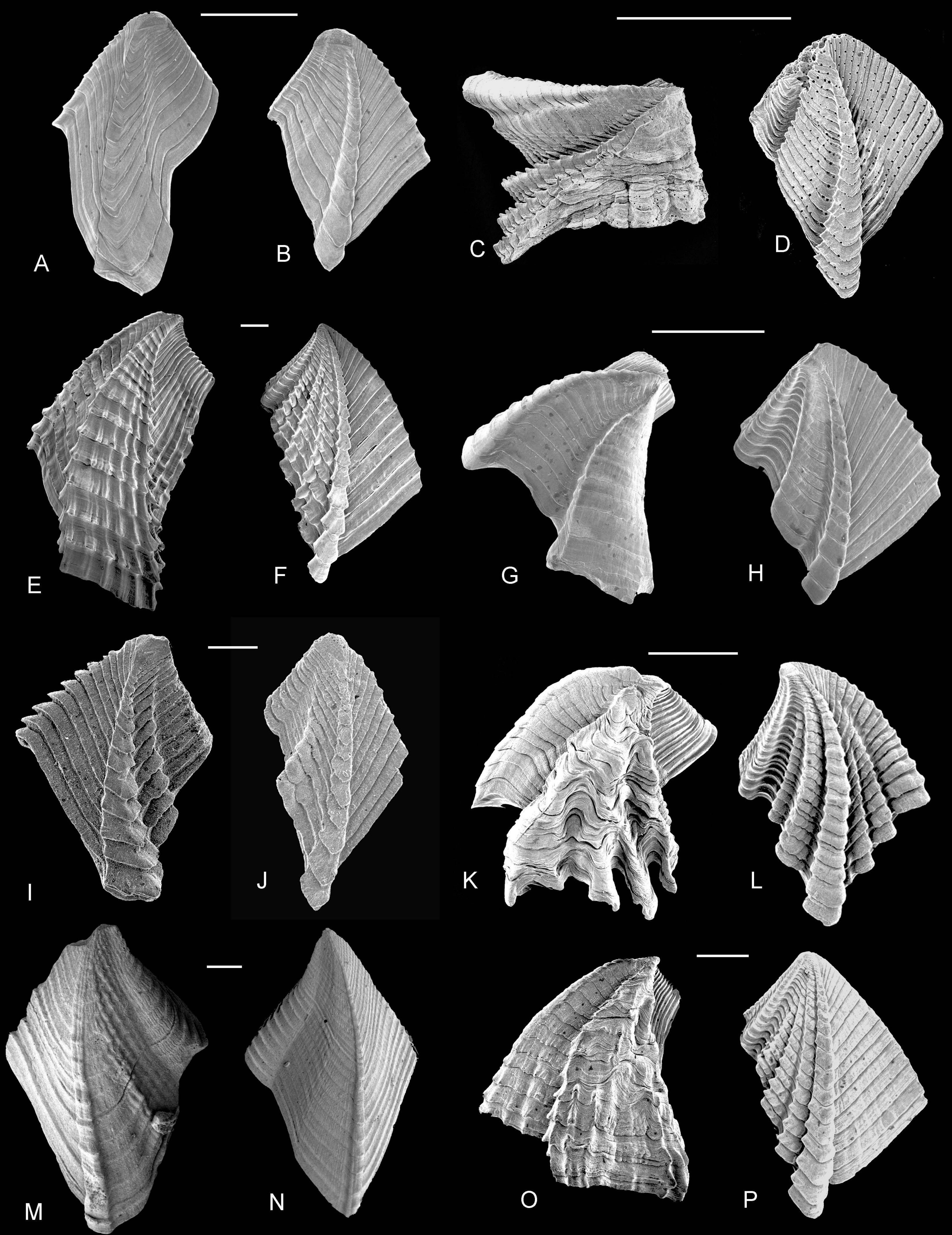


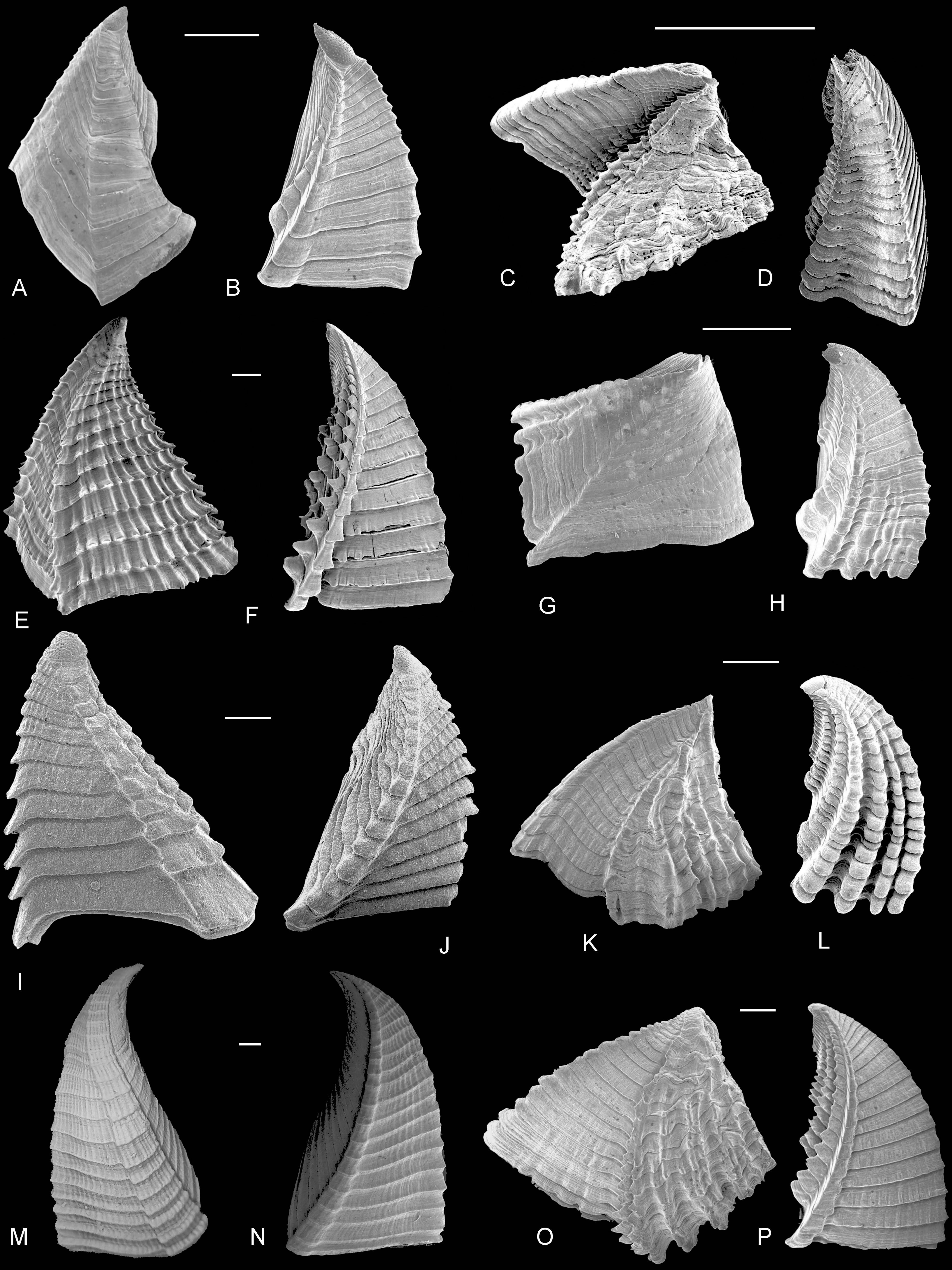



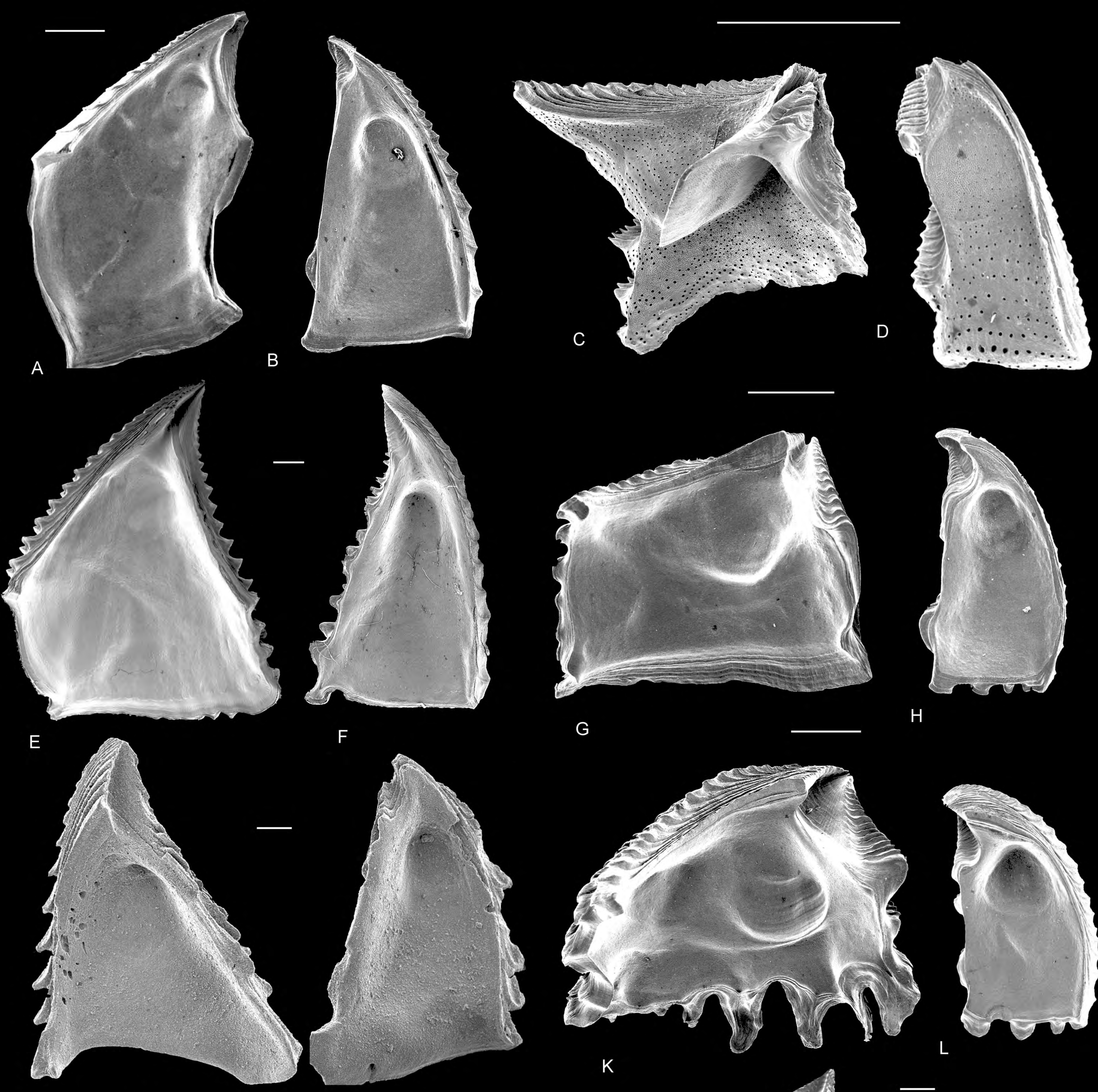

F
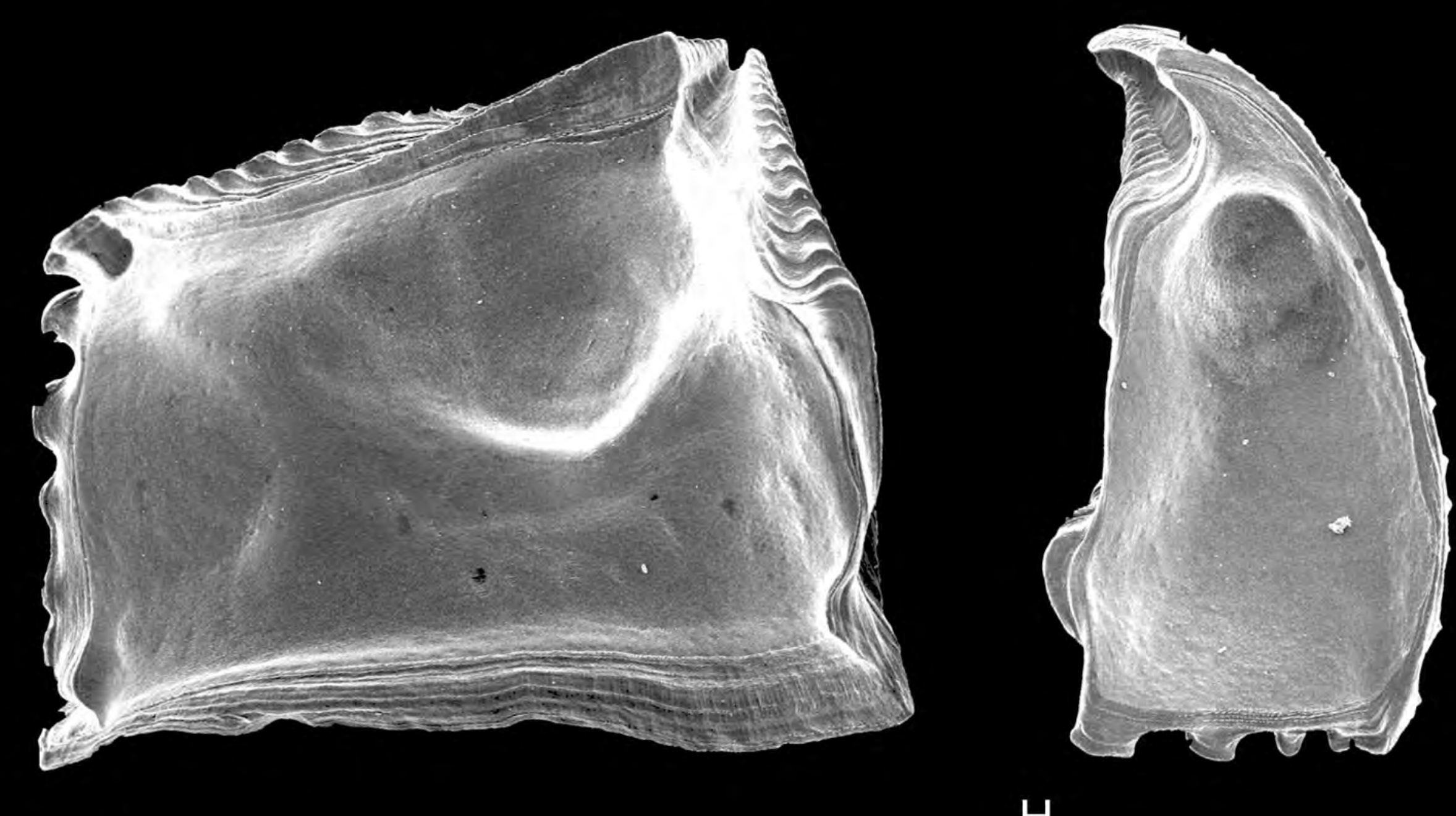

G

H
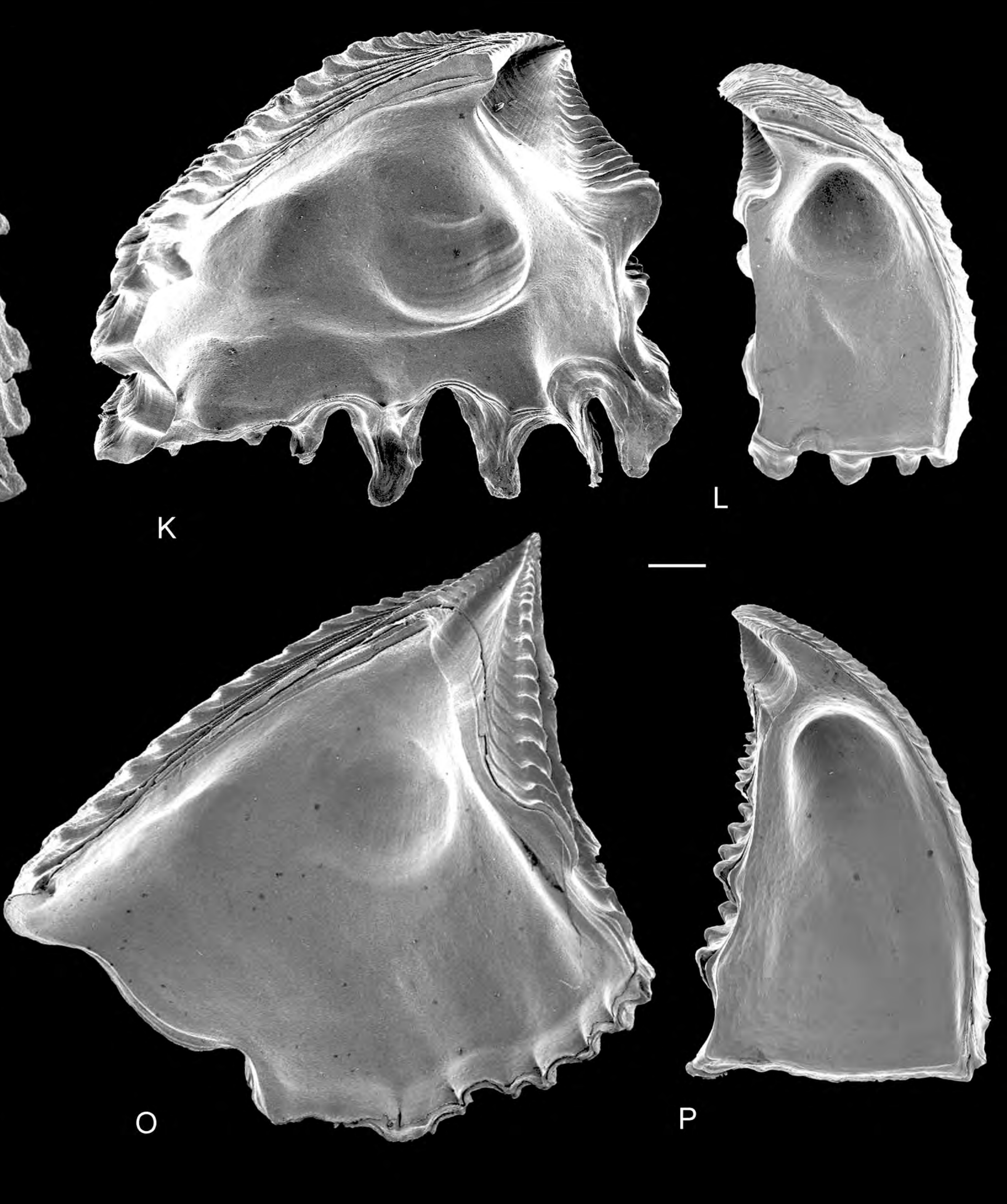


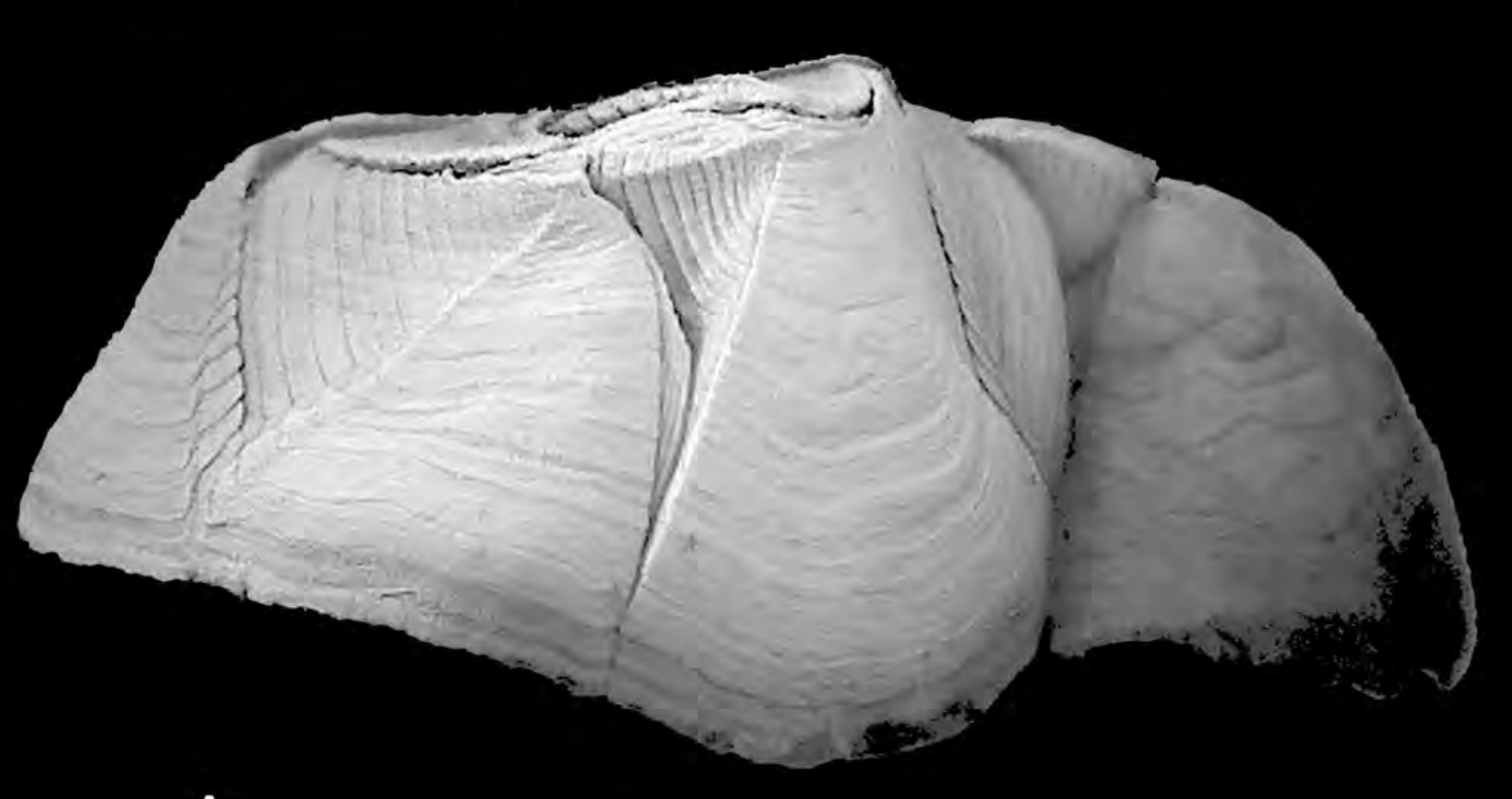

A
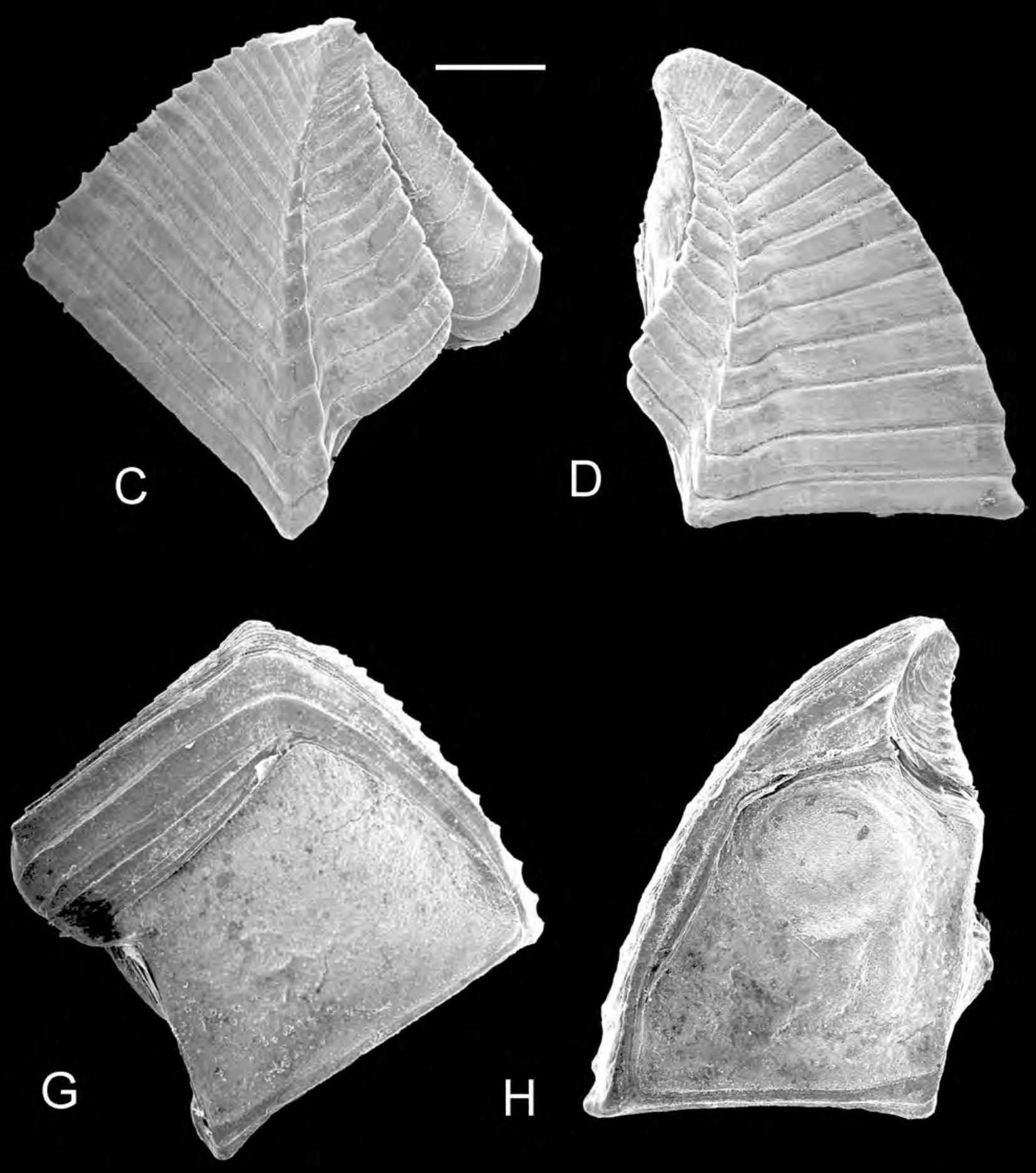
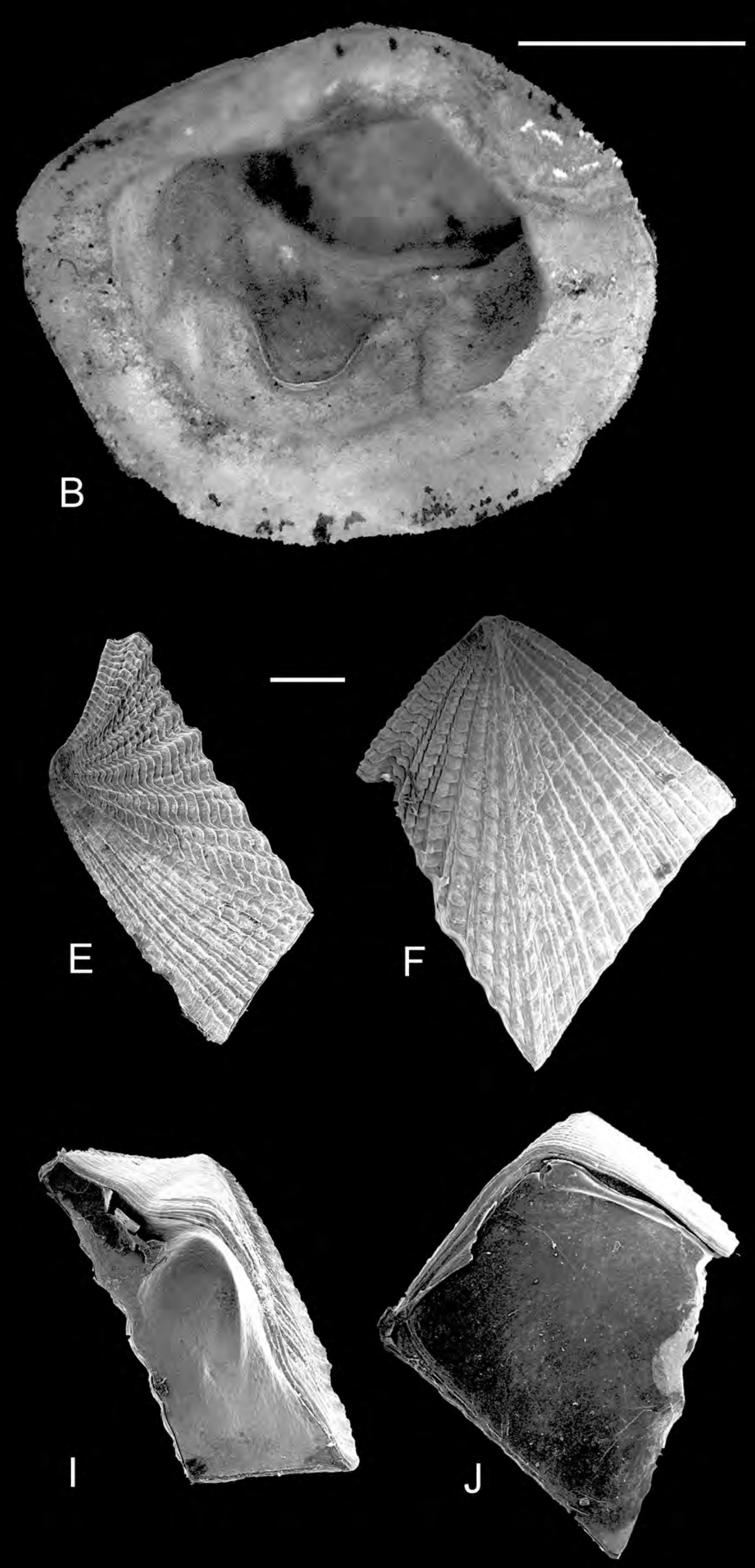


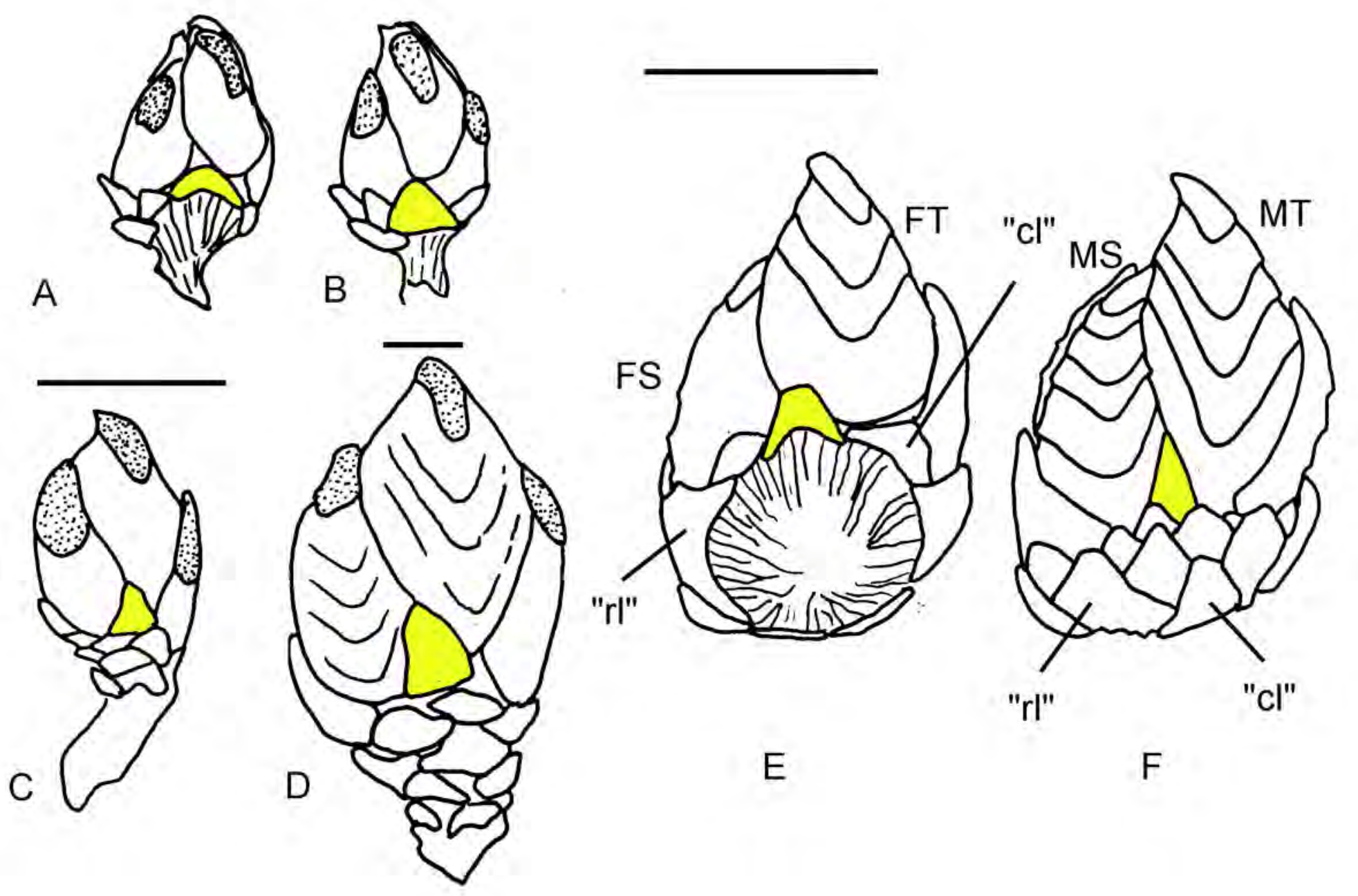



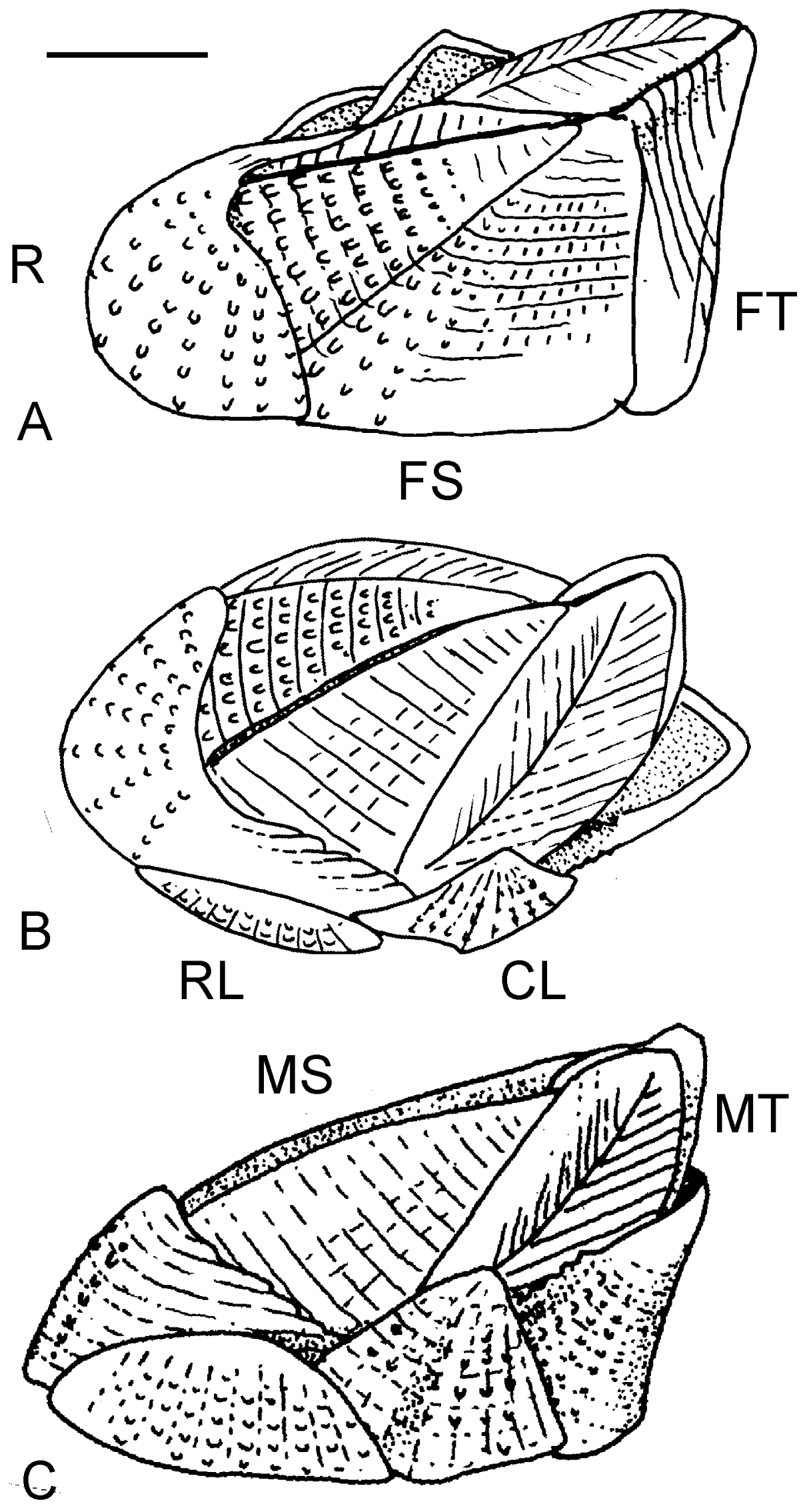


\section{E. durotrigensis}

P. articulata

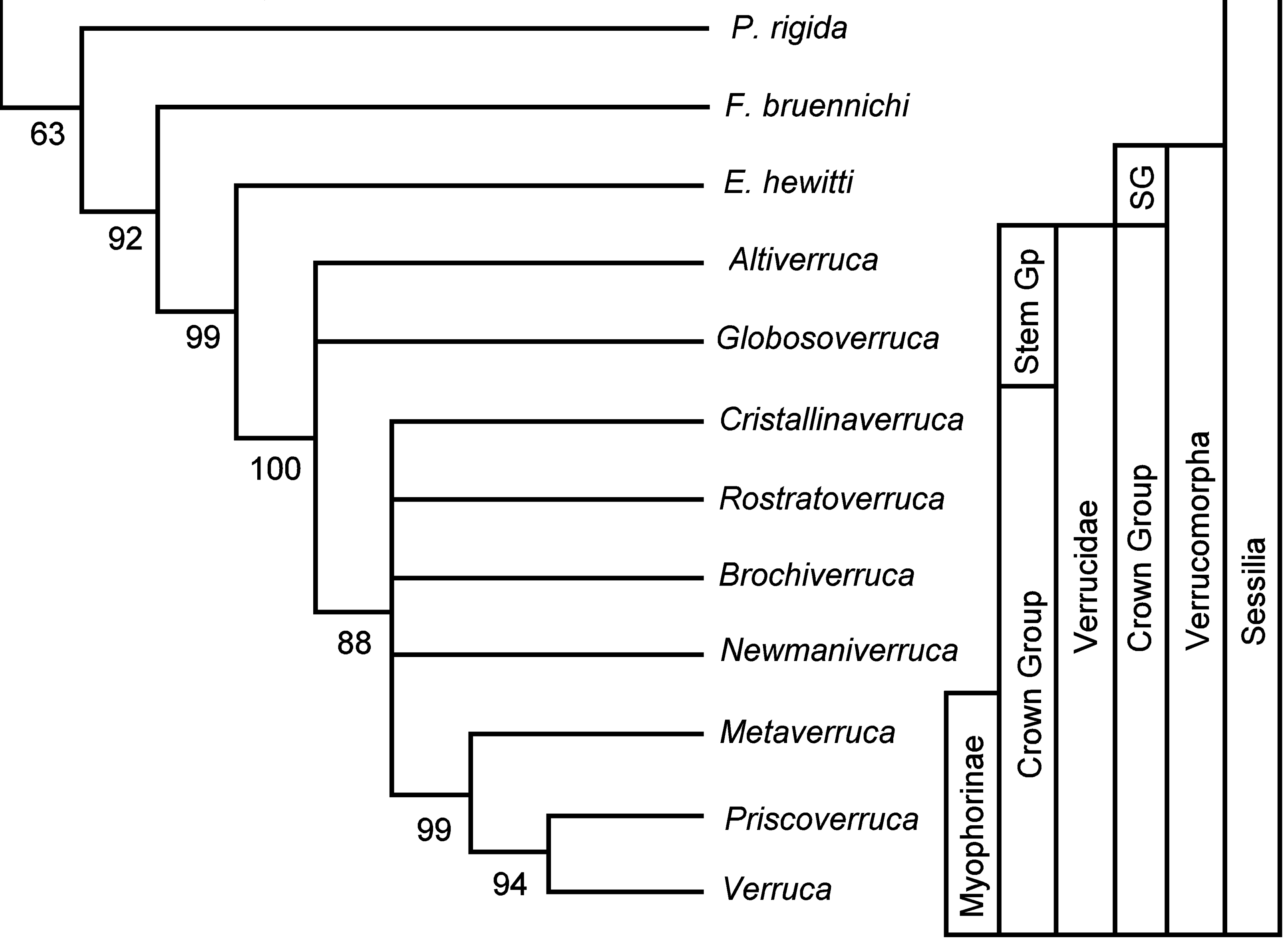




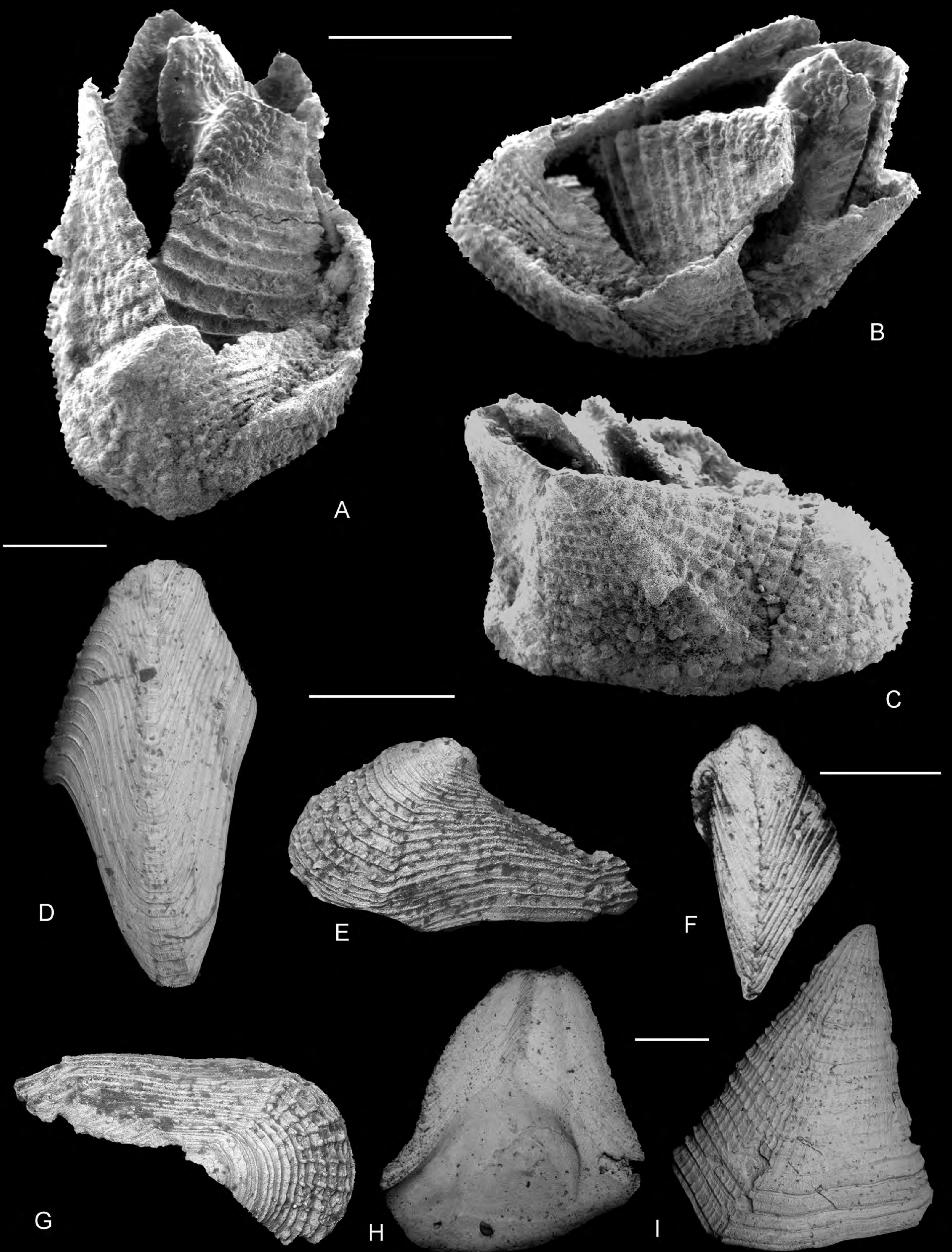




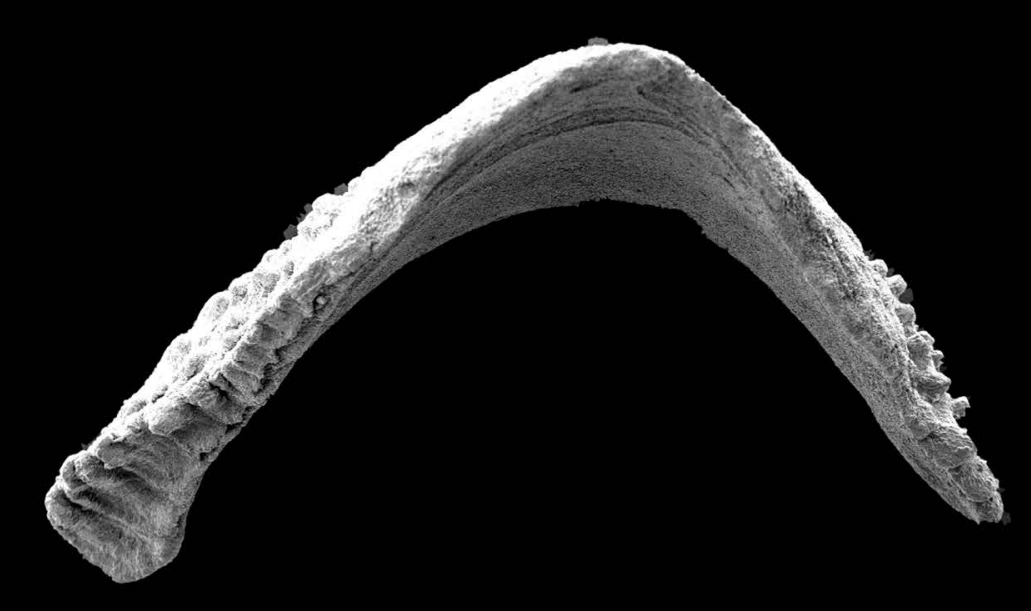

A

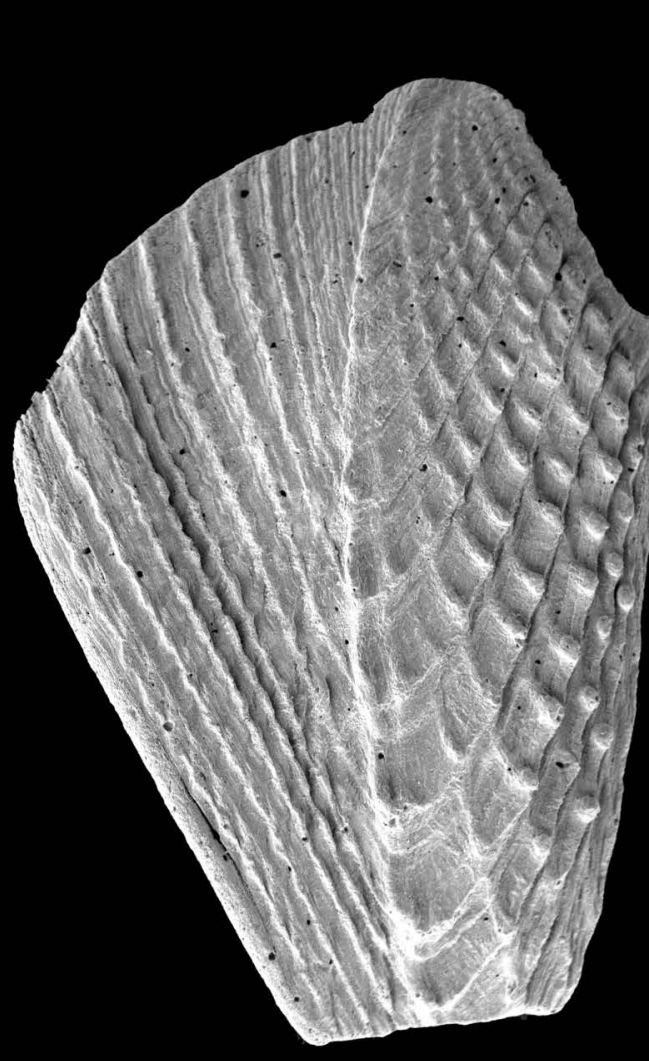

D

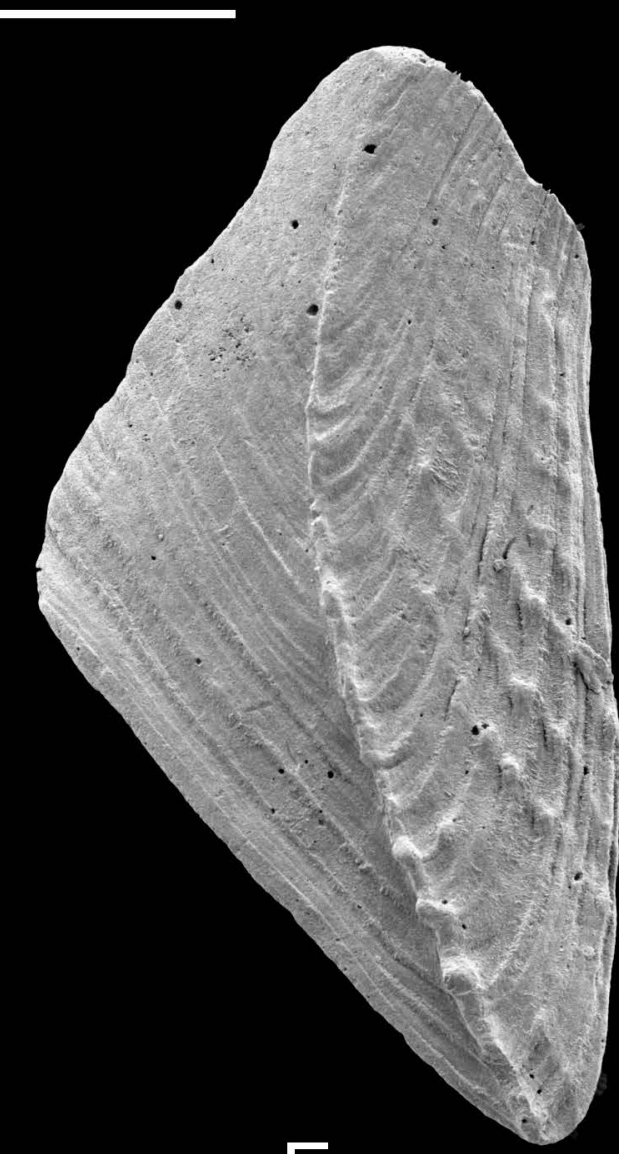

E

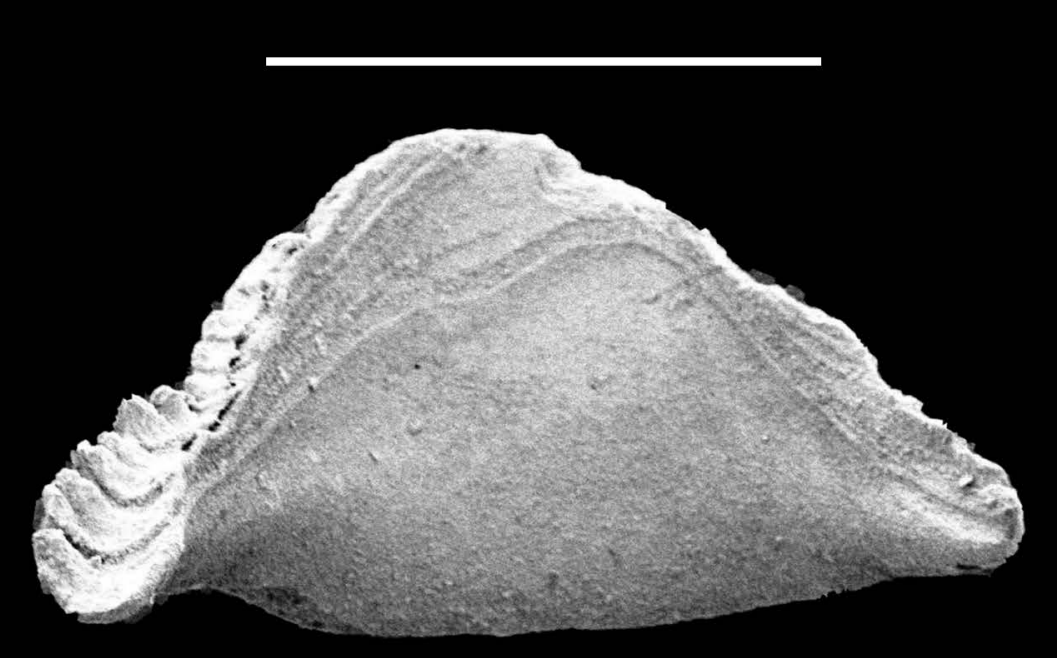

B

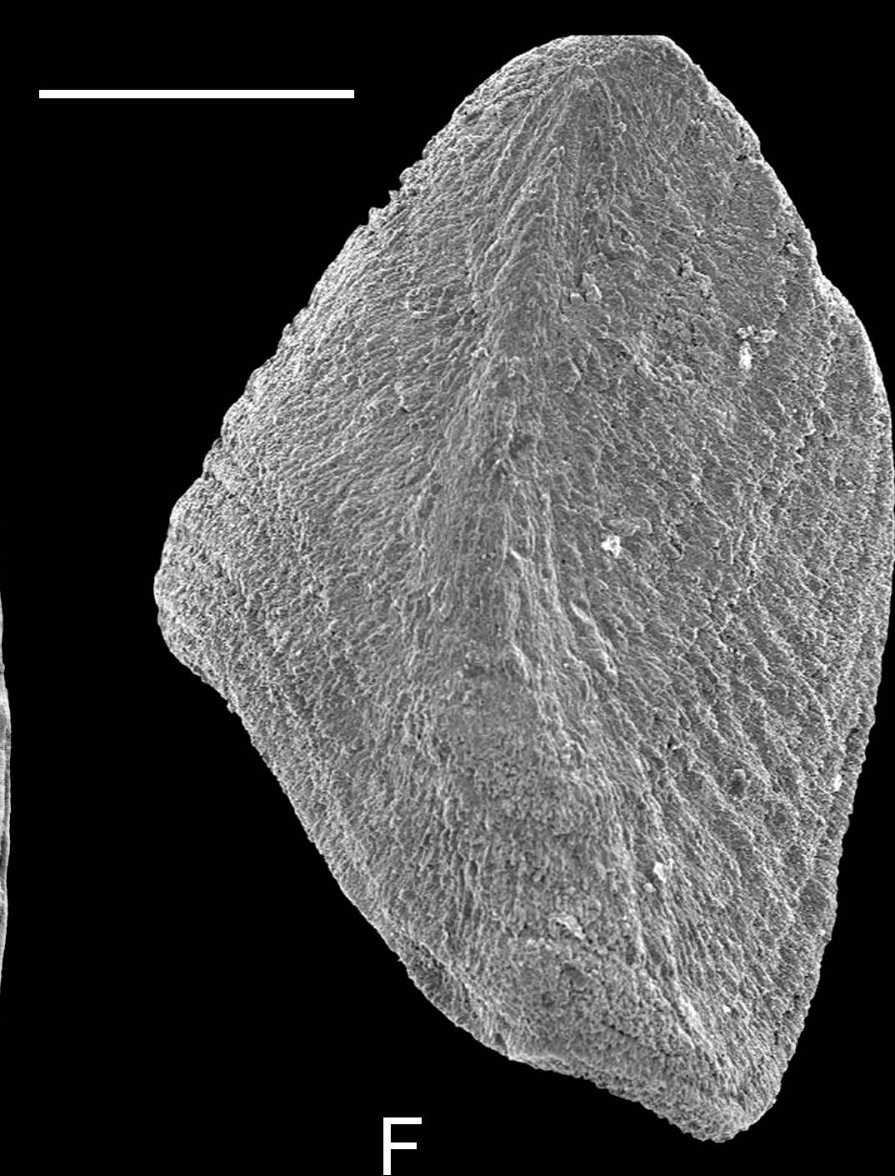

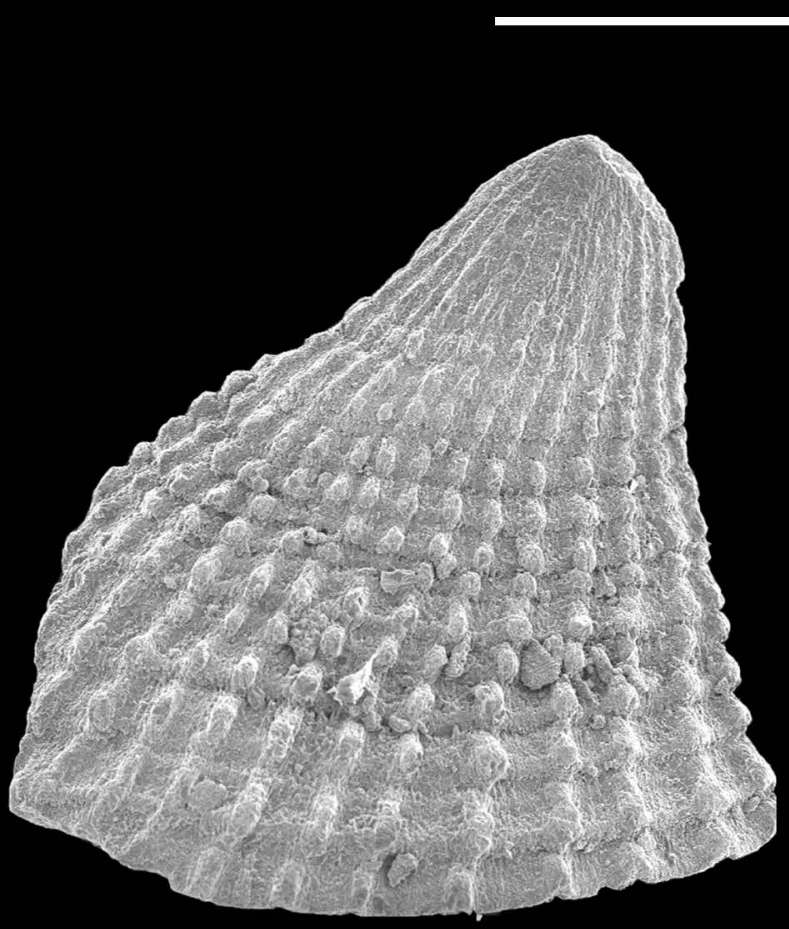

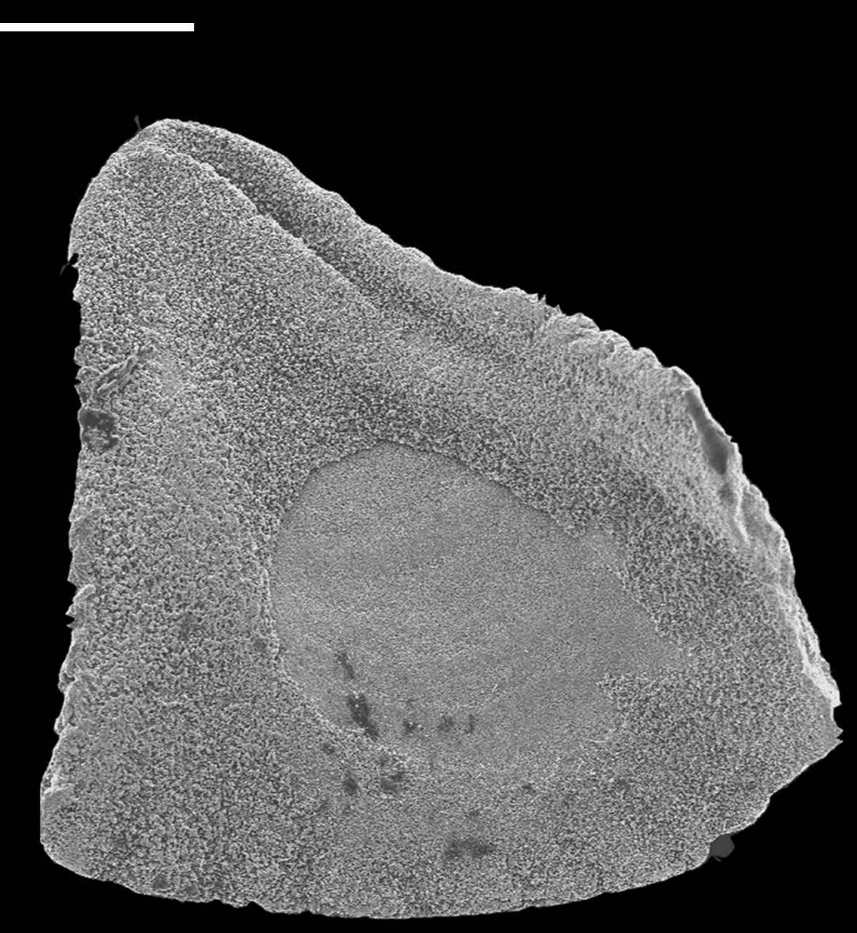

J

C
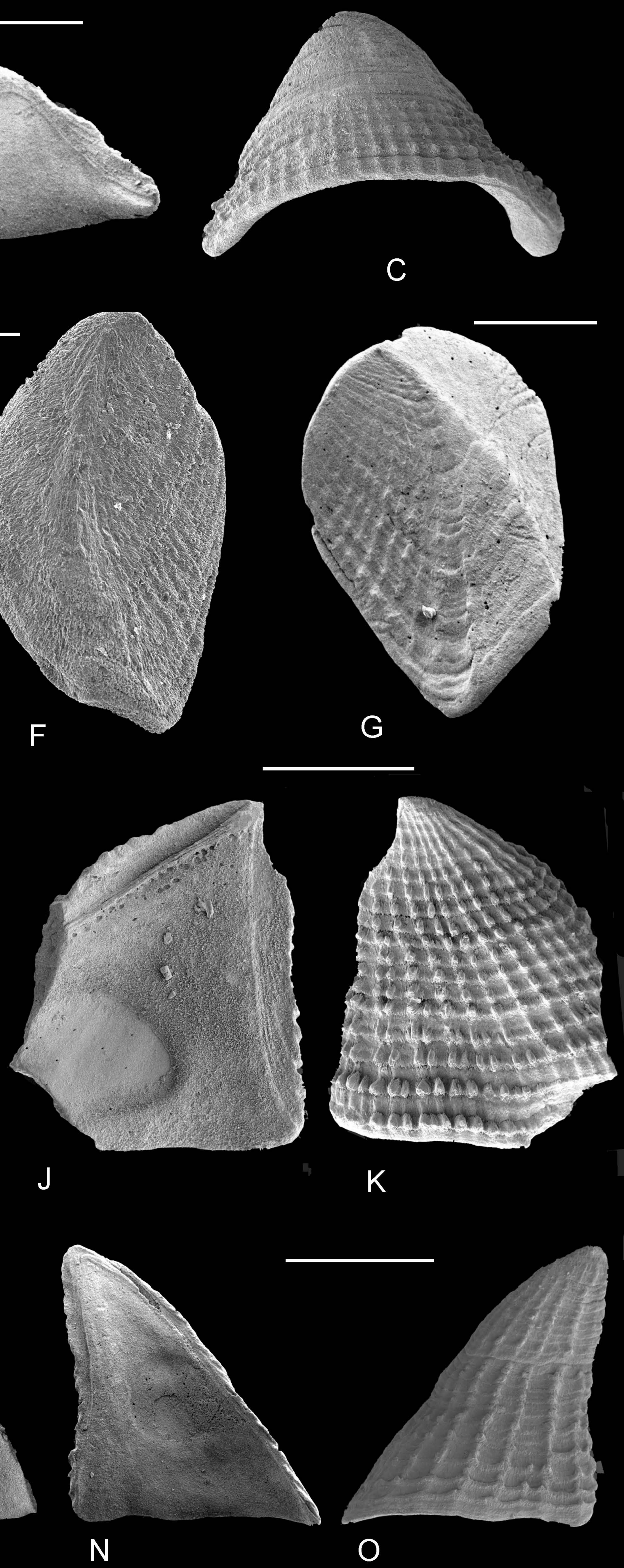

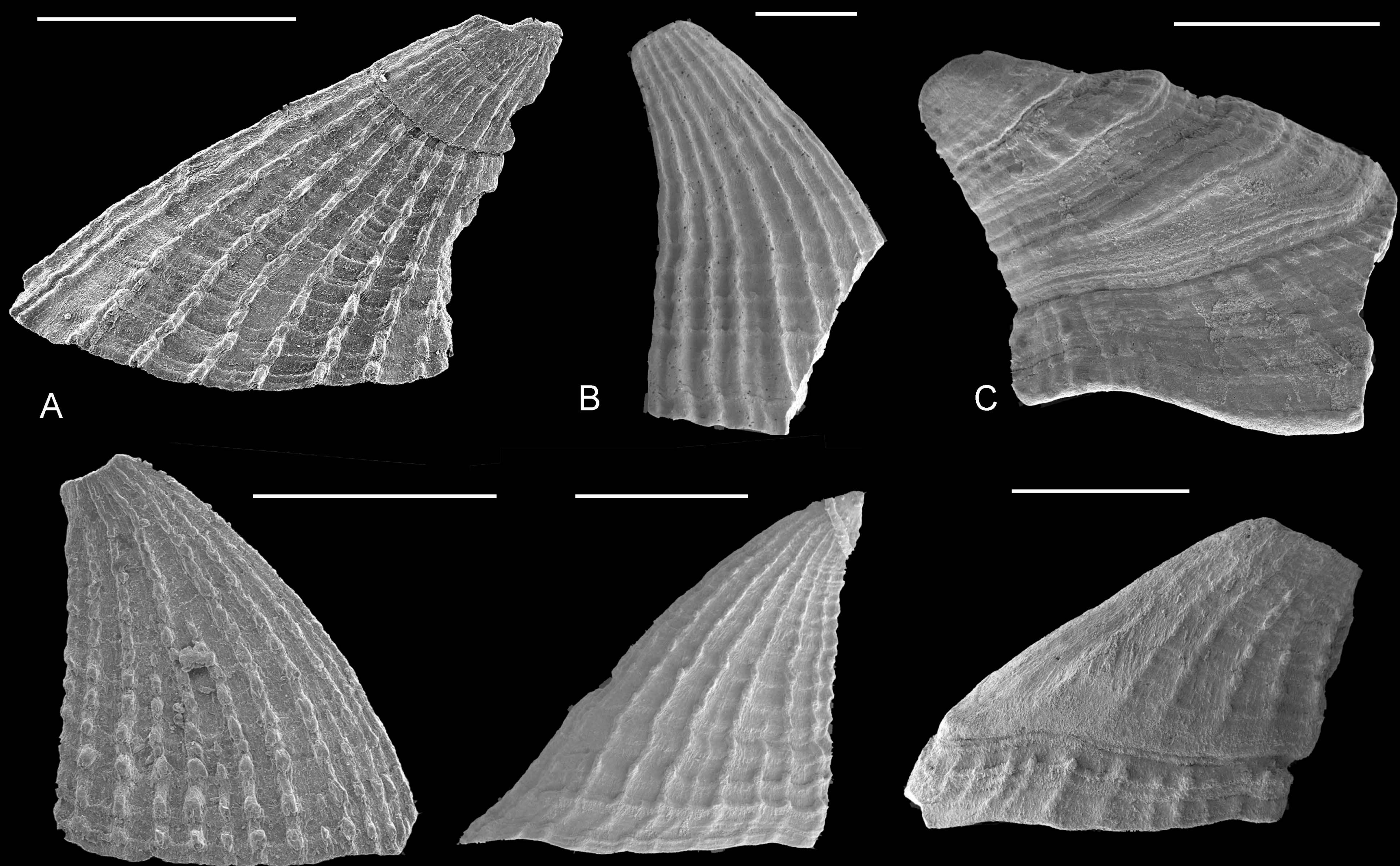

D
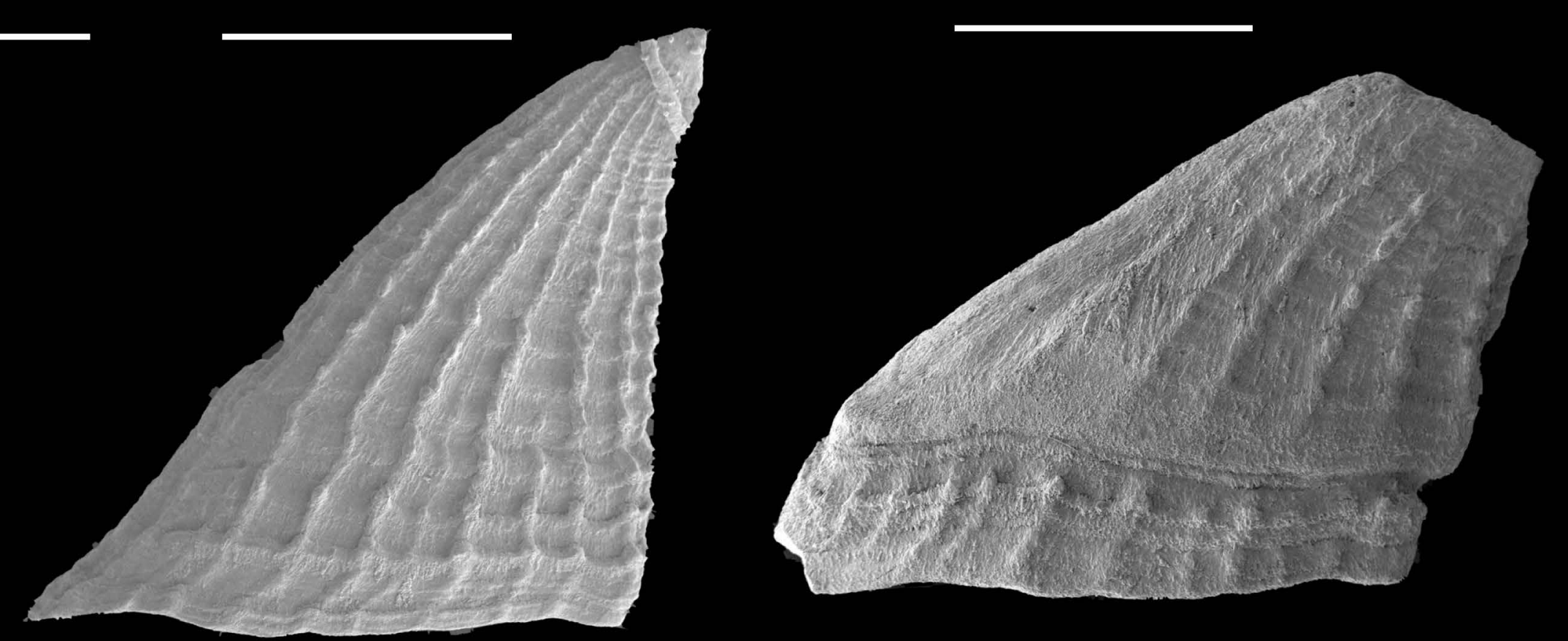

E

F
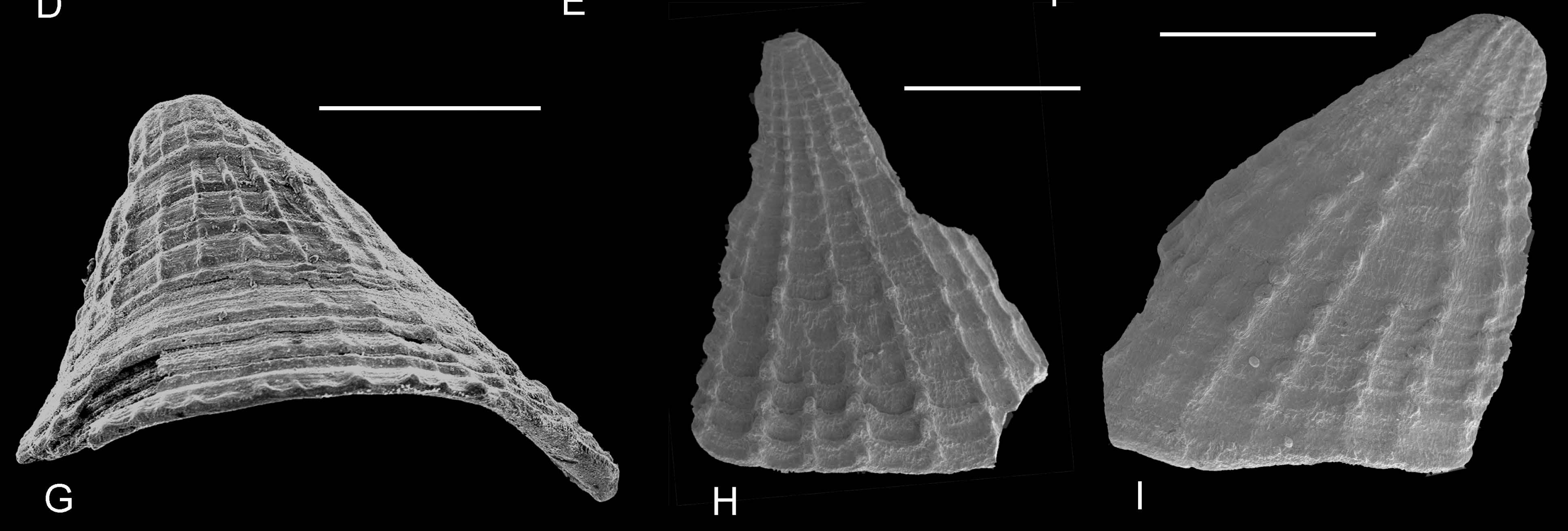

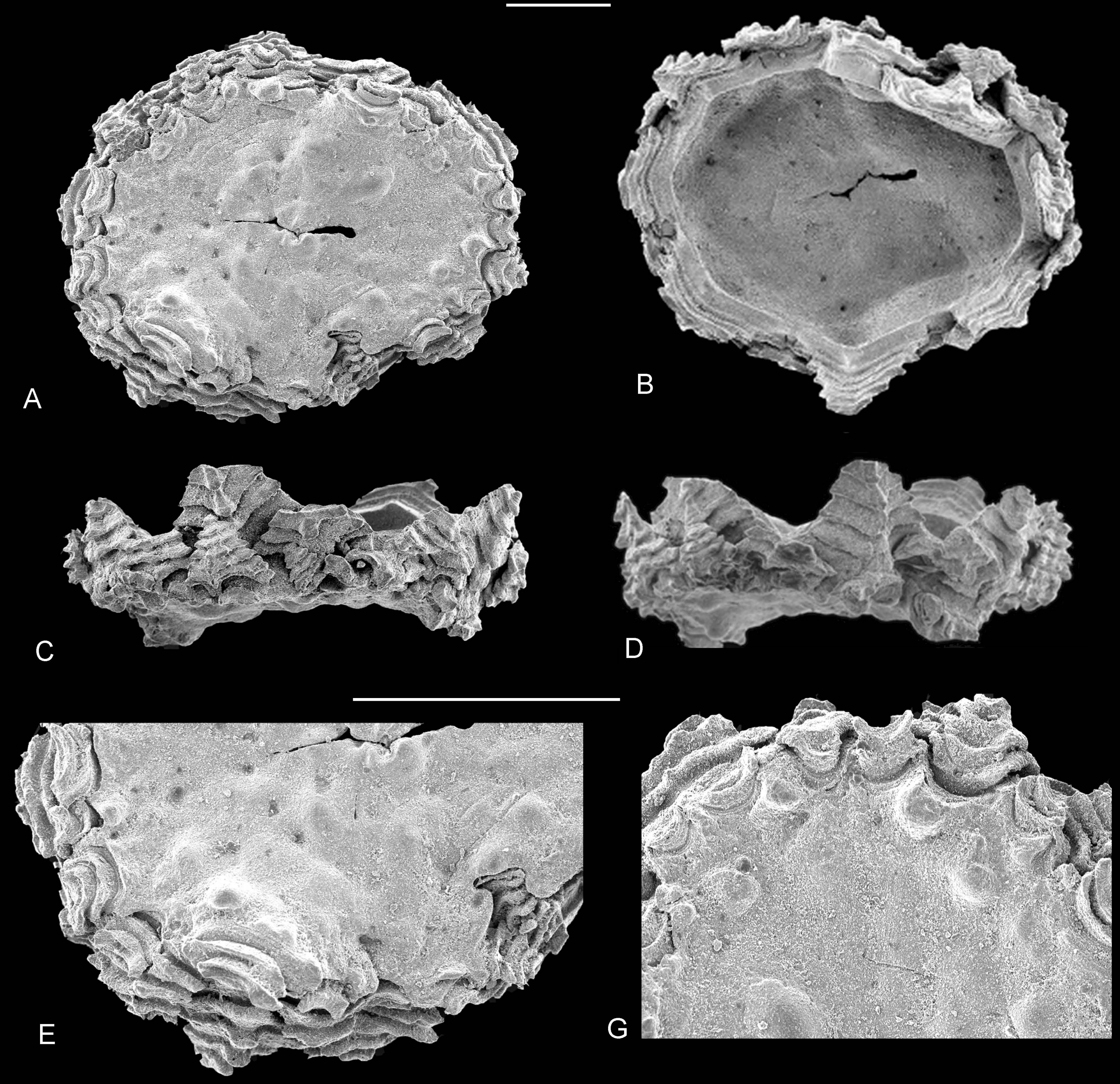

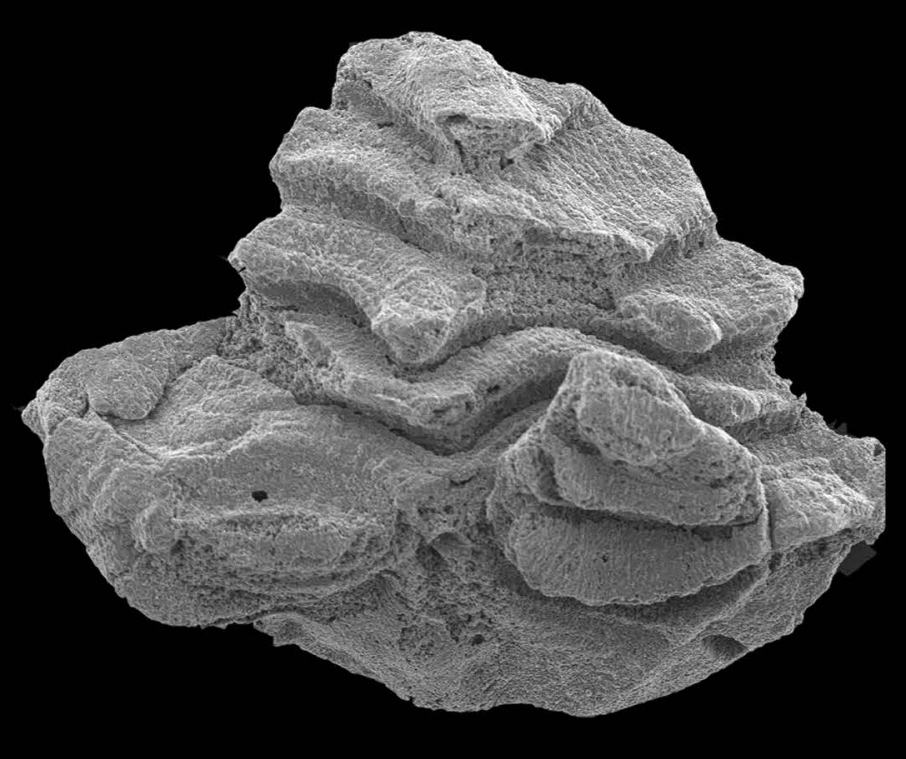

H

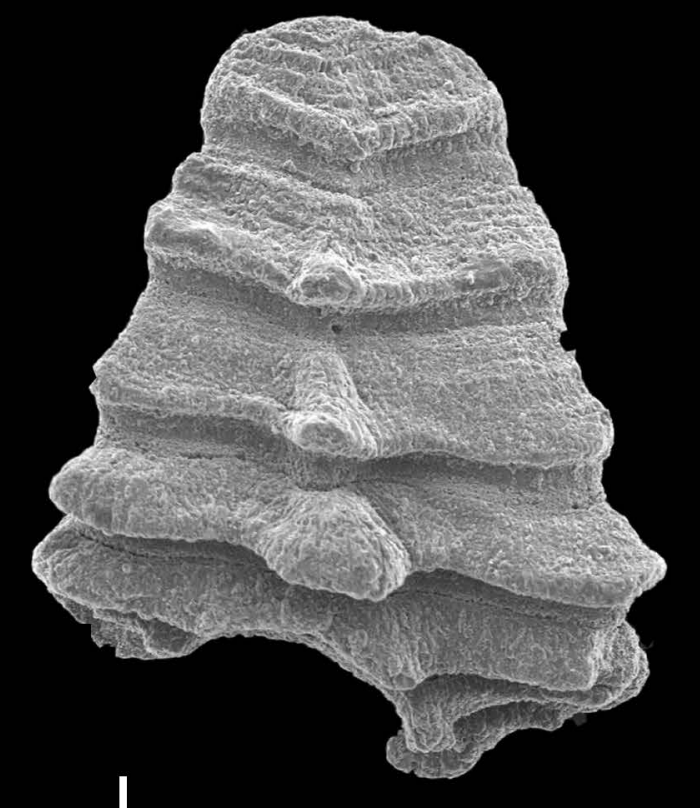

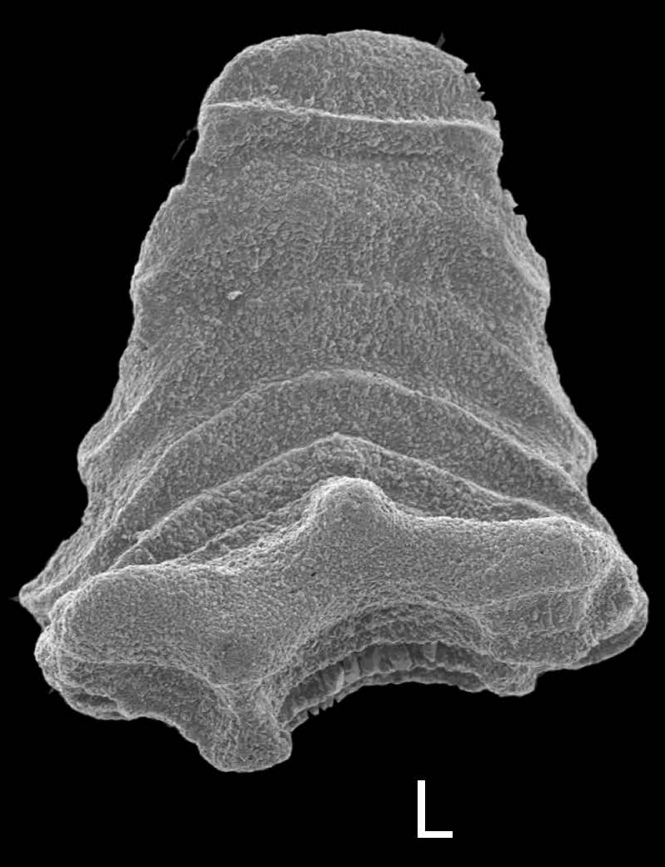



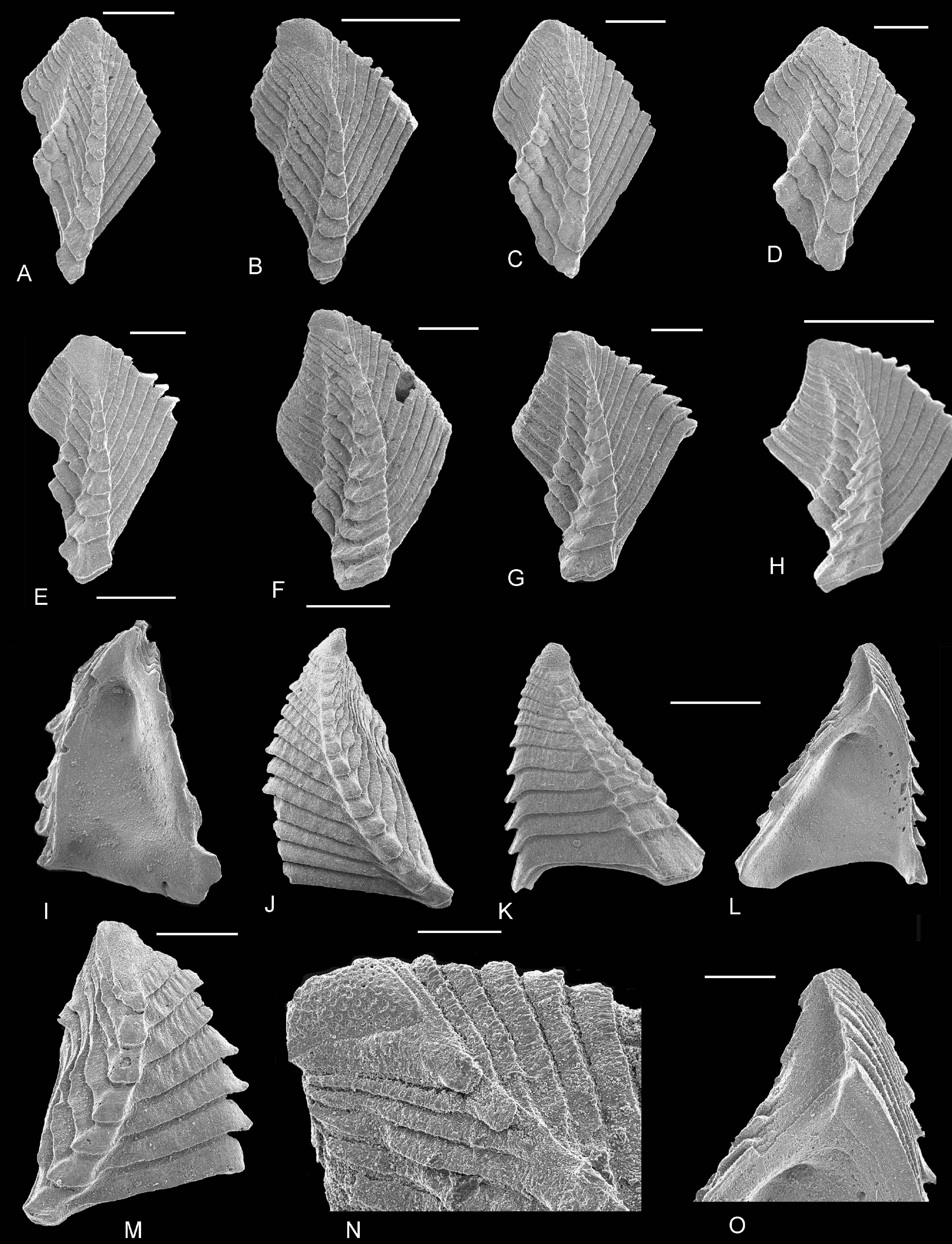


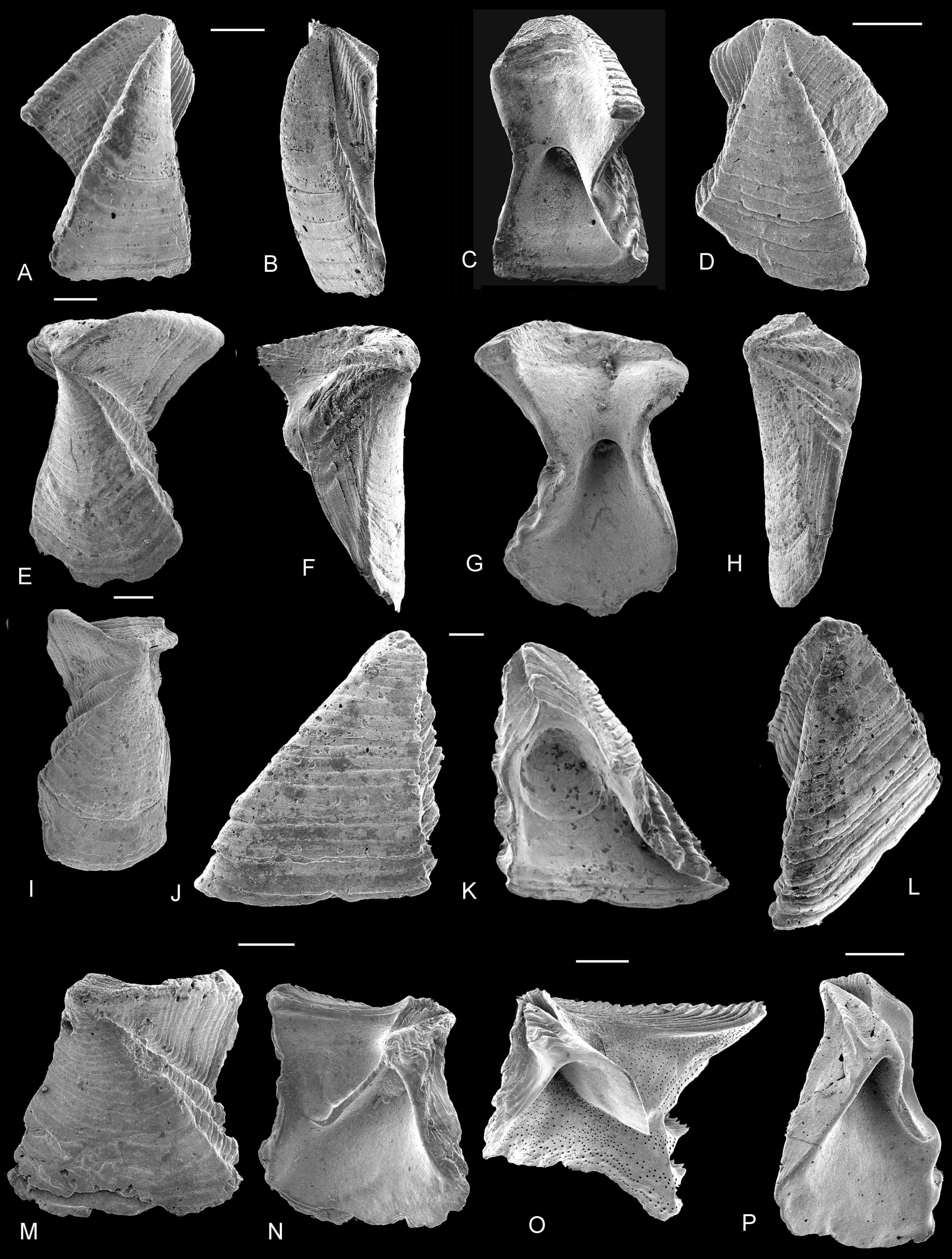




$$
80 B 18
$$




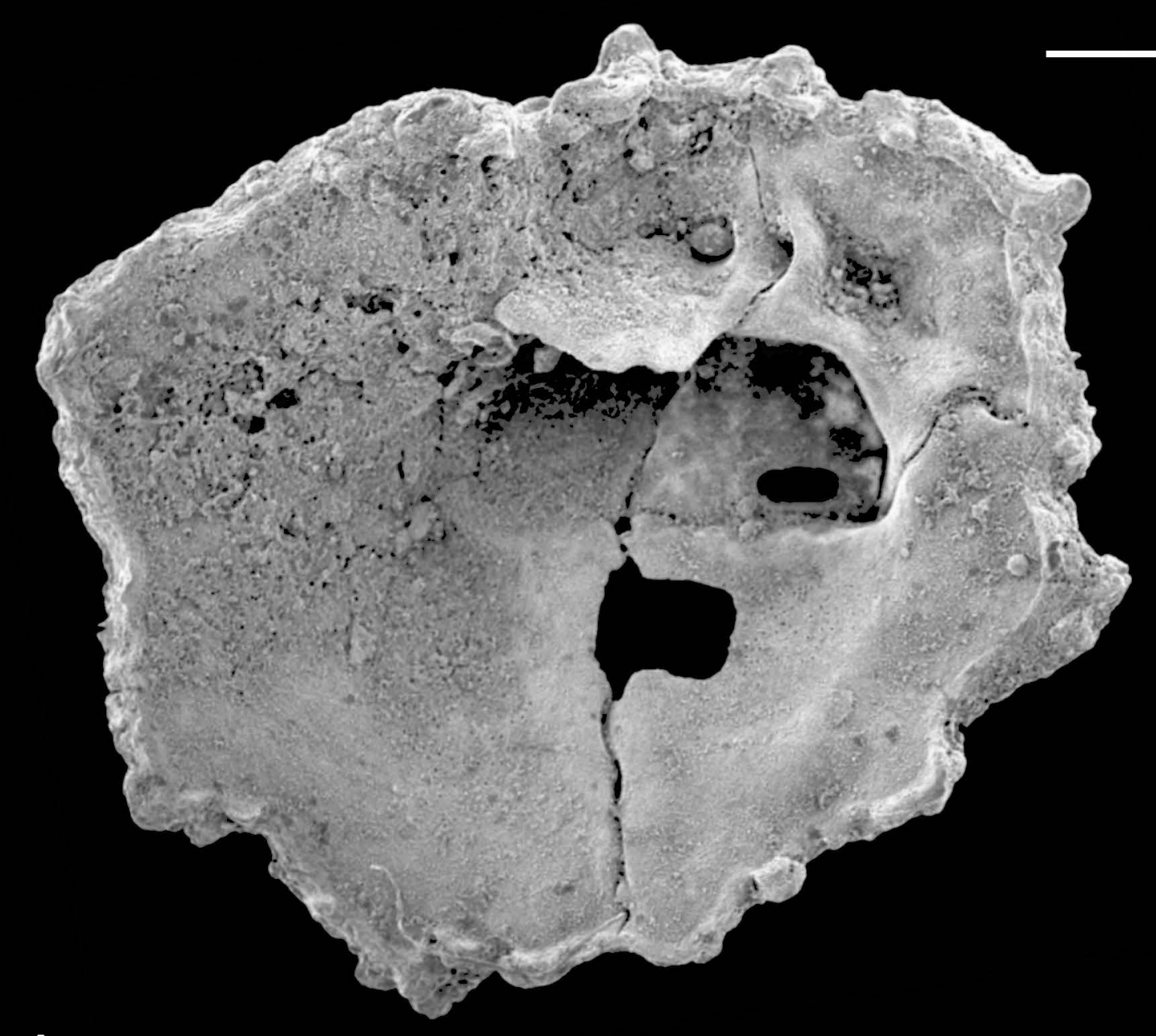

A
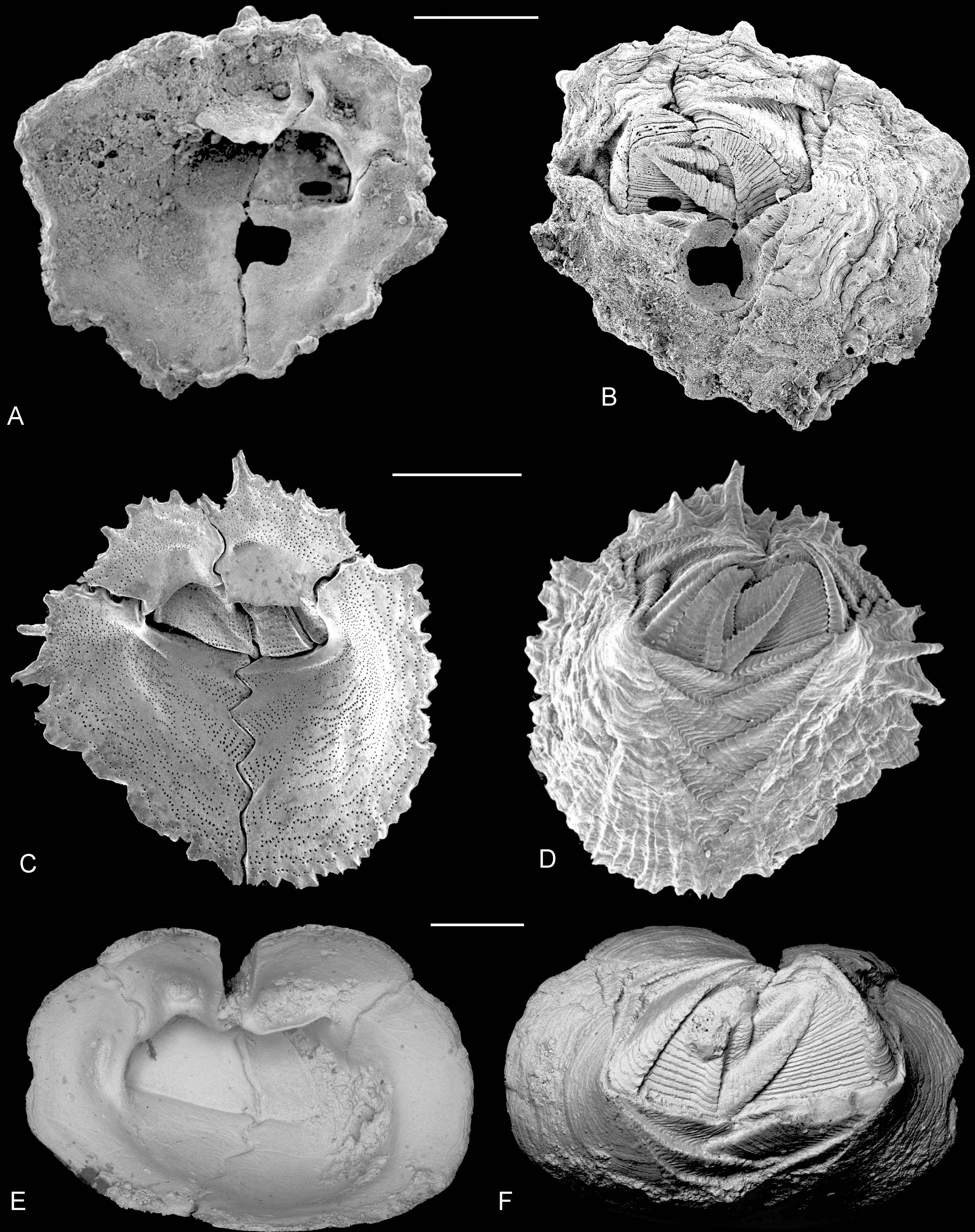